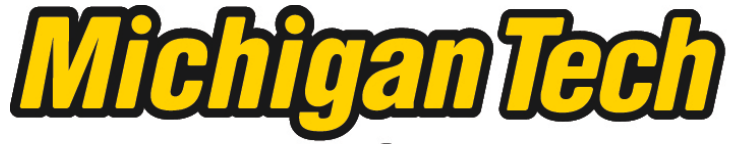 \\ Michigan Technological University Create the Future Digital Commons @ Michigan Tech
}

Dissertations, Master's Theses and Master's Reports - Open

Dissertations, Master's Theses and Master's

Reports

2005

New media reading strategy

Cheryl E. Ball

Michigan Technological University

Follow this and additional works at: https://digitalcommons.mtu.edu/etds

Part of the Rhetoric and Composition Commons

Copyright 2005 Cheryl E. Ball

\section{Recommended Citation}

Ball, Cheryl E., "New media reading strategy", Dissertation, Michigan Technological University, 2005.

https://doi.org/10.37099/mtu.dc.etds/82

Follow this and additional works at: https://digitalcommons.mtu.edu/etds

Part of the Rhetoric and Composition Commons 


\title{
A New Media Reading Strategy
}

\author{
by \\ Cheryl E. Ball
}

\begin{abstract}
A DisSERTATION
submitted in partial fulfillment

of the requirements for the degree
\end{abstract}

Doctor of Philosophy

in Rhetorical and Technical Communication

Michigan Technological University

2005

Cheryl E. Ball 2005

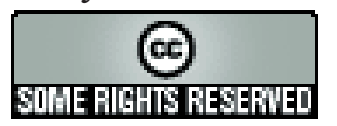

This work is licensed under the Creative Commons Attribution-NonCommercial-ShareAlike License.

To view a copy of this license, visit http://

creativecommons.org/licenses/by-nc-sa/2.0/ or send a letter to Creative Commons, 559 Nathan Abbott

Way, Stanford, California 94305, USA. 


\title{
A New Media Reading Strategy
}

\author{
Abstract \\ This dissertation addresses the need for a strategy that will help readers new to new \\ media texts interpret such texts. While scholars in multimodal and new media theory \\ posit rubrics that offer ways to understand how designers use the materialities and \\ media found in overtly designed, new media texts (see, e.g, Wysocki, 2004a), these \\ strategies do not account for how readers have to make meaning from those texts. In this \\ dissertation, I discuss how these theories, such as Lev Manovich's (2001) five principles \\ for determining the new media potential of texts and Gunther Kress and Theo van \\ Leeuwen's (2001) four strata of designing multimodal texts, are inadequate to the job of \\ helping readers understand new media from a rhetorical perspective. I also explore how \\ literary theory, specifically Wolfgang Iser's (1978) description of acts of interpretation, \\ can help audiences understand why readers are often unable to interpret the multiple, \\ unexpected modes of communication used in new media texts. Rhetorical theory, \\ explored in a discussion of Sonja Foss's (2004) units of analysis, is helpful in bringing \\ the reader into a situated context with a new media text, although these units of analysis, \\ like Iser's process, suggests that a reader has some prior experience interpreting a text-as- \\ artifact. Because of this assumption of knowledge put forth by all of the theories explored \\ within, I argue that none alone is useful to help readers engage with and interpret new \\ media texts. However, I argue that a heuristic which combines elements from each of \\ these theories, as well as additional ones, is more useful for readers who are new to \\ interpreting the multiple modes of communication that are often used in unconventional \\ ways in new media texts. I describe that heuristic in the final chapter and discuss how it \\ can be useful to a range of texts besides those labelled new media.
}




\section{Acknowledgements}

The idea for this dissertation is borne out of a project in which I was asked to create exercises to help teachers and students learn how to intergrate visual rhetoric into composition classes. That CD-ROM, ix: visual exercises (Bedford-St. Martin's Press, 2004), turned out to be much more useful than I could have imagined, in ways too numerous to count. Although I have many people to thank for their help and support in completing $i x$, the person I need to thank first and repeatedly is my colleague and close friend, Kristin L. Arola. Without her willingness to work on the project, her insightful look at visual rhetoric, her unsurpassed teaching skills, her ability to not be exasperated when I'm being headstrong, her sauna-persuasion (and pronunciation) skills, and her attitude of try-anything-go-anywhere (including Boston, overnight), the $i x \mathrm{CD}$ simply would not have been what it turned out to be. Thank you endlessly! (And many thank yous go to Jeff Kuure, who cooked delightful meals and provided excellent company and non-school conversations to get me out of school mode.) Here's to many afternoons on the DT deck and rounds of "The Wreck of the Edmund Fitzgerald" at Monte's.

I must also thank the amazing women at Bedford-St. Martin's, without whom ix never would have been conceived or produced. To Leasa Burton, whose idea it was for a CD of visual exercises, approaching me at CCCC and taking a risk on a graduate student's ideas. To Alanya Harter, our editor, who let Kristin and I monkey around with the 13 terms we drafted to use in the exercises. Alanya performed the inconceivable by simultaneously letting Kristin and I do our convoluted, thought-process thing while teaching us volumes about working for (and editing our work for) a publisher. To Harriet Wald, new media editor, who spent countless hours making $i x$ the most cool product in every sense, thank you. Harriet also spent hours editing chapters of my dissertation for me--only a feat that a long-lost friend would perform. Welcome to my life!

Finally, I most humbly thank my committee--Anne Wysocki, Cynthia Selfe, and Diana George--who were patient and kind and trusting, even when I didn't trust myself, 
and about whom no amount of words (or pictures or singing and dancing) can express the gratitude I feel for the support and encouragement and professionalism they showed. Thank you many times over. 


\section{Table of Contents}

Introduction: Finding a new media reading strategy 1

Chapter 1: The need for a new (-media) reading strategy 7

$\begin{array}{ll}\text { Introduction } & 7\end{array}$

$\begin{array}{ll}\text { A brief background on the term new media } & 7\end{array}$

The cliché of new media 10

A new view on new media 18

The necessity for new media reading strategies: An example 24

$\begin{array}{ll}\text { Conclusion } & 38\end{array}$

Chapter 2: Multimodal and new media rubrics $\quad 40$

$\begin{array}{ll}\text { Introduction } & 40\end{array}$

Multimodal theory $\quad 40$

The New London Group: Beginnings of multiliteracies $\quad 40$

Kress and van Leeuwen $\quad 43$

$\begin{array}{ll}\text { Defining the four strata } & 47\end{array}$

Using the strata to describe a new media text 49

Manovich's new media theory $\quad 52$

The five principles applied to a new media text 53

Description versus interpretation $\quad 56$

An interpretation of "Red Peppers" 58

$\begin{array}{ll}\text { Conclusion } & 68\end{array}$

$\begin{array}{ll}\text { Chapter 3: Using literary theory as a framework } & 70\end{array}$

$\begin{array}{ll}\text { Introduction } & 70\end{array}$

Iser's reading process outlined $\quad 71$

Lexia to Perplexia: A blanked-up reading 73 
The need to choose significant elements $\quad 89$

Chapter 4: Rhetoric and new media texts 93

Introduction $\quad 93$

"Digital Multiliteracies": An example 94

Foss's methods of rhetorical criticism 100

$\begin{array}{ll}\text { Generic criticism } & 102\end{array}$

$\begin{array}{ll}\text { Cluster criticism } & 104\end{array}$

A generative reading of "Digital Multiliteracies" 109

$\begin{array}{ll}\text { Getting started } & 110\end{array}$

$\begin{array}{ll}\text { The interface } & 111\end{array}$

Starting with what readers know: The alphabetic 112

The meaning of sound: Examining the audio clips 116

$\begin{array}{ll}\text { Transcribing the oral text } & 117\end{array}$

$\begin{array}{ll}\text { Hearing the oral text } & 119\end{array}$

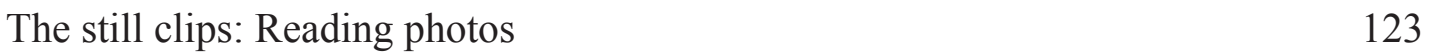

$\begin{array}{ll}\text { Composing a vog: Argument in action } & 126\end{array}$

A generative, clustered meta-analysis: Paying attention to significant elements 128

Chapter 5: A reading strategy for new media texts 133

Introduction 133

An e/merging new media reading strategy 133

$\begin{array}{ll}\text { Text } & 134\end{array}$

$\begin{array}{ll}\text { Element } & 136\end{array}$

$\begin{array}{ll}\text { Purpose } & 139\end{array}$

$\begin{array}{ll}\text { Context } & 142\end{array}$

$\begin{array}{ll}\text { Audience } & 145\end{array}$ 
$\begin{array}{ll}\text { Emphasis } & 147\end{array}$

$\begin{array}{ll}\text { Contrast } & 147\end{array}$

$\begin{array}{ll}\text { Color } & 149\end{array}$

$\begin{array}{ll}\text { Framing } & 153\end{array}$

$\begin{array}{ll}\text { Bringing emphasis together } & 154\end{array}$

$\begin{array}{ll}\text { Organization } & 156\end{array}$

$\begin{array}{ll}\text { Alignment } & 157\end{array}$

$\begin{array}{ll}\text { Proximity } & 159\end{array}$

$\begin{array}{ll}\text { Sequence } & 160\end{array}$

$\begin{array}{ll}\text { Benefits of a new media reading strategy } & 161\end{array}$

$\begin{array}{ll}\text { Conclusion } & 163\end{array}$

$\begin{array}{ll}\text { Conclusion: Possibilities and issues } & 167\end{array}$

$\begin{array}{ll}\text { A new media reading heuristic } & 167\end{array}$

$\begin{array}{ll}\text { The pay-off } & 170\end{array}$

$\begin{array}{ll}\text { Questions to carry away } & 172\end{array}$

$\begin{array}{ll}\text { References } & 174\end{array}$ 


\section{List of Figures}

Figure 1.1. A typical electronic thesis/dissertation (ETD) in PDF format.

Figure 1.2.A typical screen design for scholarship about new media, which relies on written text.

Figure 1.3. A screenshot of Erin Smith's "Reading and Mis[s]reading the eneriwomaninterface."

Figure 1.4: Design of Sirc's "Nevermind the Tagememeics," the online version.

Figure 1.5. The opening screen of Anne Wysocki’s “A Bookling Monument.”

Figure 1.6. Another screen from "A Bookling Monument."

Figure 1.7. The opening screen of Hypertext Gardens.

Figure 1.8. StorySpace map for Hypertext Gardens

Figure 2.1. The opening HTML screen of "Red Peppers."

Figure 2.2. A screenshot of the opening scene of "Red Peppers."

Figure 2.3. The red pepper with the shadow of the father over the shadow of the girl. 60

Figure 2.4. The figure of the slouching young woman. 62

Figure 2.5. The swirling red and gray men.... 64

Figure 3.1. The index screen for Lexia to Perplexia.

Figure 3.2. The original title image for Lexia to Perplexia.

Figure 3.3. The moused-over title for Lexia to Perplexia. $\quad 76$

Figure 3.4: Section of “f...f” screen shot from Lexia to Perplexia.

Figure 3.5. An example of the negative eye in Lexia to Perplexia. $\quad 81$

Figure 3.6. Creolizations such as NO.where, N.tmp, and exe.change appear. 82

Figure 4.1. The opening screen of "Digital Multiliteracies." 98 
Fig. 4.2. The Hay-Wain painting by Bosch.

Figure 4.3. An example of the iMovie interface.

Figure 4.4. A screenshot showing the clip "reading \& writing" in the viewer.

Figure 4.6. A compilation of several of the still clips.

Figure 4.5. The fluorescent lights in the first still clip.

Figure 4.7. The "reading \& writing" and "flourescent" [sic] clip combined.

Figure 5.1. The opening scene of "Murmuring Insects."

Figure 5.2: Contrast shown between black and white elements and size of elements. 147

Figure 5.3. The index screen links compared to the gradient of the background color. 150

Figure 5.4. The background color in the air scene mimics the color of a daytime sky. 151

Figure 5.5. The nighttime lake with reflected light in the water scene.

Figure 5.6. Examples of frames possible in screen-based texts.

Figure 5.7. Yellow lines indicate where the frame is.

Figure 5.8. Two lines of poetry show the invisible horizon on which they land.

Figure 5.9: A sequence of screen shots showing the geese covering the contrails. 


\section{List of Tables}

Table 1: Three possible ways to read "Murmuring Insects."

Table 2. Heuristics for a new media reading strategy

\section{List of Files and File Formats (on CD-ROM)}

\section{Filename}

ball_diss.pdf

fig_list.pdf

\section{Description}

Full PDF version of dissertation

Screenshot list of all figures in dissertation
File Size

18.9 MB

$1.9 \mathrm{MB}$ 


\section{Finding a new media reading strategy: An introduction}

"What is new media?" This question underlies a larger issue — how do readers interpret new media texts - that this dissertation will address. New media texts, as I describe more fully in chapter 1 , include overt use of nonalphabetic elements that, within the context of English studies, readers struggle to interpret given their unfamiliarity with how these elements can convey meaning. "New media" may seem new to many readers because their reading familiarity is with alphabetic texts. Thus, I explore and focus on how some readers (e.g., students, teachers, colleagues in English studies, etc.) struggle to acquire reading strategies appropriate to understanding the visual, aural, interactive, and other modes of communication in a new media text, and I propose a strategy that could provide solutions for helping readers make meaning from new media texts.

I begin this dissertation by defining the term "new media" as a text that consciously uses multiple modes of communication (e.g., visual, audio, linguistic, etc.) as part of its persuasive meaning and in ways that readers often are unaccustomed to having to interpret. (What constitutes interpretation or meaning is central to this dissertation and is a point to which I will return shortly.) Readers often understand how visual or aural or linguistic pieces of communication work — with basic literacies in these areas, readers can generally determine what a text is and, perhaps, why the text fits a particular genre, given some recognizable conventions. For instance, a reader who has taken several English classes would recognize that this text I am writing uses a genre like a class paper because of its appearance. Similarly a reader would probably understand that Hieronymus Bosch's painting, The Hay-Wain (which I discuss in chapter 4) is, in fact, a painting based on the reader's having seen certain genres of paintings before. She may even be able to suggest that there's a connection between the triptych form and the appearance of God in the painting. 
But what readers are sometimes unable to do is understand what a new media text is because such a text often combines features of genres in ways that are unexpected or unfamiliar to a reader. For instance, one of the texts I discuss in this dissertation is "While Chopping Red Peppers" (Ankerson \& Sapnar, 2000), which is based on a written poem - a part of the text that readers tend to recognize - and also includes animated graphics and audio elements from which readers should also make meaning in order to understand the whole text. Another example text is "Digital Multiliteracies" (Miles \& Taylor, 2003), which uses written text, photographs, and audio clips that readers have to select and place on a timeline for playback (as if the readers were editing a short movie) to be able to interpret the text. As I show in chapter 4, some readers encountering "Digital Multiliteracies" for the first time aren't yet able see how the nonwritten elements in the text - that is, the photos, audio, and more over, the necessity of interacting with these elements - contribute to a persuasive meaning. Instead, they focus on the parts of the text that are written and try to form a reading based only on those parts. The problem with reading the text this way is that it incorporates less than a quarter of the possible elements the designer intended for the reader to use to form an interpretation. A primary goal of this dissertation is to demonstrate that readers are relying on written modes of communication to make meaning in new media texts because focusing on the linguistic is what many readers have been taught to do, generally, in their writing classes. A second goal, as I will be arguing throughout this dissertation, is to demonstrate that the theories potentially useful to interpreting new media texts either:

a) focus on describing the historic context and technologically available materials a designer used in her design processes rather than describing the text in ways that help readers make meaning from those materials and design processes, or

b) reinforce the written paradigm by offering reading processes that don't suggest to readers that they can shift their linguistic interpretive training to other (and multiple) modes. 
In chapters 1 through 4 of this dissertation, I will show that many of the available theories for reading new media texts also need to accommodate readers' needs when they have to interpret such texts. I conclude in chapter 5 by offering a heuristic for interpreting new media texts that expands on linguistic reading strategies to include making meaning from multiple elements and modes in a text.

Two underlying issues that I address in helping readers new to understanding new media texts are this: (a) What does it mean to interpret, or make meaning from, a new media text? and (b) Why is it important to have a way to interpret new media texts? I will address these questions here.

The idea for this dissertation came from trying to apply several rubrics for understanding multimodal and new media texts to "While Chopping Red Peppers" (Ankerson \& Sapnar, 2000) and realizing that there was a difference between the way those rubrics provided information about the text and how I wanted to make meaning from the text using a poetic and rhetorical perspective. In order to help me understand the differences in readings that these rubrics provided, I needed to create a taxonomy that differentiated between describing a text's features (which is what the rubrics I was using tended to do, as I show in chapter 1) and interpreting the text in a way that, say, would satisfy a writing teacher. I began to distinguish between understanding a text and reading a text. As I watched other readers try to make sense of new media texts, I noticed that they were able to recognize some of the elements of those texts based on how those elements related generically to other texts with which the readers were familiar - they could, that is, recognize conventions in segments of the text and understand the how those segments made meaning if taken outside the context of the entire new media text. But those readers while being able to recognize certain elements were not able to assign meaning (which I will address momentarily) to those elements within the context of the whole text or a section of it. (I will demonstrate this partial recognition in more depth in 
chapter 3.) These readers were not yet able to provide readings of the texts in the same way a reader who has more familiarity with interpreting multiple modes could do. A reading of a text can be more or less sophisticated than, say, what a writing teacher might want, and a reading can even be a failed reading if, for example, the reader is unable to even recognize a text because a basic understanding of the text's elements is not possible. I use the term reading throughout this dissertation to refer to how readers interact with and make meaning from new media texts, and with each use I hope to show that readers of such texts often have highly variant levels of understanding the many modes of communication generally found in a new media text.

My familiarity with conventions of new media texts, which I have drawn from experience reading literary hypertexts and poetic texts, has helped me assign meaning to new media textual elements in ways that some readers were unable to do in the example new media texts that I discuss in this dissertation. Out of this initial inquiry into reading new media texts, I created the following equations to describe the difference between understanding and interpreting new media texts:

understanding $=$ familiarity/recognition and understanding $\neq$ interpretation

That is, if a reader recognizes a text, she may understand how it can function within its generic conventions, but her recognition or familiarity with the text does not necessarily suggest that she can interpret it. In other words, she might understand what the text is but not how or why it makes meaning. I use the terms understanding, recognizing, or familiarity with a text or its elements interchangeably to signal that a reader's identification of how elements in a text make meaning is equivalent to her understanding of how those element's conventions normally work in similar texts. For instance, a reader might recognize that Bosch's The Hay-Wain is a painting; because of this recognition, the reader understands that the painting needs to be read with attention to the visual elements within the painting. 
The same reader, however, may not yet know how to read, interpret, or make meaning from those elements. The difference between defining a text according to genre, for example, and being able to interpret the text becomes evident in this dissertation. I use the terms reading, meaning, and interpretation (and later in chapter 3, this term will be addressed more fully as a consistent interpretation) interchangeably to refer to how a reader is able to assign semiotic value to elements within a text, and I demonstrate using those values how the elements relate to the text's overall purpose or argument. For instance, a reader who is able to make meaning from the multimodal elements in a new media text like "Red Peppers" (Ankerson \& Sapnar, 2000) would be able to form an interpretation of the text suggesting, as I will show in chapter 2, that the daughter/ speaker in the text feels that her father's intrusion into her life has become overwhelming and is causing a tension in their relationship that seems insurmountable. Coming to such a reading requires integrating the various elements' meanings-written, aural, and visual, in this case - the process of which is an act of interpretation. Being able to read a text with attention to all of its multimodal elements - and show how those elements make sense within the whole text - is equivalent to interpreting the text. In this way, interpretation is like reaching gestalt when viewing an art object or performing a rhetorical analysis of a text, concepts that I address in depth in chapters 3 and 4 . Using this differentiation between understanding and interpretation, I hope to show that readers who are unfamiliar with reading/interpreting/viewing new media texts often struggle to understand how those texts make meaning because readers are more accustomed to assigning meaning to linguistic elements than to multimodal elements. In contrast, I show how more robust interpretations of a text are possible when all of a new media text's multiple modes are taken into consideration.

I am now left with one final question, which is the impetus for this dissertation: Why is it important to have a way to interpret new media texts? One answer to this question is simply that these texts exist, and people need to be able to interpret them. As a teacher, 
I see that students are encountering new media texts more often in their daily lives (e.g., on the Web, on TV, and in their commutes to school). And so with a new kind of text - a text that requires a different reading strategy than those currently available — students and other readers need a way to help them interpret such a text, which will give them more agency in their cultural landscape. A more formal answer to why it is important to give readers means to interpret new media texts is to look at the current scholarship in writing studies. As I discuss in this dissertation, the New London Group (Cope \& Kalantzis, 2000) described in Multiliteracies: Literacy Leaning and the Design of Social Futures that students need to become multiliterate, which they can do by producing texts in their classes that address how readers interact with texts in ways that address more than just written communication. Pedagogies of multiliteracies have found their way into writing class curricula, including redesigns of first-year writing classes to be multiliteracy communication classes (e.g., Lynch \& Wysocki, 2003), publication of textbooks that help students design a range of texts (e.g., Selfe, George, Faigley, \& Palchik, 2004; Wysocki \& Lynch, 2005), and scholarly texts that address how to incorporate the production of multimodal and new media texts in writing classes (e.g., Anderson, 2003; George, 2002; Reid, 2003; Ross, 2003; Sorapure, 2004; Wysocki, Johnson-Eilola, Selfe, \& Sirc, 2004). There is a definite trend in composition studies that addresses the use of students' designing new media texts, and part of being able to produce such texts is the need to analyze them. Thus, how to help students and other readers of new media texts analyze them is the focus of this dissertation. 


\section{The need for a new (-media) reading strategy}

\section{Introduction}

In this chapter, I explore the current use of the term new media within English studies. I argue that most current scholarship on new media, rather than providing a way to make meaning from new media texts, compares it to old media by exploring the digital technologies that separate and remediate the two. I show how the kinds of texts that are being called new media still carry codex traditions as the foremost mode of communication, which limits the ways readers can make meaning from texts that aren't conventional according to print or digital traditions. Expanding on one of the most recent definitions of new media (Wysocki, 2004a), I suggest that the term new media should be applied more specifically to texts that engage readers by using multiples modes of communication including, for instance, visuals and audio. I argue that such texts combine modes in ways that are often unfamiliar and unexpected - in other words, new - to readers who are accustomed to mainly having had to interpret written text. Because these texts challenge readers' assumptions of how (and from what) to make meaning, as I show through an example of readers engaging with a hypertext essay, I believe that a broader reading strategy that considers multiple modes of communication is necessary in order to interpret new media texts. Within this larger argument, this first chapter lays the foundation for addressing the question of what new media is by considering the current scholarship within writing studies.

\section{A brief background on the term new media}

In composition studies, much of the scholarship on new media references two books: Jay David Bolter and Richard Grusin's (2000) Remediation: Understanding New Media and Lev Manovich's (2001) The Language of New Media. The focus of these books 
is to make readers aware of the technological and historically intertextual connections on which new media texts draw in order to show their relationship to texts already understood within humanities-related fields.

In Remediation, Bolter and Grusin (2000) explained the characteristics of new media prior to 1999 , demonstrating how new media texts undergo a process of remediation whereby readers find old media patterns in new media texts and vice versa (and that readers use these familiar patterns to help them decode the new media texts). Bolter and Grusin highlighted the technological change that happened in the late 1990s, focusing on how newer technologies (e.g., computer games, digital art, the World Wide Web, and other media) remediated, or refashioned, texts to draw on older media. They used an example that also shows the inverse: The $\mathrm{CNN}$ television network remediated its design to mimic the multiple screens and frames available on the Web (p. 189-91).

Bolter and Grusin (2000) pointed to the "new" of new media, suggesting that "what is new about new media comes from the particular ways in which they refashion older media and the ways in which older media refashion themselves to answer the challenges of new media" (p. 15). Remediation focused on visual media, inferring that new media texts make meaning foremost through graphic (and sometimes aural) modes rather than through written or other modes. But by focusing almost exclusively on the graphic aspects of new media, the authors limited the extent to which readers of Remediation might understand what new media could be. Indeed, Bolter and Grusin did not address how readers might interpret new media texts presumably because new media draw on older media to make meaning and thus, they implied, the reading strategies necessary to interpretation are already available.

Like Bolter and Grusin (2000), Manovich (2001), in The Language of New Media, attended to the historical, intertextual trajectories of new media by aligning the chronology of media technologies to that of computing. He argued that because texts can be transcoded into digital data via (relatively) new computer technologies, the resulting 
objects can contain an amalgam of media including "graphics, moving images, sounds, shapes, spaces, and texts" that are available for inclusion because they "have become computable: that is, they comprise simply another set of computer data" (p. 20). In other words, the ease with which designers can incorporate multiple media into one text is made possible because of computer technologies. Manovich's claim that new media at its most fundamental level is computable, which signaled the break between old media and new media, may seem too broad a definition of new media. However, he argued that while popular definitions of new media suggested that this broadness is acceptable. He intended to demonstrate that the digital presentation of new media texts was "too limiting," and that paper texts could be new media as well because "there is no reason to privilege the computer as a machine for the exhibition and distribution of media over the computer as a tool for media production or as a media storage device" (p. 19). After all, it is rare to find a contemporary text that has not been manipulated in some way, such as word-processed by a computer. Word-processed texts, Manovich claimed, could be considered new media because they have encountered a process of digitization even thought the "product" of that process is a text distributed on a piece of paper.

Manovich (2001) also suggested that older media can sometimes act like new media, as in the case of early cinema or illuminated manuscripts, which function as multimedia texts without the computer screen as a viewing medium (p. 50); but these texts are not actually new media, he cautioned. Unfortunately, he did not explain why older media could not be considered new media except for its lack of digitality, which suggests that he holds firmly to his definition of new media as media influenced by computability. Nor did Manovich address what might become of an illuminated-manuscript-as-old-media should someone digitize it. Thus, his main argument in describing new media is that such texts are new because they either are or have been digitized during the process of design.

Bolter and Grusin (2000) discussed the flexible remediating possibilities of new media, and Manovich (2001) claimed that new media must be digital (either in 
presentation or production). Their arguments created a space in which the term new media has come to stand for any kind of digitized text, including link-node hypertexts and Portable Document Formatted (PDF) texts, as I show next. When scholars like Bolter, Grusin, and Manovich, as well as others who specialize in composition theory and practice, broadly apply the term new media to many kinds of digitized, and especially online texts, the term becomes a catch-all for digitized, and especially online, texts. Online scholarship in composition studies is one area where the term new media is being applied with a broad stroke, which creates a cliché that I will discuss below.

\section{The cliché of new media}

The current trend in online publication venues is to label online texts new media scholarship. For instance, the Networked Digital Library of Theses and Dissertations (NDLTD), which is an international clearinghouse for electronic theses and dissertations (ETDs), uses the term new media scholarship to refer to its collection (Edminster, 2002; UNESCO, 2001). The ETD initiative has greatly expanded since its inception in 1987 to include formats such as hypertext, hypermedia, video, VRML, and others. But the primary method of creating an ETD is to have students type their dissertations in a word-processing program and save it in Portable Document Format (PDF) using Adobe AсRоват. A PDF version of the print document keeps the print-based formatting intact for online presentation.

Essentially, most ETDs resemble a print dissertation - they can be downloaded and printed just like a document from Microsoft WORD (See Figure 1.1). These documents follow the conventions of a print thesis or dissertation, varying to the extent that an author may have included bookmarks, which function like a hyperlinked table of contents in the PDF, so that readers can jump between chapters and sections without having to scroll. ETDs function as print texts in that they encourage readers to use the same printbased strategies to read the text that readers would apply to a printed copy. Although they 
do use electronic bookmarks and scrolling, these features relate to print-based reading strategies in that, like a table of contents, they function to move the reader to specific, linear points within a text. It is doubtful, in fact, that most readers would actually read the PDF online when they could print it easily and read it under less eye-strained conditions. Because of their digital accessibility, ETDs often are called new media scholarship. Yet, applying this term to such online scholarship seems unnecessary; one wonders why it should be termed "new" when the "old" name (ETD) sufficiently describes its characteristics. The same can be asked of most hypertexts - even those that claim to be pushing the boundaries of traditional scholarship and that might require reading strategies that take visual or other modes into account.

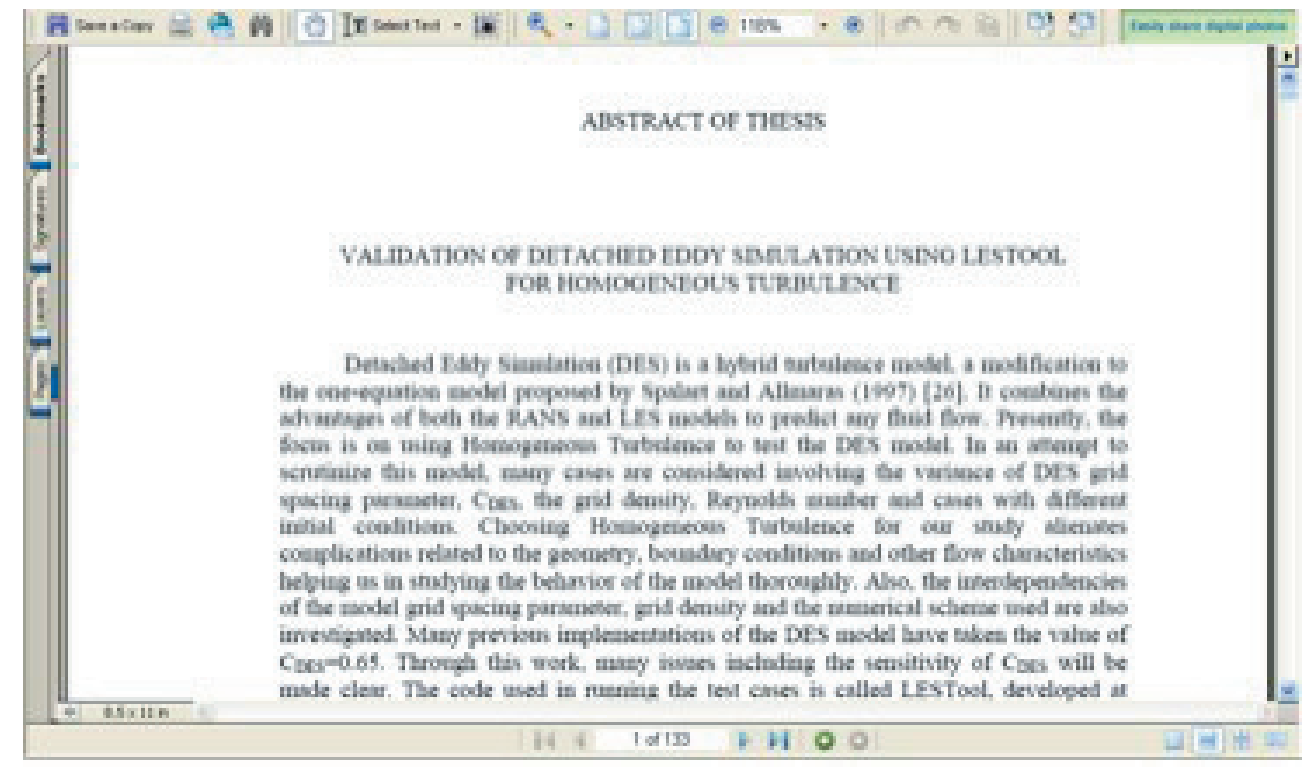

Figure 1.1. An example of a typical electronic thesis/ dissertation (ETD) in PDF format.

For instance, in CCC Online Steven Krause (2002) said that "increasingly, the only significant difference between online journals and their more traditional counterparts is the [publication] medium." The problem is that online journals have the ability to costeffectively publish texts that can technologically push beyond reading habits associated with the limits of the printed page, but they don't. Patricia Webb Peterson's (2002) 
analysis of Kairos, for example, demonstrated that this journal is a venue where authors can publish experimental texts - texts that might require a different reading strategy than those of print-based and many online journal articles. In her article, Peterson remarked that Kairos "identifies its purpose as both conforming to while still challenging traditional disciplinary definitions of scholarship and scholars." Kairos has, however, also "adopted print-based, traditionally accepted strategies for structuring" certain elements of the journal such as the table of contents. Peterson suggested that this switch from challenging the conventions to using the conventions is based on how "we are used to reading." In other words, she seems to believe that readers are more comfortable navigating a wordbased table of contents because it is what they expect in regards to a scholarly journal's generic format.

Even so, Kairos began and continues to offer itself as a place where authors can publish scholarly texts that could be considered nontraditional for the purposes of print journals. In other words, Kairos could publish texts that require reading strategies quite different from those of paper-based scholarly texts. The journal attempts to achieve "a balance between tradition and innovation... a fact that suggests that the physical (or virtual) medium directly influences the kinds of scholarship that is allowed/encouraged," as Peterson's close reading showed. But does Kairos follow through on the innovative potentials of publishing online scholarship? If a reader finds link-node hypertexts still innovative, then, yes, Kairos does push scholarly boundaries. With the exception of a few new media texts that break away from using written text as their main mode of communication (notable exceptions that I will discuss later in this chapter were authored by Anderson, 2003; Reid, 2003; Ross, 2003; Miles, 2003b; Wysocki, 2002), Kairos and other online composition journals have had limited impact within the field of new media in regards to publishing such texts. To quote one Kairos reviewer after he received a linknode webtext for review in early 2005: "I want to confirm that I am seeing this webtext right: I am seeing six pages with standard left nav[igation] and embedded notes. No 
hidden nonlinearity." His confirmation-as-question implied that he was expecting more attention to be paid to the technological, hypertextual qualities available to webtexts. Given that the text had been written for Kairos, he seemed to be expecting something different from, and maybe more than, a print-based text published online. Although he judged the text to be well written, he read it with a linear eye rather than the hypertextual one he was hoping to use. This is not to say that authors have not used or discussed new media technologies in online journals - just that the ways in which those technologies have been used don't require readers to expand their reading strategies beyond conventional, linear compositions as the example below further indicates.

In a Fall 2002 Kairos webtext, "[Continuing to] Mind the Gap: Teaching Image and Text in New Media Spaces," Kathie Gossett, Carrie Lamanna, Joseph Squier, and Joyce Walker stated on the first screen that their intention was to "claim academic legitimacy" in multimedia by creating a new media text. Their argument focused on the need to incorporate multimodal literacies with written literacies - a notion not new to this field, as evidenced through the New London Group's Multiliteracies (Cope \& Kalantzis, 2000) and Gunther Kress and Theo van Leeuwen's (2001) Multimodal Discourse. "Mind the Gap" used multiple modes of communication including video clips of the authors in a roundtable discussion and still images that added visual immediacy to the text. These multimodal elements allowed readers to see and hear the authors add to their written arguments, but the elements didn’t work as focal meaning-making points — they acted as footnotes to the written text—-supplemental areas to explore—not necessary paths to follow to fully interpret the text's meaning. It is the written text on which readers were asked to rely; the written text was central to the design of the screen, and its prominence required that readers use it as the main meaning-making mode to understand the authors' point (see Figure 1.2). This webtext was instrumental in explaining why one should use new media, and it is crucial to have conventional scholarship that addresses the meanings and potentials of unconventional, new media texts. "[Continuing to] Mind the Gap: 
Teaching Image and Text in New Media Spaces" is an example of scholarship about new media but that doesn't mean readers (and authors) should label this text—nor any of the similarly designed, link-node, writing-intensive hypertexts that the online scholarly journals typically publish—as new media.

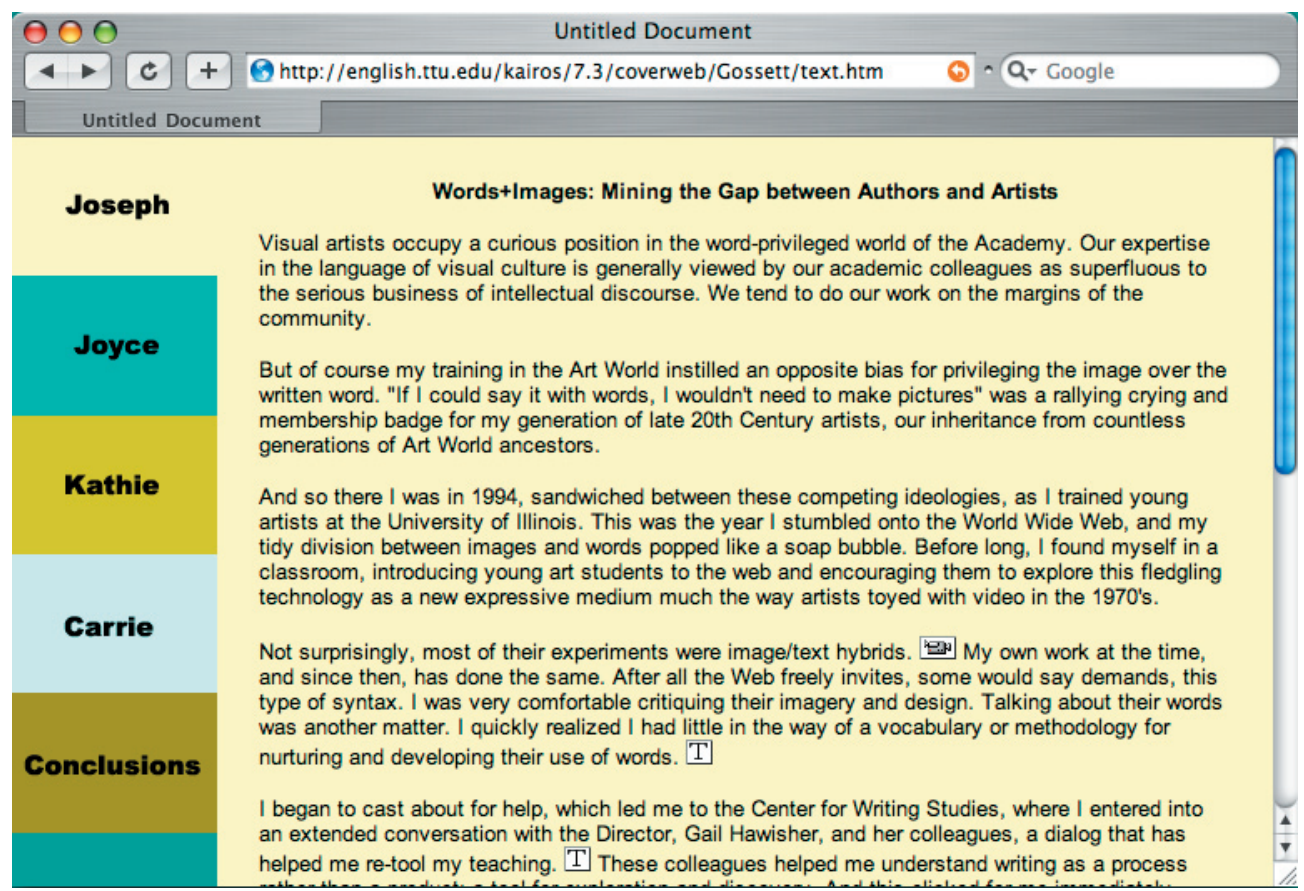

Figure 1.2. A typical screen design for scholarship about new media, which relies on written text.

As with ETDs, the question of labeling a conventional, digital text remains: Why give a text a new name simply because it (a) is digital/has been digitized or (b) includes nonwritten modes of communication - especially when readers are using the same strategies to make meaning from these texts as they would if they read the text in print or cinematic or other traditional (i.e., old media) forms. In general, hypertexts still mimic linear, print conventions to such a degree that it is difficult to find a text that doesn't follow a traditional link-node or next-button navigation. Indeed, this characteristic of hypertext is not necessarily bad, since the possibilities of HTML and the link-node structure are what first gave authors the incentive to create digital scholarship. 
Nonetheless, this characteristic seems limiting given that authors now have other modal and technological possibilities for creating new media texts.

Yet, Peterson (2002) referred to one text (of the handful of examples in Kairos' history) that tried to move slightly beyond conventional reading strategies_-Erin Smith's (2001) "Reading and Mis[s]reading the eneriwomaninterface," which has an opening screen where words fade into view (see Figure 1.3 for a static version). Peterson (2002) said, "the opening represents an innovative use of the technological possibilities that are now available to online publications." Smith's text was groundbreaking in many ways; it was one of the first online, scholarly texts to discuss Macromedia FLASH script and to show readers how such scripting could be interpreted. However, Smith's hypertextual design is mostly transparent, relying primarily on chunked written text with several illustrative screenshots - in the end, it is remarkably print-reminiscent.

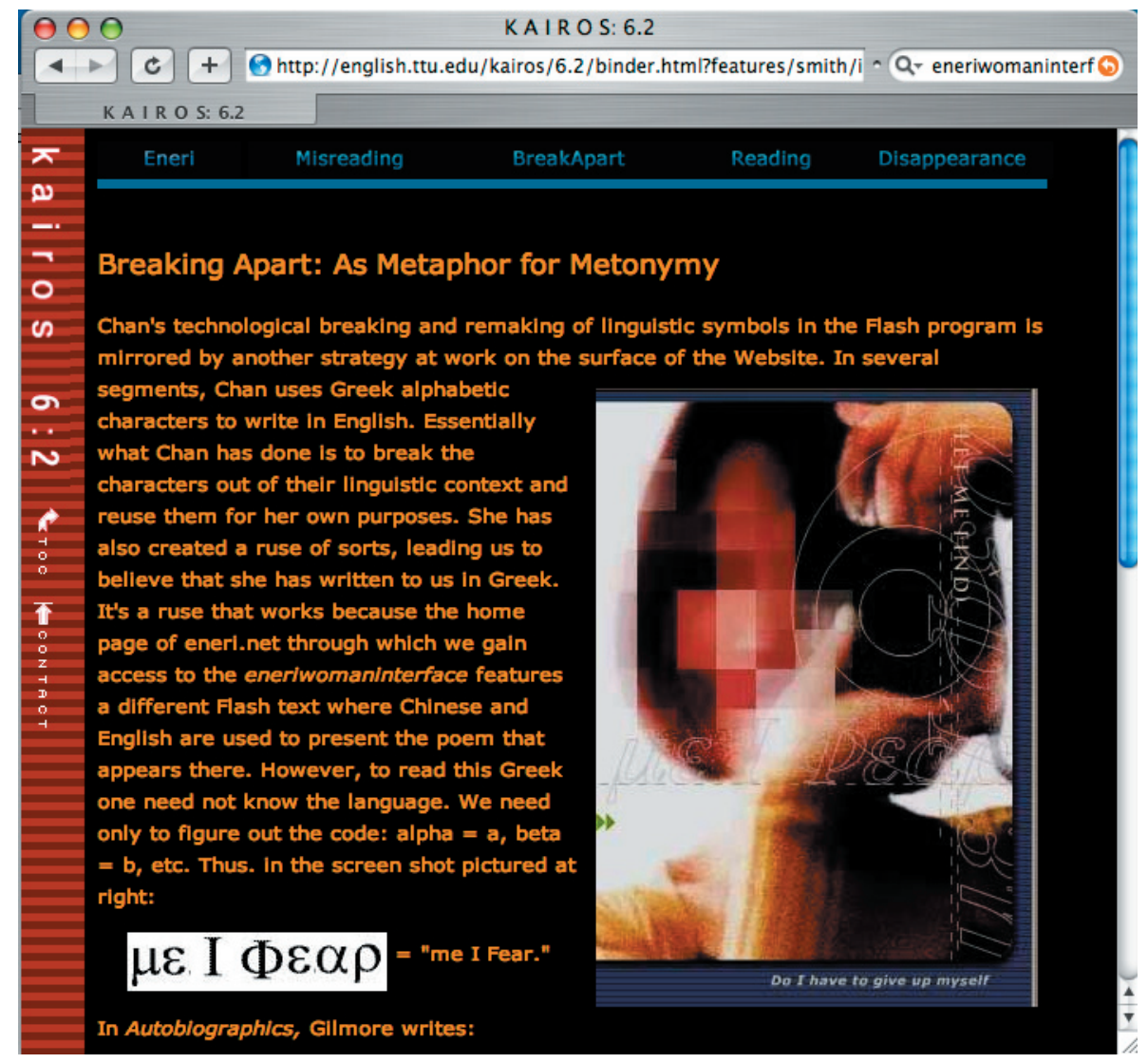

Figure 1.3. A screenshot of Erin Smith's "Reading and Mis[s]reading the eneriwomaninterface" 
Peterson (2002) found Smith's use of “pictures as moving images...new to a scholarly publication [, which] creates an artsy feel that is echoed in the style of writing." This design may have been new to Peterson in 2001-02, but it is dated in 2005. Peterson also referred to Smith's work as having "more snazzy graphics" while still being "clearly located in the academic realm, as evidenced by her topic, her citations, her tone, and her theoretical knowledge." Peterson's analysis appears to create a scholarly split between Smith's "snazzy graphics," which Peterson seemed to read as frilly or inconsequential and lacking rhetorical purpose, and her written text, which Peterson concluded must be academic based on its evidentiary clues. Peterson did acknowledge the text's design to some extent when she said, "a scholar's creative design can shape the ways in which scholarship in our field gets defined." However, her acknowledgment left composition's scholarly conventions in the realm of old media.

I think that the "rhetorical presentation" (as Peterson called it) of Smith's navigation, use of color, and placement of images should be considered just as important in persuading the audience as the written text. Otherwise, why include it? Indeed, one wonders why an author would compose a web or new media text when she could, perhaps, spend less time and energy by composing in a medium through which scholarship in English studies has almost always appeared—print—especially if it means not having to think about which graphic to use in the menu, what the background color should be, and how to get the links working, all to make the argument stronger. The easy response is that an author should think about and incorporate these elements into online texts because she can. The more rewarding response may be that composition studies now has a brief but growing history of incorporating multiple modes of communication into its curricula. Because visual rhetoric — as an example — is being taught to students in both analysis and production of texts, then teachers need to consider including other modes in addition to the written and the visual. In addition, if compositionists fail to address the rhetorical questions of their own visual webbed and multimodal work, then 
teaching moments about multimodality will go unaddressed as well. This is not to say that Smith didn't pay attention to her text's design (I believe she did because she used several unconventional elements, like the fading text) but to suggest that readers who ignore or overlook the importance of elements other than writing are missing part of the text's meaning, part of its argument. The valuation of the author's design may be what separates new media texts from other online scholarship for readers. How a designer rhetorically composes an interface as well as the written text (if any) — and how a reader understands that composition — needs to be as important to the technologically changing face of English studies as reading print-based, or print-like scholarship. Otherwise, the design becomes an unnecessary addition, technological fluff, or a distraction, as the next example shows.

An early webbed text in which the authors tried to incorporate visual elements as part of the text's meaning was Geoffrey Sirc's (1997) "Nevermind the Tagmemeics [sic], Where's the Sex Pistols?," which appeared in the first issue of Pre/Text: Electra(lite). Sirc's purpose in this piece was to remind readers that the value of counter-culture (in this case, the Sex Pistols) can play an extremely useful role in composition classrooms and that students might react more congenially to first-year composition courses if instructors asked them to read and write nontraditional texts. This text was memorable for shocking readers out of their print-based complacency with its neon green background, colorization of words for emphasis, and horizontal scrolling text. The design of the text, which supported Sirc's written argument to shock students out of their complacency using punk lyrics, showed a conscious effort to use the technology at hand to make readers aware of and think about the implications of layout, images, colors, and typefaces. The bulk of the page (I call it "a page" because it is one web page in total) is written text. It is reminiscent of print, and because the article was republished in Pre/Text from the original, print version in College Composition and Communication, readers would not be surprised to 
find its text-heavy presentation, especially given typical web-design conventions in 1997 (see Figure 1.4).

However, its purposeful horizontal scrolling and use of color for words that aren't links ran counter to contemporary web traditions. Once a reader figures out this small disjuncture between web conventions and print conventions, Sirc's article requires old-media reading strategies, not new or different or more robust ones, although his scholarship maintains a sense of newness, as I show next.

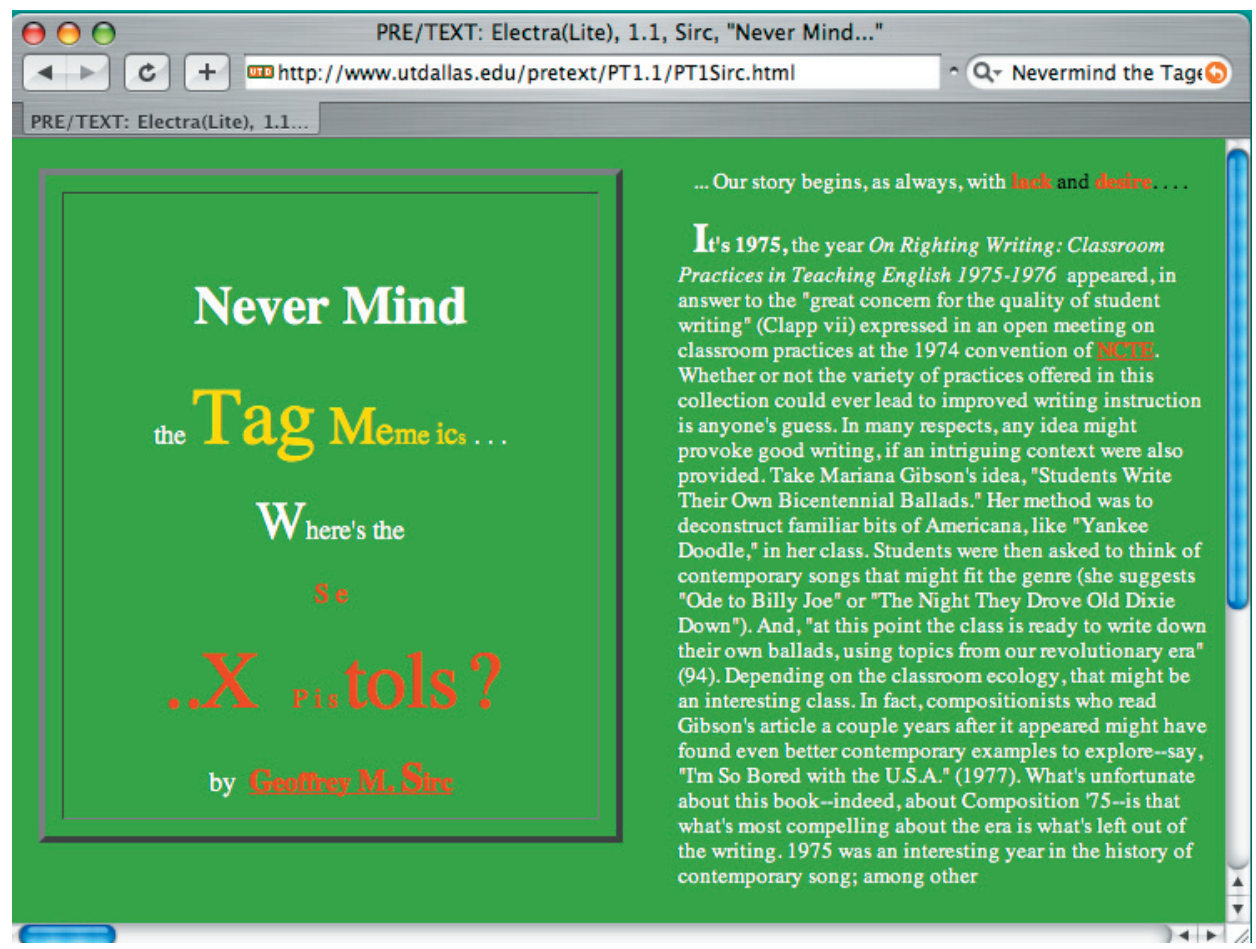

Figure 1.4: Design of Sirc's "Nevermind the Tagememeics," the online version.

\section{A new view on new media}

Sirc's scholarship on unconventional texts has progressed from using punk (1997) and rap music lyrics in class (2001) to having his students produce avant-garde compositions (2002). In "Box-Logic," his chapter from Writing New Media (Wysocki, Johnson-Eilola, Selfe, \& Sirc, 2004), Sirc (2004) demonstrated how composition teachers can draw 
on the work of avant-garde and experimental artists to teach students how to compose unconventional texts. Writing New Media is the only collection to date in which the authors specifically discussed how and why a composition teacher should incorporate new media texts into her classroom. (Here I am making a distinction between new media and multimodal, visual, or other kinds of texts - a distinction I will discuss in more depth in chapter 2.) The focus of their book was on the impact that producing new media texts has on students' agency and literacy practices, as well as on instructors' pedagogical practices. In the book's introduction, Anne Wysocki (2004a) said:

I think we should call "new media texts" those that have been made by composers who are aware of the range of materialities of texts and who then highlight the materiality: such composers design texts that help readers/consumers/viewers stay alert to how any text-like its composers and readers-doesn't function independently of how it is made and in what contexts. Such composers design texts that make as overtly visible as possible the values they embody. (p. 15, italics added)

This statement sums up why I believe online texts such as ETDs and scholarly hypertexts cannot be called new media - the authors of most such texts do not make their design values (e.g., the value of using modes in addition to writing) overtly visible — an idea I will return to in a moment.

In her definition of new media, Wysocki (2004a) made explicit that "new media texts do not have to be digital; instead, any text that has been designed so that its materiality is not effaced can count as new media" (p. 15). By taking this turn, Wysocki shifted away from Manovich's (2001) idea of new media as digitized text. For her, the point behind new media was that readers and designers should pay attention to how and why a text is constructed through its materiality; not that it is digital or that it "incorporates text and sound and graphics and animation and photographs or illustrations in some combinatorial 
ratio other than that of a traditional academic or literary text" (Wysocki, 2004a, p. 19). She stated:

Just because there are the (relatively) new technologies of computers and printers and scanners and cameras and sound recorders and personal digital assistants and cell phones does not mean that those new technologies....cause us to produce texts that break away from or ask us to think and act differently than print technologies...did and do. (p. 19)

In other words, technologies do not create new media texts; designers do. Technologies simply facilitate that production in some cases. But it is designers who choose how to use technologies (and not just computer technologies) to compose a text whose materiality is central to its meaning. Wysocki seemed to suggest that new media technologies are those that a designer constructs with careful consideration of how the material elements will openly and intentionally reflect the designer's argument/purpose/meaning, and the design of which readers must acknowledge and interpret in order to understand the text. The open and intentional use of materials by a designer provides the text with an overt design.

This definition of new media — as texts that have "overtly visible" designs - is the one on which I base my own use of the term new media throughout this dissertation. When I refer to a new media text's overt design, I mean to imply that the example text was designed with attention to and value placed on its material elements (such as visual, aural, spatial, and other modes of communication), which a reader has to interpret.

I agree with Wysocki (2004a) that attention to a text's design is important to consider when making meaning from a new media text. However, the texts used as new media examples throughout Writing New Media, while designed in ways that readers should pay attention to (i.e., their designs are not meant to be transparent to readers), are based in relatively conventional genres. For instance, in "The Sticky Embrace of Beauty," Wysocki (2004b) focused on a magazine ad from The New Yorker as an example of a new media text and showed how readers interact with visual texts through issues of 
form. Those forms, she argued, overlook the rhetorical and aesthetic aspects of texts. Wysocki analyzed this ad, demonstrating how using prescriptive rubrics of visual design can mislead audiences to only partially interpreting a text and missing, for instance, the naked, female body that features prominently in the ad. Such an analysis is useful as a model to help readers understand how to interpret a text with a range of rhetorical and visual reading strategies and shows, as I hope to, that reading strategies for new media texts still have room to grow.

There is a relatively long history (in relation to computer technologies) of authors modeling analyses of texts that incorporate visual modes of communication (see, e.g., Fischer, 1996; Golson, 1995; Halio, 1996; Heba, 1997; Markel, 1998; Salvo, 1997; Sorapure, Inglesby, \& Yatchison, 1998). More recently, the scholarship about visual rhetoric and visual literacies has increased, addressing texts that incorporate graphics and other designed elements (see, e.g., George, 2002; Gruber, 2003; Handa, 2001; Hocks \& Kendricks, 2003; Takayoshi \& Huot, 2003; Syverson, 2001; Williams, 2001a, 2001b; Wysocki, 2001). Much of this scholarship focused on the combined meanings of written text and static images within student texts. But, Wysocki (2003), in "with eyes that think, and compose, and think: On Visual Rhetoric" [sic], wrote that "learning to analyze and compose rhetorically effective visual communication is not (simply) a matter of working only with whatever it is we have named "images"' (p. 182) but that it "requires trying to understand and work with (or sometimes against) the expectations and assumptions and values of one's audience concerning ALL the visual aspects of a text" including the way written text is designed to appear on page or screen (p. 183). Wysocki's argument for the need to understand the design of texts foreshadows her later work in Writing New Media.

Another author, Mary Hocks (2003a) in "Teaching and Learning Visual Rhetoric," also explored the visual aspects of texts by analyzing an interactive CD-ROM. In this article, she argued that theories of visual rhetoric versus visual literacies require 
a separation between word and image — visual culture versus print culture-which represents a binary, modernist way of thinking (pp. 203-204). She further argued that

When brought into the online environments of our computer classrooms, visual literacy falls short of describing the interactive environments of many new media and new technologies... Thus, if we want to help our students explore the integrated and visual nature of electronic writing and design, we ought to stress the continuum between visual and verbal forms of expression. (p. 204)

By "stressing the continuum between visual and verbal," she argued that teachers should instruct students not in visual literacy, but visual rhetoric, which enables students to

critique the visual world around them, and to make apparent what has been transparent in the printed pages and online conventions we have inherited. They can study audience, style, and argument in all kinds of visual media and become better cultural critics and rhetoricians. (p. 205)

Hocks (2003a) demonstrated this kind of cultural, rhetorical critique in the assignments she discussed, specifically in the rhetorical analysis of a CD-ROM about artists. She highlighted the need to pay attention to "visual, verbal, and interactive elements" as rhetorical, meaning-making modes (p. 206). The students who designed this $\mathrm{CD}$ were asked to "explore the meanings conveyed by the still and moving images, layers of image and text, colors, and color schemes" to discover "how meaning is not just verbal or visual but rather is multimodal" (p. 214).

Scholarship such as that put forth by Wysocki (2003) and Hocks (2003a) suggests that there is a differentiation between paying attention to writing or static image as visual texts and paying attention to the impact of a text's overall (and overt) design. But what this scholarship does not yet suggest is how to make meaning from texts that readers aren't accustomed to interpreting, including texts whose overt designs readers have never encountered before and thus may be less skilled in interpretation or less able to 
comprehend interpretation strategies. A good example of a new media text is Wysocki's A Bookling Monument (2002), in which she explored the relationships between the body and texts using an image of a torso (see Figures 1.5 and 1.6). This text combined the media of photography, written text, animations, and other design elements so that readers are not always able to rely on conventional, print-based or visual reading strategies in order to interpret the text. Figuring out how to navigate this text may pose a large enough obstacle for some readers to keep them from entering it, let alone engaging with it in order to make meaning from its overt design.

Because there are texts like $A$ Bookling Monument and others that I will explore throughout this dissertation - texts that require different reading strategies than those that readers are traditionally equipped with-I want to suggest a definition of new media that builds on Wysocki's (2004a) definition mentioned earlier. While that definition emphasized a designer's attention to the materialities she chooses when composing a text, a process that infuses interpretable values in a text's design, I suggest that new media texts also require broader reading strategies than print-based ones to help readers make sense of the multiple materialities used in a texts' overtly visible design. I will detail this need for broader reading strategies in the next section.

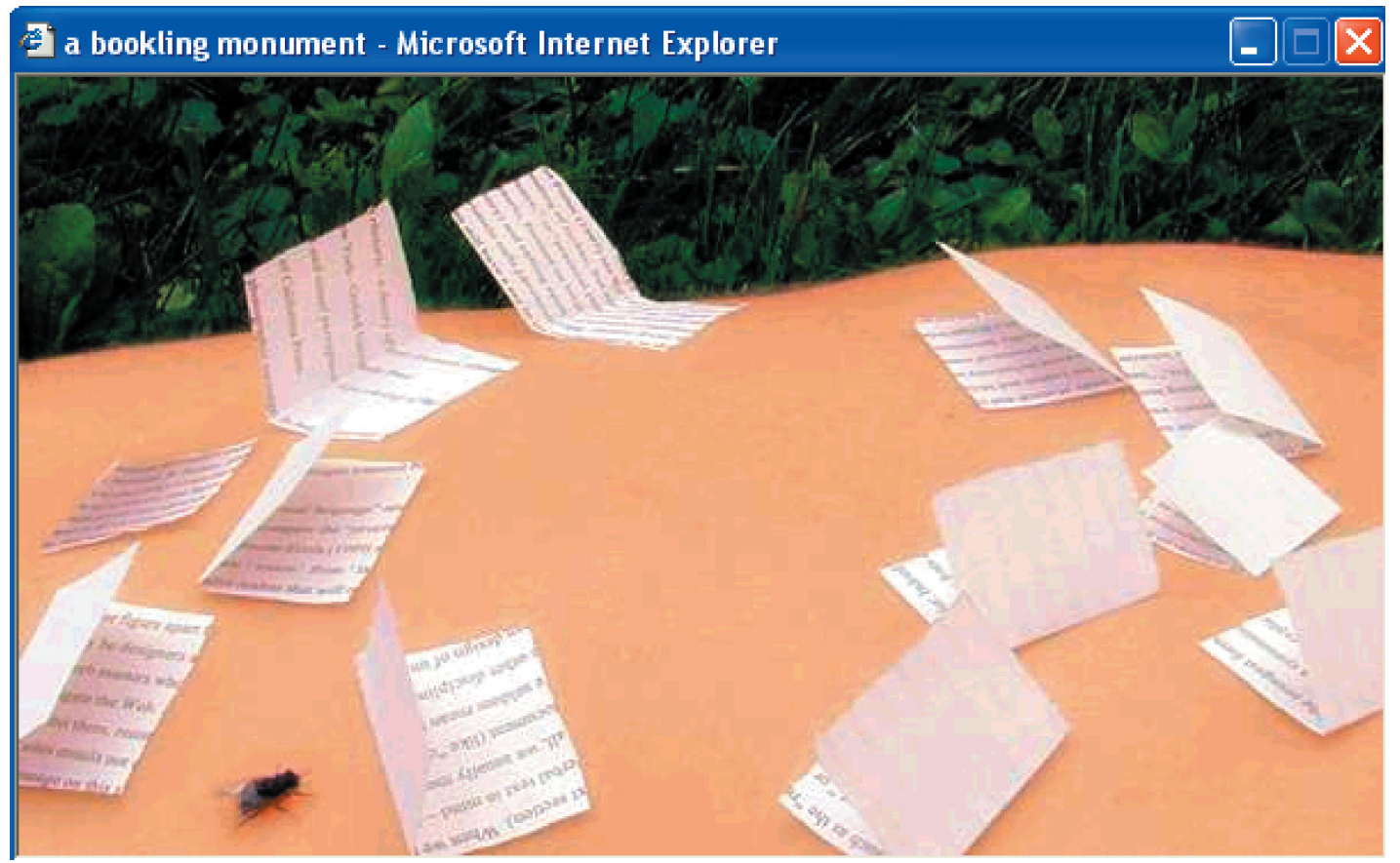

Figure 1.5. The opening screen of Anne Wysocki's "A Bookling Monument" 


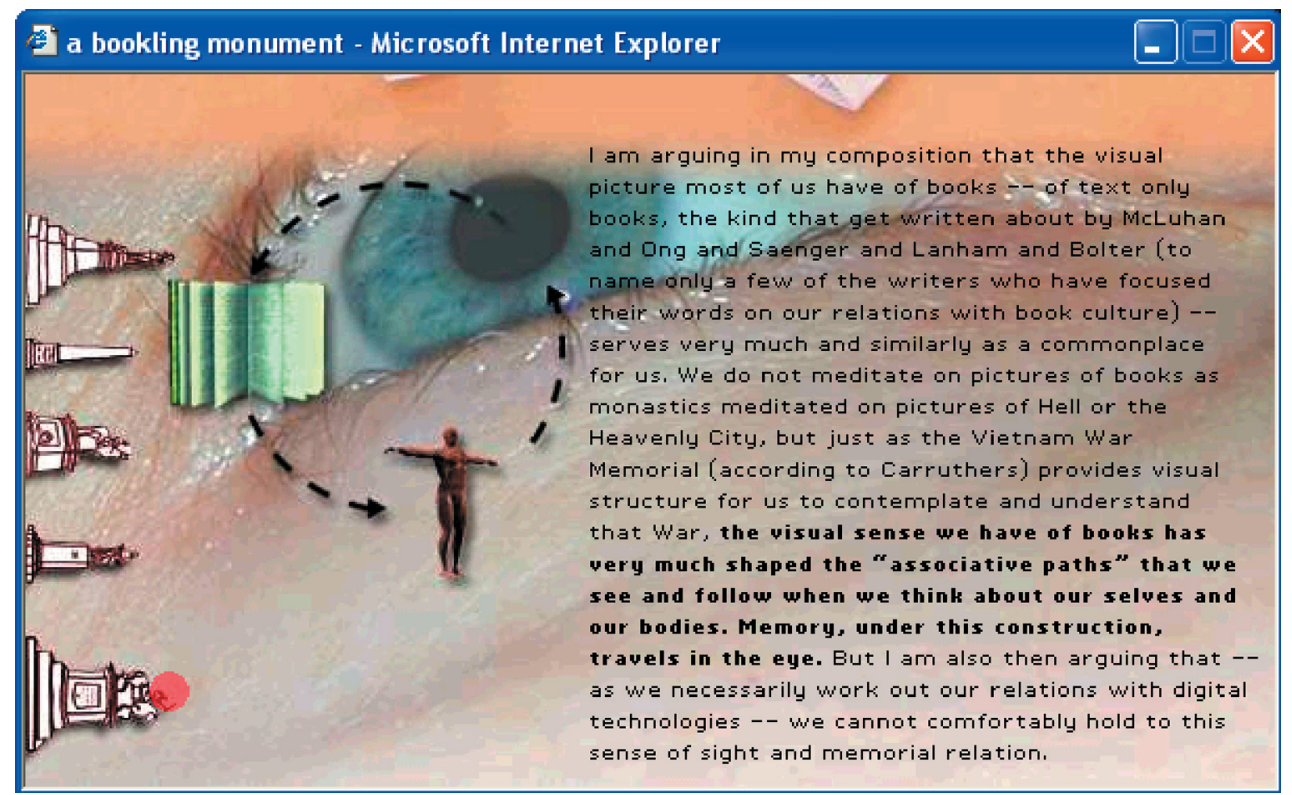

Figure 1.6. Another screen from "A Bookling Monument" highlighting the connection between seeing, bodies, and book technologies in which the memorial statues were used as navigational elements.

\section{The necessity for new media reading strategies: An example}

When readers approach a print or hypertext article, they know they are supposed to be reading the written text to find the argument, the "so what" factor. Yet, with new media texts, the argument (or, rather more generally, the persuasive meaning) isn't necessarily foregrounded as it would be in a print/linear/hypertextual article or webtext. The reader must discover the meaning with the help of the text's overtly visible design. Readers have become more accustomed to rhetorically interpreting electronic texts and still images based in print conventions, but those same readers may not be aware of the need to interpret the design of a text as carrying meaning, nor do they necessarily have strategies for doing so. Katherine Parrish (2002), a designer of new media texts, described her reading strategies of such texts as making "visible the strategies we already use, or ones that we could or should use when reading any text" (p. 93), but unless readers know how to make those varied strategies visible to themselves, this advice doesn't help. 
In the context of composition courses, new media texts are typically new to students, or at least unexpected. To ease students into examining texts whose designers have paid attention to their use of materialities, I have used Hypertext Gardens (Bernstein, 1996), a hypertextual essay that includes written language, graphics, color, and a wandering, recursive navigational structure. Mark Bernstein argued in this text that design (especially seen through nontraditional navigation strategies) adds to a text's meaning, which he showed in part by designing the text with links that seemed to let the reader "wander" through its metaphorical parks and gardens. Using Hypertext Gardens as a jumping off point, I typically ask students to question their composition processes which, up to that point, have nearly always been linearly structured within academic settings. In the following paragraphs, I describe the assignment sequence in which I tried to have students understand the different elements (including graphics and nontraditional navigation strategies) that are available to authors and designers, and to themselves as composers of texts.

Before I explain the assignment sequence where I introduce students to the idea of reading and producing new media texts, I should describe the university and the course in which I taught this sequence. Michigan Technological University is in a remote area of the Upper Peninsula of Michigan with a student population of about 6,000 (graduate and undergraduate). The engineering programs (electrical, mechanical, civil, and biomedical, among others) draw many of the students, most of whom are male and between 18 and 22. Michigan Tech does not have an English department, and when I arrived on campus (in Fall 2000), there were no longer any first-year composition courses. There is a Humanities department, which (because of the school's transition that Fall from quarters to semesters) was responsible for teaching nearly all of the replacement courses for first-year composition. That class was now being offered as one of a four-course, general-education sequence at the sophomore level and it included writing instruction in addition to direct instruction in speech communication and visual design. The way 
the class was design, students would write one research paper, present two types of speeches, and re/design one piece of communication during the semester (these were minimum requirements). So, part of the class, called Revisions, incorporated aspects of design. Some teachers integrated these three modes of communication more seamlessly than others depending on their experience teaching in (or working in) each mode. I had informally taught some web design classes by the time I taught this course, so my classes tended to focus more or less on the design component. It was my first time teaching Revisions with a focus on design, and I learned a lot from the experience-especially how not to teach students about design.

I should also note that the example class I describe below was in the Spring of 2002, four semesters into the general-education curriculum change that included this new course. The students - even the ones I show below, who had never been at Michigan Tech under the old system — were still having a tough time buying into the multimodal aspect of the class. There seemed to be three reasons/guesses why the students came into the Revisions class with lackluster enthusiasm. (a) The course had been misrepresented to them by classmates who had already taken the class and had had a bad experience for whatever reason; (b) They brought with them misconceptions about what the class was supposed to be about (originally, the plan was for the sophomore-level class to literally revise the writing the students did in the first-year communications course - thus the name Revisions, which stuck even when the recursive-writing plan didn't); and (c) None of them believed it was necessary to take communications classes, unless it was a technical communication class in which they would learn how to write memos for their soon-to-have corporate bosses in the engineering world. In other words, those of us teaching in the Humanities continually struggled with students' complaints about the liberal education we were foisting upon them. They wanted a purely technical education, and many of them brought their surface-level disbelief to the first day of class. I knew all of this going into this Spring term, so I was hoping that by focusing on design (and 
telling them that learning about design could help them make really good PowerPoint presentations for future engineering classes) that they would become slightly more invested in the class than they had wanted to, which was unanimously not-at-all on day one. All of this is preface to the assignment sequence I am about to describe and to their reactions to the assignments, which demonstrated their reliance on texts that were already familiar to them.

For the assignment sequence, I wanted to begin the unit on hypertextual composing processes by having students examine how images affect the meaning of texts and how alternate navigational strategies could be used when composing texts. I chose Hypertext Gardens (Bernstein, 1996) to show students that online texts do not have to be designed with a business-oriented, left-margin menu. A second reason for using this text was to show students that images could enhance a text's purpose on a fundamental level. I also wanted to give students an idea of what alternate designs were available to them in their own projects so they would be able to draw on designs other than typical web site structures with which they were familiar. I guessed that students might react in a disoriented way to seeing a nonlinear text like Hypertext Gardens for the first time, so I started instead with a print-based text that I believed they would be able to interpret more easily for their first foray into hypertext.

We read the first chapter of Italo Calvino's (1981) If On a Winter's Night a Traveler. This chapter detailed how the speaker/narrator reads a book and, in doing so, the narrator breaks the novel's fourth wall by addressing the audience with a second-person "you," telling the audience how they like to find a book and how they like to read it (curled on the couch, no television, with the lamp just right, etc.). Calvino's work is often cited as a print-based hypertext — that, combined with its overt attention to the reading process of novels - and that is why I used it here. In addition to the reading, I asked students to respond by writing what their own writing and reading strategies were. The purpose of this assignment was to call attention to their reading and composition processes, a by- 
product of which could have been how, outside of class, students read and composed texts all the time and in nontraditional and/or multimodal ways (i.e., text-messaging, posters for organizations, scrapbooks, etc.). However, every student equated composing with the process of writing essays for English classes in high school and college.

None of them mentioned emails, speech outlines, online role-playing games, or instant messaging as texts that they composed. Although I had hoped students would tell me about the texts they wrote outside of English classes, their responses were situated fully within the assignment parameters of what they expected the "English teacher" wanted to hear. I could tell they were not invested in the response assignment, and their critical reflections announced this. One student commented in his response that after "four years of advanced English courses, my habits remain the same. Do it fast, write an excellent paper, and finish off with a crappy closing." That response was one of the most in-depth ones I received and reflected my lack of explicitly broadening the scope of the response assignment to include composition practices outside of school.

I hoped they would become more invested (or at least interested) in nontraditional composing strategies through the course of the term especially since two of their major projects required them to design a piece of communication. In wanting students to expand beyond written text traditions when they would have to design texts for this class, I found the task of getting them to recognize their own design processes - let alone thinking critically about others' processes by analyzing texts-was a challenge. I thought that introducing them to texts whose structures varied greatly from their own experiences of texts they would typically analyze and produce in "English" and other classes would expand their awareness about design and help them incorporate alternate structures into their own compositions. I introduced them to Hypertext Gardens (Bernstein, 1996) by showing them the (original) print version of the essay first. The subtitle(s) of this text included the following phrases: "Beyond the navigation problem," "the limits of structure," "the virtue of irregularity," "7 lessons," "paths," and "gates" (see Figure 
1.7). These phrases pointed out the benefits of nontraditional navigation that would be explored in the author's discussion of irregular architectural patterns in hypertexts.

Since I was showing them the traditional print version, I believed that if the students could see the argument in linear form — a genre they were familiar with — they could translate the meaning they gained from their linear reading strategies to making meaning in the hypermedia version. But they did not receive the article in its linear form; I cut it into various-sized pieces, written text or image, and gave three random sections to each student, asking them to arrange, or restructure, the article according to whatever order made sense to them as a group. They discovered several possible structures over the

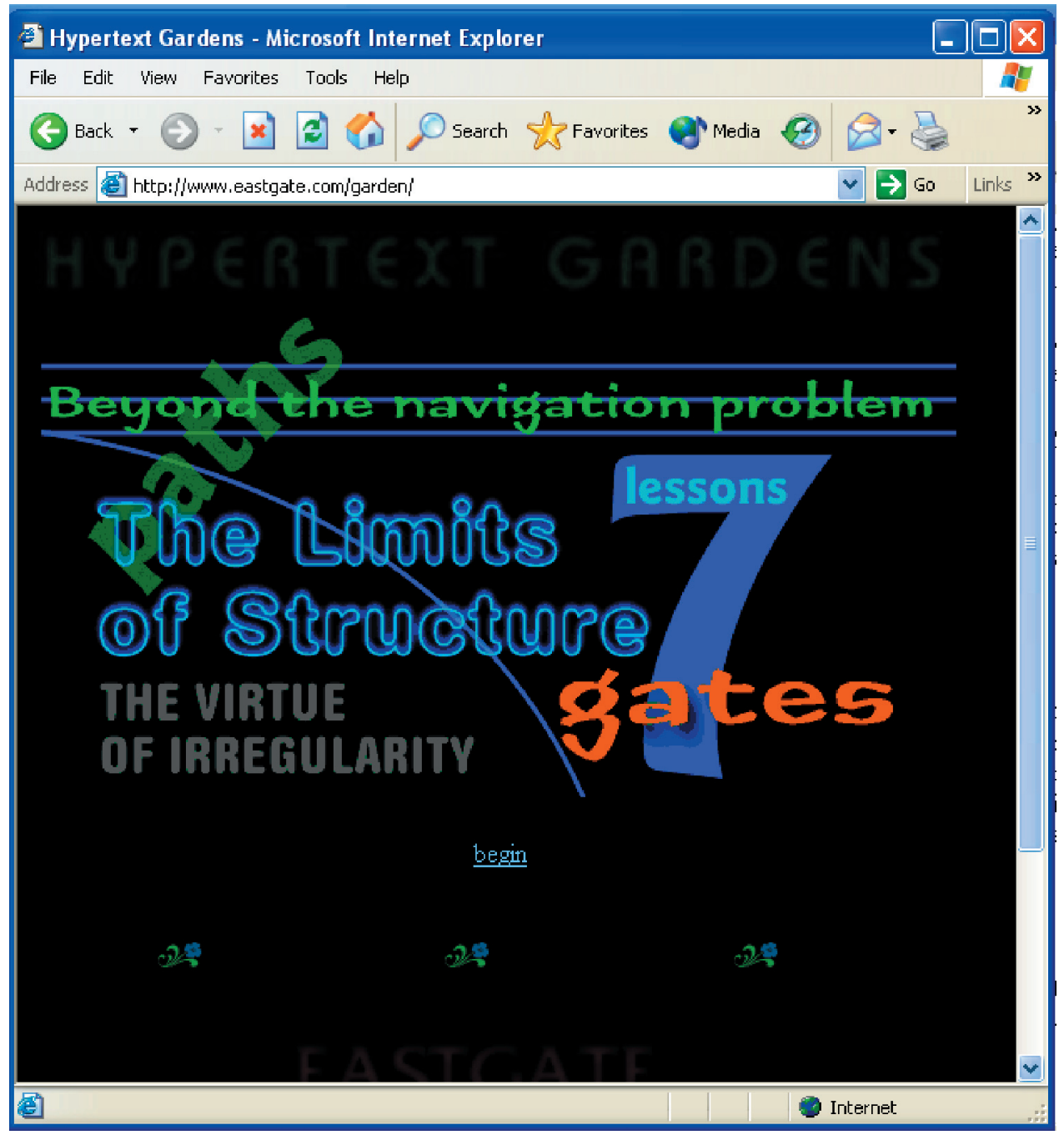

Figure 1.7. The opening screen of Hypertext Gardens. 
course of the hour until they settled on a definitive reading based on the scissors pattern of the original text - they had pieced together the cut-ups, aligning the scissors marks of each section until they had found the original, linear, $8.5 \times 11$-inch structure of the piece. We discussed their choices and how the pictures fit into the text to complement what the text was saying. They acknowledged that there were multiple ways of reading the text but, in the end, they wanted something that was right, so they pieced it together based on the scissors marks. The assignment was intended to help them understand the ability to move away from codex and linear traditions of writing and move toward an understanding of design choice, and while it functioned in that way because they were able to see how the text could be constructed alternately to a linear organization, they preferred the print-based design with which they were familiar.

The next step of this assignment was to read the hypermedia version of the text. I assigned the online version to help them see the relations between nodes that hypermedia afforded, the realization of which, I hoped, would further challenge their traditional notions of design. The online version contained the exact same written text and images but was arranged to take advantage of the designs available in HTML, using hotlinks to demonstrate alternate navigation strategies. After they had time to navigate through much of the piece, I asked them to discuss their initial reactions: Collectively, their reading strategies could be summed up in their desire to get "to the end" of the piece as fast as they could. When the hypermedia version didn't follow the linear paths that the print version had, they grew frustrated and kept returning to the beginning to see if they could find the right way through. Consistently, most of the students chose the word "right" to define the path they wanted to take but couldn't find because there was no right path. The students strove to find the one way of interpreting the text that would be the only meaning.

To help the students move past a "right" reading path, we reviewed the text's STORYSPACE map (see Figure 1.8) and discussed the multiple paths the designer had 
incorporated into the navigation. With this visual, they were able to see the complexity of the text's organization, which they rejected as being unnecessarily confusing. I asked them to respond in writing to show how they reacted to reading a hypermedia text for the first time, how they made meaning from it, and what path they took through the text (I had asked them to keep a record of the lexias' filenames as they read through to help them remember).

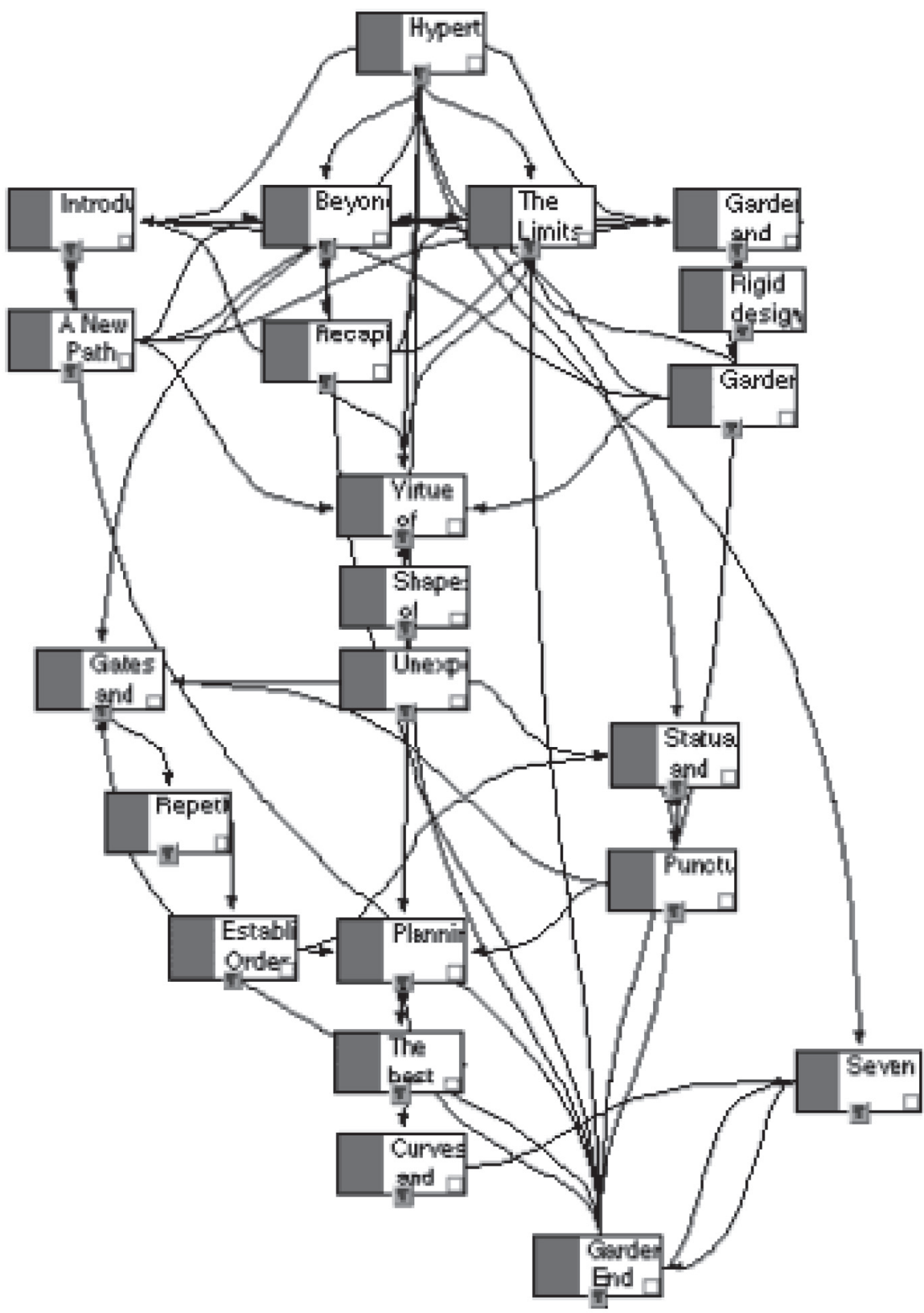

Figure 1.8. StorySpace map for Hypertext Gardens 
Most students in the class responded with remarks that showed the limited interaction they'd had with noncommercially designed hypertexts. Comments could be grouped into their experiences with different genres as students compared Hypertext Gardens (Bernstein, 1996) with its print version, or with personal and corporate web designs. In regards to the text's print counterpart, one student remarked that the print version showed "the type of document that I like, which is straightforward, linear, and easy to follow." In comparison, the student qualified the design conventions that several students touched on in their responses, defining how he expected a web site to function even though we had discussed the purpose of Hypertext Gardens' navigation before reading it online:

The website was a totally different story [than reading the print version]. With no navigation buttons, you are left with little choice but to go where the author wants to take you, and that is not how a webpage should operate, in my opinion....A good website needs to have some way to navigate you back and forth from wherever you are.

This student's response suggested that he valued efficiency in a web site more than any other quality and if a literary hypertext didn't have efficient navigation, then it must not be "good." He further explained that the kind of design he expected to see on all "good" web sites would include a "general structured navigation" which he defined as

a homepage with an index of what comprises the website and then if you click on those individual links, there is usually that same index or there is a link to the home page, or if the site is constructed "linearly" there are navigation buttons.

Although he didn't define what he meant by a site that is constructed "linearly," I'm guessing that he meant a site where audiences click from one lexia to another in a linear order such that the text could be printed on paper but is, instead, chunked into paragraphs and linked sequentially online so that there is only one reading path. Essentially, it was a link-node, next-button hypertext. But what this student (and others in their responses) pointed out was that Hypertext Gardens (Bernstein, 1996) did not follow the design conventions with which they were familiar and comfortable. Consistently, they tried 
to make meaning from the site by comparing it to web genres they knew. But those comparisons didn't help because Hypertext Gardens was like no other site they had seen, so conventional reading strategies didn't apply. They could understand the chunks of text and a few of the students understood why the picture examples were placed in certain nodes (we had discussed prior to this assignment the idea of genre and meaning in photographs), but the wandering, nonlinear navigation eluded them. This reaction was not surprising given that they had no formal (or informal, other than guessing) strategies for understanding why the text was linked the way it was.

Another student likened the text's navigational structure in relation to commercial and informational sites, which was for most students their only comparison point:

A good web page design is layed [sic] out in a manner where it is easy to obtain the information that is being looked for. The structure must be presented in a fashion which enables easy access to information. This site was the opposite. Other comments suggested that the site lacked "formatting" in its "nonstandard image placement and varying font sizes between pages," which was viewed as poor design choices, akin to a "hastily developed Angelfire or Tripod directory" (e.g., free webhosting spaces where persons upload personal sites that often lack an attention to design). And, specifically, students felt that the colophon was simply a "flowchart" where "all of the lines are curvy and it looks unprofessional." At an engineering school such as Michigan Tech, it is no wonder they compared the literary hypertext of Hypertext Gardens (Bernstein, 1996) to typical informational web site designs-business and corporate sites were what they were comfortable and familiar with. Before this class, they had neither read nor seen a text that required them to expand their notions of design, or reading, in the ways I was asking them to do.

There were two students, however, who did see the potential of these designs; both were vocal in class about their extracurricular artistic endeavors. One student participated in the jazz band and the other worked part-time as a photographer. Based on their 
responses to reading Hypertext Gardens (Bernstein, 1996), which differed drastically from the other students' responses, it seemed that their artistic experiences gave them a partial understanding of how to interpret design as part of a text's meaning. The jazz musician was more reserved in his comments, stating that the text was "designed in a way that made it confusing but you learned for [sic] the confusion" by digging "deeper into the whole article... and getting more involved with the subject matter."

The other student, a photographer, had consistently shown his capacity to interpret graphics as having persuasive meaning in previous class assignments and that knowledge helped him understand not only the a-typical navigation strategies in Hypertext Gardens (Bernstein, 1996) but the importance of the graphics the designer used in each lexia. The student wrote:

Throughout my journey through the gardens, I am presented with pictures of gardens and pathways...The affect [sic] can be compared to wandering through a garden maze and finding a beautiful flower....It provides a visual clue to what the page is going to be about.

The Hypertext Gardens were designed to provide a visual reference on how hypertext can be used to present information in a way that keeps the reader interested in the material. Without the pictures, the hypertext is no longer the "artful combination of regularity and irregularity" [as Bernstein argued on $<\mathrm{http}: / /$ www.eastgate.com/garden/Virtue_of_Irregularity.html $>$ ].

Although this student was able to see the value of design to create meaning in a text, this response was certainly not typical of the class in general. Even though we had discussed image analysis strategies before this assignment, not many of them mentioned the images, and thus this particular student stood out in his responses because he had addressed the multiple aspects of the site's design. His responses showed that his 
photographic eye had already trained him to be open to visual designs, which he easily translated into meaning in this text.

The rest of the class, however, demonstrated what Kress and van Leeuwen (2001) said regarding cultural understandings and interpretations of designs:

only some [designs] are officially recognized, and, therefore, available to design processes. These modes are likely to be highly developed-with an awareness by members of that culture of their grammar-like organization. Other modes are not recognized, or are recognized only in relation to certain specific domains, or are semirecognized. (p. 56)

In this case, Hypertext Gardens (Bernstein, 1996), a literary hypertext recognized as a typical communicative mode within a member community of literary hypertext authors was similarly not recognized by the students. Its design was only recognized according to its shortcomings in relation to the "grammar-like organization" of commercially prominent web sites, with which the students were familiar based on their suggestions of Hypertext Gardens needing an index page and repeating menu links on all subsequent lexias. They had not been exposed to reading strategies that would accommodate a text that didn't fit the pre-ordained, commercialized genre. Although they understood the intention of this text based on their reading of the linear version, most students were unable to make meaning from the full range of materials Bernstein used in this text's design.

These student-readers were unable to interpret the text because, as Wolfgang Iser (1978) suggested, they couldn't fill in the blanks of an experimental text, blanks created when the text differs from traditional genres:

[T] exts always take place on the level of their reader's abilities. Now, if a literary text does not fulfill its traditionally expected functions, but instead uses its technique to transform unexpected functions into "minus functions"-which is the deliberate omission of a generic technique - in order to invoke their 
nonfulfillment in the conscious mind of the reader, anyone who is not familiar with these traditional functions will automatically miss the communicatory intention of this technique widely applied in modern literature. He will experience a sense of disorientation and may react accordingly, thus involuntarily revealing the expectations to which he appears to be irrevocably committed. (pp. 207-208) In the students' reading of Hypertext Gardens (Bernstein, 1996), they "missed the communicatory intention" of the hypertext because it differed not only from their expected print traditions but also from the hypertext/web traditions for which they had practiced commercially based reading strategies.

Similarly, the design team of Oren et al (cited in Kress \& van Leeuwen, 2001) discovered in a usability test of an educational multimedia database that users failed to make meaning between nodes in the database, became disoriented, and ended up clicking aimlessly from screen to screen. This habit, the designers suggested, kept users from learning anything from the database because users did not take the opportunity to explore and branch out within the text. Instead, users "relinearized" the text (p. 56), much the same way that the students in my class re-assembled the print version of Hypertext Gardens so that it would follow the reading structure they felt was right.

This re-linearization happened again when I asked the students to form two groups and to design a web site containing an analysis of a video they had critiqued. I suggested that they could structure the website however they wanted, and that they could consider the structure of Hypertext Gardens (Bernstein, 1996) as a starting place to find a more creative way to present the analysis. Both groups, however, designed sites that contained traditional, left-menu navigation options, among other commercially based design elements. In their individual responses to working on the web site project, the students explained why they had chosen to stick with the design practices with which they were most familiar. The first group used a computer science major as the lead designer who modeled the analysis site on his personal web site. In turn, his personal site resembled an 
academic or business site in that he used the school's logo, color scheme, and left-side navigation menu, matching the design of the university's web site. Reflecting on why the group had chosen to design the site as they did, the designer said the group "wanted to offer a linear way of viewing the page, but not force the surfer to adhere to that order." In other words, they designed the site based on those sites with which they were familiar and liked themselves; they wanted to give the audience a linear (i.e., right) way of reading the text without the interference of an overtly visible design. The second group's lead designer, a computer engineering major, commented about his design process in the following way:

The page was easy to do...Using some $<$ table $>$ and $<\mathrm{li}>$ tags made the whole thing look nice, and I added some images that went along with what I was commenting to stay with the graphical standards of the web [but with an] interface that would be able to link and be consistent.

He did attempt to include images that illustrated the analysis, but the point for him was that the site was "easy" to design and, for better or worse, the main coding responsibilities fell to the majors in each group who happened to be well-versed in designing linear, commercial/informational pages.

What this example shows is that when the students encountered the online version of Hypertext Gardens (Bernstein, 1996), the majority of them couldn't recognize the nonwritten modes of communication (e.g., the images and the noncommercial linking structure) as central elements of the design that contributed significant meaning to the text. Their inability to understand the importance of these elements was reflected in their responses to reading the text and to designing their own web sites, both of which reinforced their familiarity (and comfort-ability) with traditional, informational web design conventions. Although we had addressed in class how to interpret graphics (such as photographs) and why a designer would want to create a nontraditional linking structure (via the print version of Hypertext Gardens), these assignments did not provide 
students with enough of a foundation to shift their reading and composing strategies from written-emphasized, linear traditions to understanding and composing new media texts.

\section{Conclusion}

To conclude, I return to the foundation on which I started this chapter: what is new media? The scholarship on which English studies draws suggests that new media texts are old media that have been remediated using digital technologies (Bolter \& Grusin, 2000; Manovich, 2001). Composition studies has compounded this idea in calling many digital texts new media. One of the main features of these "new media" texts is that they are remediated from print-based documents. That is, texts such as electronic dissertations and hypertexts retain conventions of print-based texts, and by using an alphabetic mode as the main mode of communication, these "new media" texts require similar reading strategies as those of print-based texts (i.e., reading strategies with which readers tend to already be familiar). The issue with using print-based reading strategies for such texts means that when a reader encounters a text whose designer has paid overt attention to how its multiple modes of communication make meaning in a text, that reader is unable to make meaning from the nonalphabetic modes (and thus the text as a whole) because those modes haven't been privileged in traditional reading strategies.

I demonstrated this reading-problem scenario in the assignment sequence example I used with students in my Revisions course. It is possible that had I not offered students the print version of Hypertext Gardens first, or, later, had I not asked them to remediate a print-based analysis into a web site, and had, instead, asked them to find an example on their own of a nontraditionally structured web site to analyze (rather than the one I chose for them), they may have chosen to give more attention to their designs. My desire to expand their knowledge about design — to add some unfamiliar but needed creativity into their composition strategies - failed. I believe now that the students' inability to expand their understanding of the role design plays in reading a text may not have happened 
so rigidly and resolutely if I had provided them with reading strategies that were better suited to the text. Hypertext criticism provides some literary-based reading strategies (see, e.g., Landow, 1994, 1997; Murray, 1997), but those strategies tend to prove useful only when analyzing written text, not other modes of communication and certainly not a more robust vision of design. In the next chapter, I look at Kress and van Leeuwen's (2001) multimodal theory and Manovich's (2001) work on new media to see if their scholarship offers a way to interpret the material elements and overt designs in new media texts. 


\section{Multimodal and new media rubrics: Methods for understanding design processes}

\section{Introduction}

In this chapter, I draw on two pieces of scholarship whose authors offered descriptive methods of inquiry for understanding texts that use multiple modes of communication. I focus on Gunther Kress and Theo van Leeuwen's (2001) Multimodal Discourse: The Modes and Media of Contemporary Communication and Lev Manovich's (2001) The Language of New Media. I describe each of the rubrics the authors used and show how the rubrics help readers determine the materialities of multimodal or new media texts. I also demonstrate, however, that these rubrics function in descriptive rather than in interpretive ways. In other words, I will show that while a reader could use these rubrics, which I will detail below, to describe some of the design elements in new media texts, readers cannot use the rubrics to make meaning from those design elements in ways that would allow them to form an interpretation of the text.

\section{Multimodal theory}

To address how multimodal theory contributes to understanding new media texts, I should begin with The New London Group (NLG) (Cope \& Kalantzis, 2000), whose work on multiliteracies helped form Kress and van Leeuwen's (2001) work on multimodality. I will describe NLG's theory of multiliteracies in the section that follows.

\subsection{The New London Group: Beginnings of multiliteracies}

The New London Group - a collection of scholars from around the globe who met in New London, Connecticut, in the mid-1990s to discuss the future of literacy practicesargued in their major text, Multiliteracies: Literacy Learning and the Design of Social Futures (Cope \& Kalantzis, 2000), that the literacies teachers know and teach are rarely 
singular in communicative mode. More specifically, they argued that written text is not the only mode of communication societies use and, more so, that there are multiple communication strategies societies use, each of which can be interpreted in their own right for meaning. For instance, even if readers were to focus solely on written text, that mode can be analyzed according to the medium through which those texts are distributed as well as the spatial and visual clues the written text presents (e.g., how chosen typefaces signify different meanings than handwritten text, etc.).

The main tenet of the NLG's argument was to show how processes of design can be used to change curricula from a singular, alphabetic emphasis to one of multiple modalities. The notion of design laid the foundation on which a pedagogy of multiliteracies could be enacted. The purpose of the NLG's (Cope \& Kalantzis, 2000) book was to provide teachers with a way to understand and incorporate multiple modes of communication into their classrooms. The NLG offered six designs, or what they called "modes of meaning," by which people communicate: linguistic, audio, spatial, gestural, visual, and multimodal (p. 26). Kress (2000), in his chapter entitled "Multimodality," suggested that his use of the word mode referred "to the (full) semiotically articulated means of representation and communication" (p. 185) and that those modes contained materials, or design elements, that create meaning in the design. A text's design - using modes and materialities - is presented through the medium (or media) in which a multimodal text is distributed (p. 186).

Design accounts for the full presentation of a text, but it also functions as a cyclical process that the NLG argued all designed texts undergo. This process includes a designer (a) understanding available designs, (b) designing the text, and (c) completing the product, which is called the redesigned text (p. 23). Available designs include "discourses, styles, genres, [and] dialects" (p. 21). These are the designs about which composers of multimodal texts are aware and work within. In addition, it could refer to the designs a reader is familiar with and uses in order to interpret the text. "Designing," 
Bill Cope and Mary Kalantzis (2000) argued, "always involves the transformation of Available Designs; it always involves making new use of old materials" (p. 22). So, similar to Jay David Bolter and Richard Grusin's (2000) discussion of how new media remediates old media and the old is remediated because of the new, the process of designing a multimodal text from available designs to produce a redesigned text (and the accompanying weaving back-and-forth, in-and-out, between these three revision processes) shows the process with which a multimodal text is created.

The most important contribution, however, that the NLG made was their argument that "all texts are multimodal" (Kress, 2000, p. 187), and all of the modes, media, and elements that a multimodal text uses in its design carry semiotic meaning for readers. Perhaps for English teachers, Kress' chapter in which he read several texts - a teaspoon holder, bottled water, a drawing of an elephant — can best help English teachers understand how to make meaning from a multimodal text's design. In that chapter, Kress addressed why it is important to recognize that texts are often multimodal - that even written text, for instance, cannot be "monomodal" because audiences typically read written text within the context of its larger materiality (e.g., via the paper on which it is printed; the screen on which it is distributed) (p. 184). He also discussed how readers don't experience modes of communication, written or otherwise, in a disembodied way; rather, readers interact with multimodal texts through nearly all of their senses (although smell and taste were two senses that he thought, perhaps, readers didn't use as much when reading texts) and because of this bodily experience, it is important for readers to pay attention to, say, why the paper on which written text is presented feels a particular way or to recognize why they see that a picture is set apart from written text in a scientific diagram.

However, using multimodal theory to understand many combinations of textual modes is a possibility that Kress (2000) seemed to suggest rather than embrace in the examples he used. He relied almost exclusively on visual-mode texts. For instance, his 
main examples include children's drawings, which he used to show how children think conceptually about events and actions and to demonstrate how visuals can have grammarlike structures (which Kress first wrote about with van Leeuwen in Reading Images, 1996). His emphasis in this chapter seemed to have been to showcase how visuals can carry meaning for readers while the other modalities that the NLG discussed (e.g., audio, gestural) were brushed over. Kress tried to extend this work, however, in his next book, which I will outline in the next section.

\subsection{Kress and van Leeuwen}

In Multimodal Discourse: The Modes and Media of Contemporary Communication, Kress and van Leeuwen (2001) built on the multiliteracies tradition by arguing that readers and designers assign semiotic meaning to all of the "modes deployed in a multimodal object/phenomenon/text" (p. 28) from which a unified interpretation of the elements in a designed text can be made. The authors provided four strata to help designers understand the process of composing multimodal texts. These stratadiscourse, design, production, and distribution - are not hierarchical; rather, they are cyclical and process-oriented, weaving through and crossing over each other to produce a final text.

Kress and van Leeuwen (2001) narrowed the scope of reading multimodal texts from the whole of language arts, math, and sciences that the NLG (Cope \& Kalantzis, 2000) offered and analyzed texts that would be of interest to a broad range of English-studies (and perhaps social-science) teachers, including those who teach cultural-studies and popular-culture texts. For example, they demonstrated how the four strata can be used to understand the design of an ad for a child's bedroom featured in House Beautiful magazine. This ad incorporated discourses pulled from such vast sources as public housing projects in Vienna, Austria; Disney's portrayal of family homes in Toy Story; working-class homes in Amsterdam; IKEA catalogues; and pedagogical practices of teaching children good behavior (Kress \& van Leeuwen, 2001, pp. 11-17). Through 
demonstrating the inclusions and exclusions of decorative items in the bedroom ad, as well as through examining the language used to describe the bedroom, Kress and van Leeuwen remarked that

The pedagogic 'children's bedroom' discourse can be realized in a number of ways. It can be realized as an actual children's room, through the multimodal 'language of interior design' in which meanings are realized by spatial arrangements (the 'dado' which runs right around the room and makes 'putting your things away' literally an omnipresent feature of the room); by choice of furniture (the sofa, a place for reading); by colour schemes (the 'bold' and yet also 'sunny' and 'cheerful' colours); and so on. All of this has to be conceptualized as 'design' before it can be produced, regardless of whether the parents themselves both design and produce the redecoration, use a professional designer or follow an explicit pre-existing model designed or endorsed by an expert. (p. 17)

In this quote, Kress and van Leeuwen showed how it is possible for them to read this multimodal text by examining the discourses and design elements used in the final room design, which they encountered as the produced and distributed version of the ad in the magazine.

Kress and van Leeuwen (2001) spent much of Multimodal Discourse repeatedly showing how readings could be performed on specific modes within multimodal texts. Their definition of mode is "semiotic resources which allow the simultaneous realization of discourses and types of (inter)action" (p. 22), a definition similar to Kress' from Multiliteracies (2000). Kress and van Leeuwen (2001) focused mostly on modes - and not media, which are the "material resources used in the production" of a text (p. 22) —as carrying the most weight toward making meaning. Kress and van Leeuwen showed the differences between modes and media using, in one example, the following explanation:

Narrative is a mode because it allows discourses to be formulated in particular ways (ways which 'personify' and 'dramatise' discourses, among other things), 
because it constitutes a particular kind of interaction, and because it can be realized in a range of different media. (p. 22)

Unlike Bolter and Grusin's (2000) argument that media play a central role in understanding how texts remediate each other, Kress and van Leeuwen (2001) suggested that distribution media (such as film, book, CD-ROM) are intended, by their design, to play a transparent, nonmeaning-making role in multimodal texts because media serve mainly as a vehicle for distribution (p. 22). In other words, they argued that distribution media are not necessarily assigned overt semiotic meaning. The authors did, however, make a distinction between distribution media, which is supposed to be transparent and only deliver modes of communication, and production media, in which modes are designed. They argued that "in the course of their development, [distribution media] usually start functioning as production media-just as production media may become design modes" (p. 22). This shift from media to mode occurs when "the particular medium gains in social importance" so that "more abstract modes of regulation ('grammars') develop" (p. 22). It is this shift from media to mode, from production tool to its purposeful incorporation as part of a text to create meaning, that invites readers to interpret what once was solely a medium, like film, as a mode when, for instance, cinematic representations are used to make meaning as an element in a multimodal text. Explicating, then, the individual modes of a text such as a child's bedroom ad (i.e., color, spatial arrangement, etc., as understood through the "language of interior design") demonstrates for readers how more encompassing meanings can be made from multimodal texts.

Yet, Kress and van Leeuwen (2001) focused on examples that incorporated only linguistic and visual designs, leaving out the other three modes the New London Group (Cope \& Kalantzis, 2000) had discussed. Kress and van Leeuwen (2001) mentioned gestural modes briefly in one example (p. 53), but most of the examples focus directly on word/image binaries as presented in print media. These texts remain 
strictly in comfortable territory for English teachers, relying on written text and static image combinations (including the child's bedroom ad) and not on examples that require expanded reading strategies, such as a new media text might. For Kress and van Leeuwen, to encourage teachers toward visual literacy practices that focused on word/image-based English studies' texts seemed to be their goal. Rather than push for examining more modes of communication or texts that break away from socially conventional reading patterns, they used examples with which readers would be familiar. Although they argued for considering texts in more complicated ways - for thinking about the designs of texts and using the strata to interpret multimodal texts - their introduction to multimodal discourse serves to introduce, to open the discussion rather than to focus on more complicated, unexpected texts, which is the next step in considering multimodal and new media texts (and which is the point I argue for in this dissertation). The four strata seem to be offered as an aid to teachers (who are the book's main audience) to help them break down multimodal texts into smaller units of meaning, a process which would be useful in relation to new media texts that are often designed with multiple modes. However, the strata don't necessarily help readers make meaning from those individual modes at work in a text.

The purpose of using these strata then brings me back to the point that new media texts require expanded reading strategies because readers need help in making meaning from new media texts' overtly visible designs. It seems that Kress and van Leeuwen's strata would be useful in reading a new media text because of how the strata describe what modes are used; but as I demonstrate below, understanding the processes of designing multimodal texts doesn't equate with readers being able to interpret new media texts. What the strata do help with is in recognizing the modes, media, and materialities in a text. In other words, the strata show how a designer created a text but not why. Let me now describe each stratum and offer an example application for each term. For this example, I use a Flash-based text called "While Chopping Red Peppers" (Ankerson 
\& Sapnar, 2000) because it is a multimodal text in that it combines all five of the NLG's basic modes of meaning - linguistic, audio, spatial, gestural, and visual (Cope \& Kalantzis, 2000, p. 26). "Red Peppers" (Ankerson \& Sapnar, 2000) is about a tense relationship between a daughter and father as seen through their interactions with each other in the kitchen. I will provide a more robust interpretation of this text later in this chapter.

\subsubsection{Defining the four strata}

The first stratum, discourse, is "socially constructed knowledge" (Kress \& van Leeuwen, 2001, p. 4) that is "independent of genre, mode, design,... which can only be realized in semiotic modes" (p. 5). Kress and van Leeuwen's notion of discourse suggested that designers must start from what they know-from the cultural, social, intertextual, technological, historical, and other contexts available to them. Discourses change as a designer has new experiences, and this knowledge forms the basis for the next stratum.

The second stratum, design, helps designers use "semiotic resources [to realize] discourse in the context of a given communication situation" (Kress \& van Leeuwen, 2001, p. 5). Thus, design is the stratum during which a designer fulfills a rhetorical or aesthetic situation by choosing which modes and media, based on the discourses on which she draws, to use in a multimodal text.

Design overlaps with the third stratum, production, in the realization of discourse (Kress \& van Leeuwen, 2001, p. 6). A designed text is produced using materials and modes the designer chooses according to his or her available discourses and the communication situation where the text will be distributed. In other words, a designer must take into account how to produce a text (e.g., in what software program), and this will affect her choice of modes that can be accommodated in that production medium. 
The fourth stratum, distribution, adds a layer of meaning because the designer must decide how to get the text to readers, which also plays a role in what production medium and, thus, what modes and materials she will use in designing a text (Kress \& van Leeuwen, 2001, p. 7). For instance, if a designer knows that her text will be distributed on a web site rather than aVD, then she might choose to design the text using smaller video clips (for easier streaming and download times) as well as to produce the text in FLASH rather than DIRECTOR because of FLASH's better movie-compression and streaming capabilities.

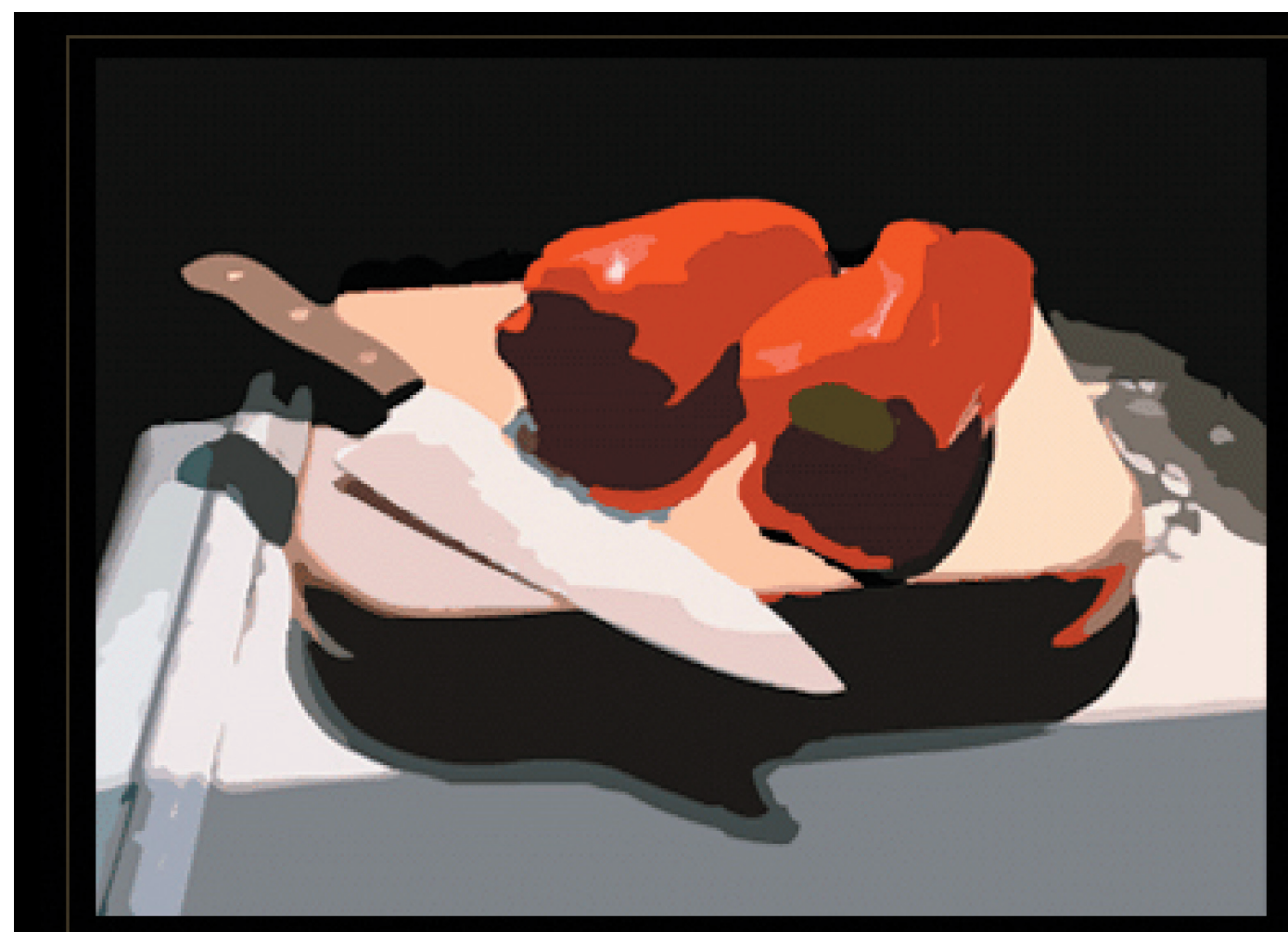

BEGIN

\section{WHILE CHOPPING RED PEPPERS}

Written by Ingrid Ankerson Design by Whirld New Media Created with: Photoshop, Flash 4, Wave Studio

Figure 2.1. The opening HTML screen of "Red Peppers" indicating what programs the designer used to create it. 
What is important to note in the outline of the four strata above is that they describe only some of the considerations a designer must make when composing a multimodal text. The strata take into account which modes and materials a designer uses and also, perhaps, which technologies she uses to produce and distribute a text. But the strata do not address how or why a designer chooses individual modes or elements when creating that text. This means that a reader could use the four strata to describe the multimodal considerations in a text like "Red Peppers" (Ankerson \& Sapnar, 2000), but could not necessarily use them to interpret the text. As I will show in the example below, these strata can neither provide a reader with reasons for why a designer has chosen specific elements, modes, or media nor what those design choices mean.

\subsubsection{Using the strata to describe a new media text}

The production medium and distribution method are good places to start exploring Kress and van Leeuwen's (2001) strata in "Red Peppers" because those strata will necessitate some of the design choices. For instance, "Red Peppers" was created in the production program Macromedia FLASH, indicated on the initial HTML title page that a reader sees when entering the text from its distribution point, the web site Poemsthatgo $<$ http://www.poemsthatgo.com>. See Figure 2.1 for a screen shot of the opening site, which indicates the text's production in FLASH. FLASH uses a timeline from which all elements placed on that timeline perform. A designer can (a) add physical interactivity to a FLASH text using a scripting language called Lingo; (b) create motion tweens, in which an element changes shape, size, speed, rotation, color, and so on, depending on the initial and concluding keyframe (indicating placement and design) of that element; (c) synchronize modal elements such as an audio track timed to change with a tweening graphic object; as well as other options.

"Red Peppers" is distributed as a Flash movie (as texts created in FLASH are called) that can be seen in the Flash Player, a free plug-in. There are constraints on distributing 
a text in these media including the download time of the text, which depends on a reader's modem speed. Additionally, a reader is required to download and install the FLASH Player plug-in to read the text. On a dial-up modem, this process might take an hour or more, by which time a reader's chance of returning to the Poemsthatgo site to watch the text would have been lost among procedural processes. (Of course, this process changes drastically as the technology changes from dial-up to broadband. However, I offer this comparison to indicate that when the text was created in 1999, dial-up modems were the most common method of web access.) The stratum of distribution accounts for how the text is delivered but not how the distribution process affects a reader's interpretation of a text. This is what Kress and van Leeuwen (2001) meant when they suggested that distribution media aren't necessarily intended to add significant meaning to the text, although a reader can make an educated guess as to why the designers used FLASH and the Internet as distribution methods even though that information may not contribute to understanding what some readers might refer to as the content of the text.

Analyzing the production medium in "Red Peppers" also doesn't help readers interpret the text. In several sections of "Red Peppers," voiceovers are heard at the same time that written text (usually repeating the voiced words) appears on screen. This synchronization occurs because the designer was able to place those elements in relation to one another on the timelines. Most readers would never get to see how the timeline functioned in this piece — only, perhaps, to know that there was a timeline. In addition to the synched elements, the designers decided to not take advantage of the physical interactivity that FLASH is capable of and, instead, designed the piece to follow the internal timeline without reader manipulation, so the text follows an always predetermined path. Most readers could realize this from watching the text, even though I've seen some readers who wanted to click to find hidden links. However, readers would not know why the designers had chosen not to use the physically interactive capabilities that Lingo scripting provides. What this gap in the interpretation of the text signals is that 
knowing how a text was produced doesn't equate to knowing why it was produced in that medium, leaving readers to wonder how production methods relate to the purpose of a text.

The next stratum to explore is design, which asks readers to acknowledge the various semiotic modes in a text. In "Red Peppers," the semiotic modes include recurring vector (algorithmic) graphics of a red pepper, a blurred outline of a girl, a knife, and a palette of vegetables, among other graphics. The designers also used modes of color, shape, motion, voiceover, animation, and written text. While each of these modes carries meaning within the text, using the basic definition of the design stratum — semiotic resources that fulfill the designer's available discourses in a communication situation-doesn't necessarily help readers understand that they have to figure out how and why those resources contribute to their interpretation of the text. In other words, how do the modes a designer chooses relate to the discourses a reader assumes that designer drew on?

Readers can't always know what specific discourses a designer intended to draw on, but a reader can apply her own discourse to understand individual meanings of elements within a text. In reading "Red Peppers," for instance, I might decide to group elements such as the knife and the red pepper with the written and spoken text indicating the female speaker's father is a chef. In doing so, I can apply discourses of familial relations (especially father-daughter bonds) and cooking. I could also group elements such as the mention of church in the voiceover and written text with the graphic of two men wearing suits, associating that connection to discourses of religious institutions. As a final example, I could group the elements of the written text with the spoken text to suggest that discourses of poetics (as well as e-poetics, given the distribution method) and cinema are working in the text. But even from all these possible discourses (and there are countless others at work), the discourse stratum doesn't suggest how I might combine discourses into an interpretation of the entire text or what the total relation of these discourses means. Part of the reason for this is because the discourse stratum 
does not offer readers a way to choose which elements to pay attention to (i.e., a reader could choose to focus only on the written text and ignore the other modes) nor does the discourse stratum help a reader to juxtapose those discourses in order to interpret those connected meanings. Although discourse is useful to describe what knowledges are at play for a reader in the text, it doesn't help her make the meanings of those juxtaposed discourses explicit.

Overall, the four strata function perhaps exactly as Kress and van Leeuwen (2001) intended - to describe the processes a designer encounters when creating a multimodal text. I purposefully did not describe the text before outlining the strata in order to show how a reader new to the text might (not) understand it if using the strata as her only means of interpretation. Readers who have never read "While Chopping Red Peppers" likely won't have an interpretation of the text after applying the four strata because the strata weren't intended to function in readerly ways. Neither, I argue, were Manovich's principles of new media, as I demonstrate next.

\section{Manovich's new media theory}

In The Language of New Media, Manovich (2001) interpreted new media in relation to old media, following a tradition of remediated texts (Bolter \& Grusin, 2000), but Manovich (2001) focused mostly on digital new media and its historical connections

with cinema (see chapter 1 for a discussion of Manovich within the context of defining new media). He described new media as being multimodal and digital, and included in his definition five principles that texts must meet to be new media objects: numerical representation, modularity, automation, variability, and transcoding, each of which I will describe below. With the publication of The Language of New Media, scholars highlighted this book's attempt to offer a common language to discuss new media texts, as its title implied. Through the five principles of new media, Manovich did offer a 
standard set of discussion points regarding digital texts, but rather than offering ways to read texts, these principles only describe or categorize texts into new media or not.

\subsection{The five principles applied to a new media text}

The first principle, numerical representation, included three main points: (a) "all new media objects are composed of digital code," (b) they "can be described... mathematically," and (b) they are "subject to algorithmic manipulation" (Manovich, 2001, p. 27). Numerical representation of texts in digital code (such as the binary code of ones and zeros that run computers) is essential to Manovich's definition because the other four principles rely on the digitality inherent to coded data. The text I have been examining, "Red Peppers," is obviously digital because it is presented via a computer, which requires that a text be made up of numeric (binary) code, among other coding languages. In addition, a reader familiar with FLASH would recognize the text's motion tweens as algorithmic manipulations of the elements. According to Manovich's definition, most any text that is or can be digitized can also be a new media text, as long as it meets the next four criteria.

Manovich's (2001) second principle of new media is modularity, which can be described as "the fractal structure of new media" such that individual elements of a new media text "are represented as collections of discrete samples" that are "assembled into large scale objects but continue to maintain their separate identities" (p. 30). FLASH offers modularity to designers because it uses individual elements within a library; the modularity of these individual elements is evident in that a designer can use them for multiple texts without changing their basic identities. Modularity also implies that an element of a new media object "can always be edited with the program originally used to create it" (p. 30). For instance, each element in a FLASH text such as "Red Peppers" can be edited at any time by a designer and exported to a new text. Typically only the designer of a text has access to the original file to make changes, but knowing that FLASH texts have this modular capability can help readers realize the potential lack of fixity that new 
media objects carry. For example, in the editable FLASH file of "Red Peppers" (which the designers supplied me), two typefaces were used - an Arial-like font and a Times-like font (each were used to represent a different speaker in the text) - but the public, online version of the text includes only one typeface. Perhaps the designers took advantage of the modularity of the text and changed the font before they published and distributed the piece. Why the designers chose to change the font, however, or what that change (or even the original font choice) might mean, is not answered by the modularity principle.

Automation, the third principle, is the combination of the numericality of a text and its modular structure such that automation of operations within a text's "creation, manipulation, and access" removes human intentionality from a text (Manovich, 2001, p. 32). Although this principle sounds like a move toward Artificial Intelligence (and in some ways, Manovich claimed that it was), it is important to note the automation in software often remains transparent for both designers and readers. In Adobe Pнотоsнор, for instance, a designer can manipulate an image by choosing a layer and adding a layer style, filter, and additional effects to change the purpose of the image. The algorithmic processes that change the original image to the filtered image do so without the designer seeing how each pixel of that image changes. In this way, the automation process is transparent to the designer. He or she doesn't expect to see how the image changes, only the final product.

Switching to an example relevant to "Red Peppers," readers see a graphic of a red pepper change from the size of a small fist to the size of a head (part of which is out of view because the pepper extends outside of the frame). Readers may not recognize that one of FLASH's built-in automation processes called tweening was in effect to create the size change. What a reader couldn't see was how the designer implemented that change. To tween that element in FLASH, the designer would have placed the small pepper on screen to correspond with the timeline at the first frame in the sequence. Then, the designer would modify the pepper to be larger, placing the large pepper at, say, the tenth 
frame. After that, the designer would select the tenth frame and click on the option to create the tween. The tween option would compose every intermediate frame, making the pepper larger in constrained proportions to the original so that, upon playback, the pepper would appear to grow larger. The designer did not have to create every individual frame of the pepper to make it appear to grow. At this point, I need to step back from this example and ask a question which may seem to have grown redundant now: Why is it important to the text that the process of automation occurs within "Red Peppers" (or within any new media text)? The principle of automation doesn't help readers uncover the significance of the growing pepper within the scheme of the whole text. Sure, automation happens, but knowing that doesn't help readers interpret the meaning of the entire text. Only, perhaps, when the text is placed within larger cultural (and artistic?) contexts can the significance of tweening be taken up in any particular text, and that's if the reader knows what the automatic process of tweening is in the first place.

Variability, Manovich's (2001) fourth principle of new media, occurs because new media "is not something fixed once and for all, but something that can exist in different, potentially infinite versions" (p. 36). A designer could create a new text based on the same elements he or she had used in another text, but arrange them in a different order, or change the size, shape, sounds, and so on to cause the text to have a completely different effect. The digitality of new media allows for these multiple variations. Without looking at the editable FLASH file, readers would only be able to guess at what elements might be variable within "Red Peppers." Readers who know FLASH would know that its library would contain infinitely re-usable elements, and while that matters in regards to how the text is designed and produced, it doesn't have any direct correlation to how readers make meaning from it.

Finally, Manovich's (2001) fifth principle - transcoding — stated that the structure of a new media text must follow "the established conventions of the computer's organization of data" (p. 45). Transcoding means that by making a new media text digital, a designer 
adheres to digital conventions - from binary code to proper filenames and file extensions to correct plug-ins - such that the text can be designed or distributed through a digital device. "Red Peppers" does follow digital conventions; it is readable through a computer via online distribution in Flash Player, which means the designer must have followed the proper transcoding conventions. A contrasting example would be if a designer trying to show a photograph on a web site presented the image as a Рнотоsнор file (with a .psd extension, which isn't viewable online) rather than saving the file with a graphical extension that is viewable online (such as a .jpg). There are no visible coding errors in "Red Peppers" that would prevent readers from seeing the text as a whole. And, yet, transcoding doesn't suggest what meanings might be inferred from a new media text.

\subsection{Description versus interpretation}

Manovich's (2001) five principles were strictly geared toward describing digital works, which can be a shortcoming if a reader does not believe that new media has to be digital. While the principles can be applied to help readers describe the technical and technological aspects of digital new media, it does not offer a language with which a reader can interpret that same text. More so, if a reader isn't familiar with the technological conventions used in a text, Manovich's principles have little relevance for that person. For instance, the examples from "Red Peppers" that I outlined above suggest a strong familiarity with how the production medium, Macromedia FLASH, functions. Yet, in the final product for most conventional texts, the medium is supposed to be transparent to readers. If a reader is unfamiliar with how FLASH works - or how a designer might use FLASH to create a new media text - then that reader may not even be able to apply the five principles to determine whether a text is new media or not, let alone understand what that text means.

Likely, readers are still wondering what "While Chopping Red Peppers" is about, and that has been the point of the above sections: Without a reading strategy that helps readers interpret a new media text, readers will likely not understand the text. A reader 
could use Manovich's (2001) principles to see if a text qualified as new media, or she could use Kress and van Leeuwen's (2001) strata to understand how a designer created a multimodal text. But, as my analysis using these rubrics indicated, all they provide is a general sense of what the text is and, sometimes, does, not how elements in a text function or, most importantly, why they function as they do to provide a reader with the potential for a meaningful interpretation. In contrast, below I offer my own interpretation of "Red Peppers." I apply metaphoric, stylistic, and connotative reading strategies pulled from my experiences of using literary traditions of interpretation and apply those strategies to the visual and aural elements in the text. In doing so, my reading provides an interpretation of the text whereas Kress and van Leeuwen's strata or Manovich's principles provided, instead, an understanding of the technological design processes in the text.

What my reading also shows is that a reader must be able to make meaning from all of the modes a text presents - that is, from a text's overtly visible design — and not just be able to describe the text generally through articulation of design processes or digitality, which is what the above multimodal and new media theories suggest is enough. In some ways, my reading explores in some depth the discourses that led to why the designer chose particular elements but, as I argued above, Kress and van Leeuwen's (2001) discourse stratum didn't encourage readers to make the connections between a chosen discourse and the purpose of the text because neither Manovich (2001) nor Kress and van Leeuwen have a notion of purpose at work in their rubrics. This process would lead to a more successful interpretation instead of just providing a description of the text. Multimodal and new media theories don't currently provide a reading strategy useful for readers unfamiliar with new media texts (i.e., a strategy that will help them interpret new media texts), but neither does my reading (although I will build such a strategy through the remaining chapters of this dissertation). Instead, I offer the reading below as evidence 
to further demonstrate what readers might miss in a new media text if they rely solely on the rubrics outlined above.

\section{An interpretation of "Red Peppers"}

Many readers, even if they are new to interpreting new media texts, will recognize the linguistic features in it since that is a mode with which they are familiar. For that reason, I start my reading of "While Chopping Red Peppers" (Ankerson \& Sapnar, 2000) by describing part of its linguistic context. "Red Peppers" can be traced to a tradition of lyric poetry because it invites readers to look into the world of the speaker (a woman) to view and experience her relationship with her father and the tension that it has caused in her life. Traditionally, a lyric poem represents a moment in time, a snapshot, an emotional experience expressed by the author through a speaker. For the audience, it's a chance to see into the window of the poem and the emotions the author presents - it's a voyeurism by necessity-through the genre of the lyric. An audience looks in on a lyric poem and reacts to the emotions the poet presents. A lyric poem, according to The New Princeton Encyclopedia of Poetry and Poetics, is an "utterance that is overheard" (Mill, cited in Johnson, 1993, p. 714). The overheard utterance is the voice of the speaker "mak[ing] the verbal world of the lyric a visible world to the mind of the reader." Making this internal world visible to readers is the method by which lyric poets comment on and "evaluate the human condition" (Johnson, p. 726). "Red Peppers" is a commentary of the speaker's condition in relation to her overbearing and abusive father.

The first lines of "Red Peppers" are spoken in a voiceover as the written words appear on screen: "In the space/ between my knife and my fingertips/ there is my father." This text is accompanied by the detailed, static graphic of a shadowy room with a cutting board and a sharp kitchen knife (see Figure 2.2). Visual emphasis is placed on the knife, as it is the brightest, centrally placed element on screen, which lends tension to the poem given the horror-film connotations associated with knives and the darkness of the room. 


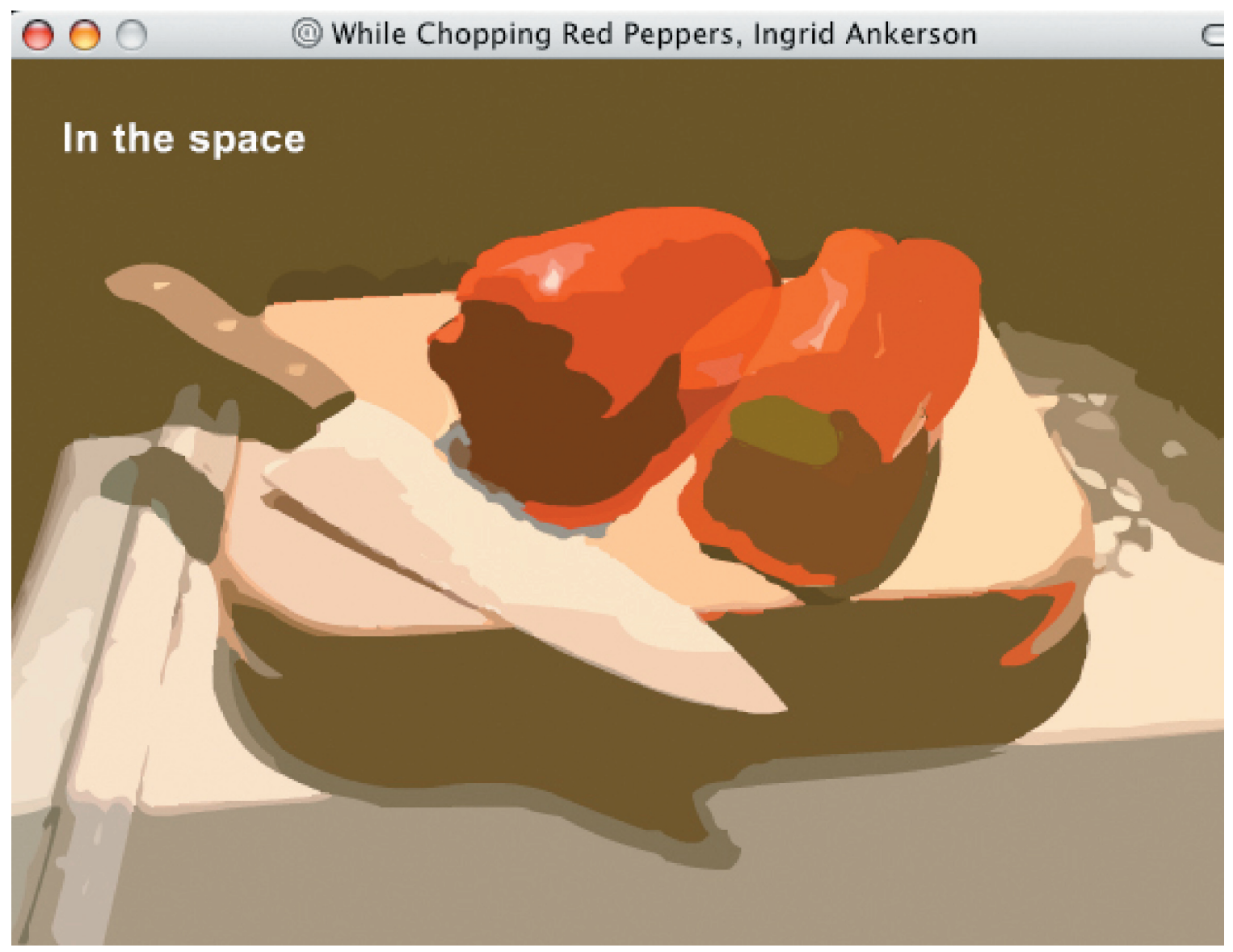

Figure 2.2. A screenshot of the opening scene of "Red Peppers." A similar image concludes the text.

This same screen returns to conclude the poem. The dark-colored and three-dimensional graphics of the opening and closing scenes act as bookends to the bright, mostly white background with colorful visual elements that appear in the bulk of the text. These dark bookends function as a reader's entrance and exit to the text - the opening and closing of a window into the speaker's world - signaling that the reader is being taken into the space of the lyric, the space of the speaker's memory of an event.

In the opening scene, tension is created by a juxtaposition of multiple modes: the voiceover and written text ("between my knife and my fingertips, there is my father") and images of the pepper being cut. The placement of these elements in this scene suggests that the father is metaphorically being held by the female speaker, under her knife. He is in a position to be cut, a dangerous position. As the movement of the red pepper happens, 
the pepper becomes more saturated with color, and the background fades until the pepper is the central element on screen. The red pepper contains the outline of the father's profile and a young girl's silhouette (see Figure 2.3). This movement, which accompanies the spoken and written text about the father, also demonstrates a tension between the speaker and father because the father's face covers up part of the girl's torso, symbolizing his power over her.

The pepper then tweens to become the partially seen red circle behind the outline of the young girl's face. The spoken and written words, "you shouldn't" are central to the tension that has been created up until this point. One wonders what situation the girl with an upturned (submissive?) face is in. (I think, at first, of an abusive situation, because that has

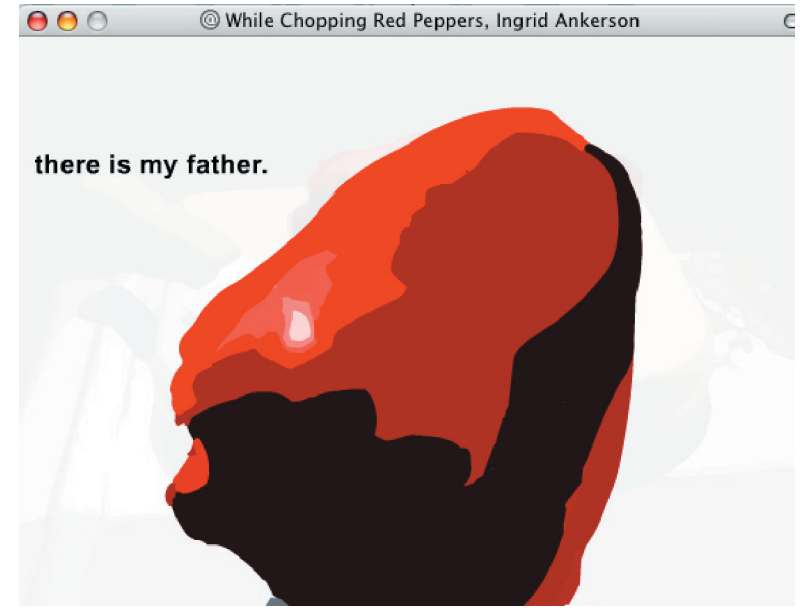

Figure 2.3. The red pepper with the shadow of the father (bottom, left) superimposed over the shadow of the girl (on the right side).

been a standard theme in contemporary women's poetry that deals with tense subjects.) And yet, the young face and the grown woman's voice in the narration don't match. The disconnection between the image of the young girl and the voice of the adult woman serves to further distinguish the tensions in the text, as seen through the separation or dissociation on the part of the speaker between the now of the 'moment' of the text versus the looking back at an older memory. This is such a brief instant in the text, but it lays a foundation, allowing me to interpret the tension between the female speaker and the father as the overriding emotional weight of the text.

The rhythm of the text has been consistent to this point. I recognized the meter of the written and spoken text to be close to iambic pentameter (which also reinforces the lyric quality of this text). I have bolded the stressed syllables as an example: 


\section{In the space $\mid$ between $\mid$ my knife $\mid$ and my fin|gertips there is $\mid$ my fath|er. You should $\mid n$ 't, he says, | wants to know, $\mid$ can't he $\mid$ just show $\mid$ me[?]}

In poetics, iambic pentameter has been referred to as the most "natural" meter because it resembles the beating of the human heart (dah dum, dah dum, dah dum). With the inclusion of the single, bright red pepper on the stark white background at the beginning of the second scene, the pepper could represent a heart, which makes the use of iambic pentameter more meaningful in relation to the graphic. This metaphoric juxtaposition adds another layer of meaning to my reading of the tensions between father and daughter. For instance, if the space that is between the speaker's knife and her fingertips is filled with the red pepper, then there are two options for my interpretation. The first option is that the text's words signify the red pepper is her father, and therefore she is methodically cutting up (cutting down?) her father. But the second option confuses, or at least changes, that possibility: The pepper is a heart (whether its hers or her father's is unclear). So, she is either cutting her own heart (representing the pain that the relationship with her father creates) or she is cutting (off?) her father's heart to try to end the painful relationship. The multiple possibilities can work together in this text to create an overwhelming feeling of strong/“heartfelt" pain for the speaker, and, thus, for me as a reader who lives/reads vicariously through the speaker in the lyric text.

The movement of the text in the next few seconds is quite quick; the first half of the written text disappears as the last half arrives on screen. The use of narration becomes especially important in this scene. While the images further compound my reading that the text is tension-filled, the voiceover provides the missing/fleeting words of the text. The actual lines of poetry that the speaker says are "he says/ wants to know, can't he just show me[?]." I put the question mark in brackets because it is not in the written text, but the narration implies it is a question asked by the father. The written element, combined with the slumping figure of what I assumed was the young woman/speaker (see Figure 
2.4), increases the tension of the text while still leaving me with an ambiguous idea of what caused the tension in the relationship. My first inclination was that the girl suffered from some kind of abuse. The aural emphasis on the father's wording of wanting to "show" the girl caused me to conclude that the abuse was sexual. The rhythm of the piece also changed from the steadiness of the first strophe, to a more choppy rhythm.

The monosyllables created an abrupt feeling which was enhanced by the breath that occurred at the end of each phrase: "he says [breath]/ wants to know [breath], can’t he just show me [breath]."

As the lines disappeared, the following text replaces it: "not... so... small," which becomes the only element

\section{? this} (9) While Chopping Red Peppers, Ingrid Ankerson my sigh against the stove

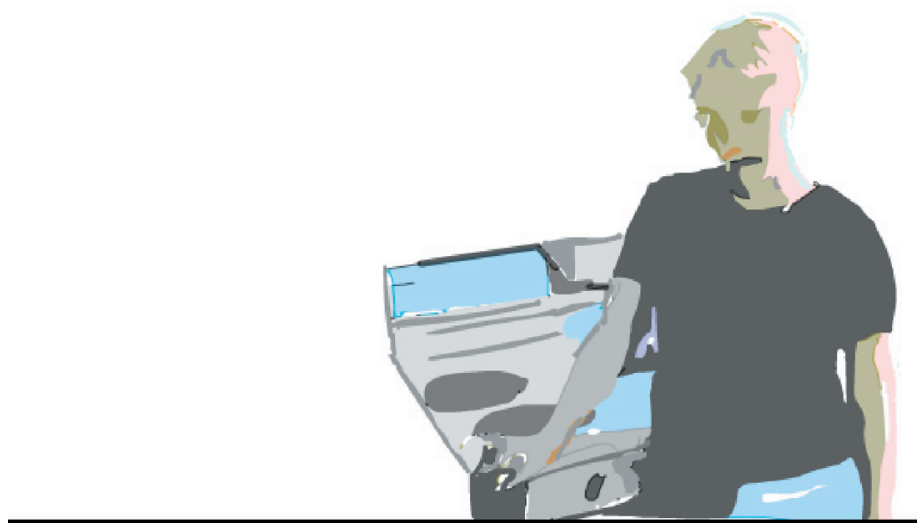

Figure 2.3. The figure of the slouching young woman.

on screen. The ellipses, while not visually in the FLASH text, represent the amount of time between each word appearing on screen. The rhythm of the piece slows considerably with this pausing between words. And the next lines helped me understand the reason for the immediate incarnation of tension: "taking the knife/ followed by the sounds of/ thick red peppers on the cutting board." The father's knowledge of food preparation becomes evident in these lines; he seems to be meddling in his daughter's cooking as he takes the knife away from her to show her how to "properly" cut the peppers. The combination of these elements suggests that the father's interruption into his daughter's cooking and life poses yet another tense moment.

The next section of the text starts with the line "my sigh against the stove" accompanied by a graphic repetition of the young-woman leaning against a stove. This 
image is followed by the words of her father, spoken through her voiceover, "Like this." The segment ends with just those words on screen. The dead-pan tone, indicated by the written and oral elements "my sigh against the stove" accompanied by the image of the slouching young woman, signals that the speaker believes nothing she could do would ever be good enough for her father. As the father (through the speaker) says, "Like this," I imagined him demonstrating how to chop the peppers while the girl feels the burden of living up to his standards in cooking and, no doubt, other areas of her life. The next element - a voiceover saying "he teaches presentation/ perfect arrangement on a plate" - is heard while a graphic of a palette with vegetable pieces spins onto screen. The father's artistry and knowledge of food presentation is presented through the metaphor of the palate, which also signifies the daughter's overwhelming sense (spinning out-ofcontrol...) that her father is trying to manage her life.

Yet, it is not just food preparation that the father knows about. According to the written text, the father taught the daughter, "how to shake hands after church, firm/ like this." Accompanying these words is the movement of two silhouetted people shaking hands (men, as evidenced by their coats and the shape of their hats). The swirling motion of the reddish silhouettes as they rotate counterclockwise contrast with the gray men moving from left to right. This movement-at-odds (i.e., objects moving in opposition) produced a feeling of uneasiness (if not queasiness) for me, reinforcing my building tension at watching this text. The tension increases with the devilish associations made possible through the larger-than-life characters' red hue in relation to the mention of "church" (i.e., a metaphor for Hell, see Figure 2.5). It is also the elements of this scene that made me dismiss my earlier inclination to suggest that the tension between the father and daughter was sexual in nature. Rather, it seems that the father is simply too overbearing, and the daughter can't handle it anymore.

The tension created by the swirling church-goers gives way to the figure of the woman, which grows larger while a puppeteer's crossbar enters on the right along with 
the written and spoken text, "making my hand fit in his,/ like a puppet." The screen turns black as the rest of the text is read- " "the way vegetables are silent under water." This text, however, is not seen onscreen; rather, the image of a pepper being washed by someone's hands fills the void. I connected the simile of the speaker being

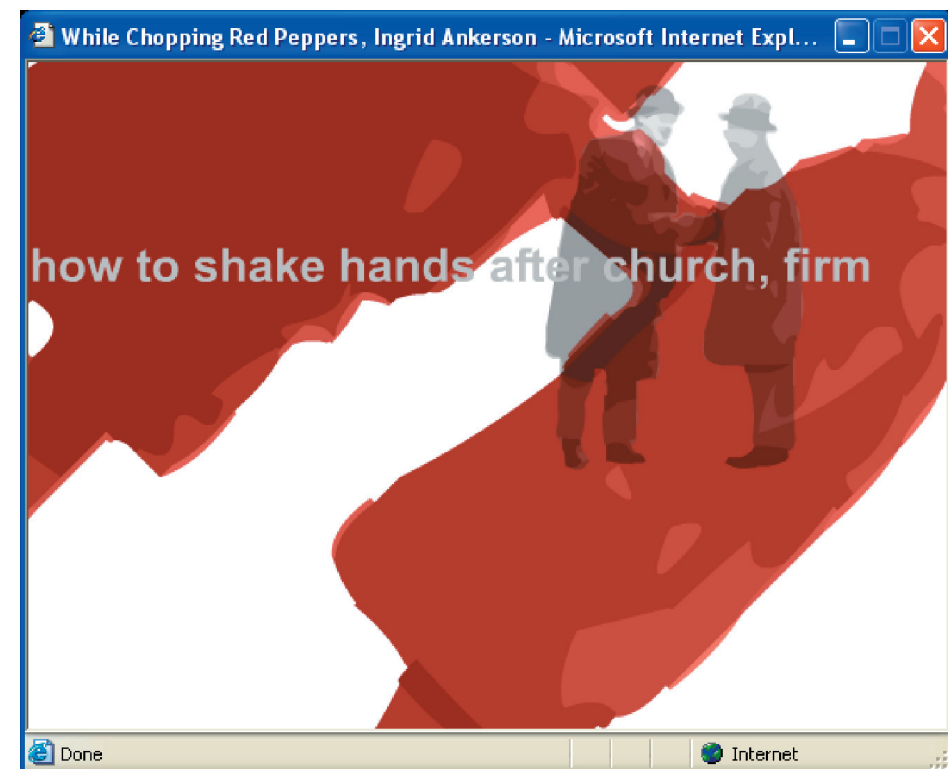

Figure 2.5. The swirling red and gray men, shaking hands, is a metaphor for religious and fatherly zeal, among other interpretations. taught to shake hands to her being a puppet of the father. Since she was controlled by her father, she was unable to speak for herself (as the vegetables would be "silent under water"). The silent vegetables juxtaposed with the daughter's hand in the father's could also represent his smothering/ drowning her so she could not live her life the way she might want.

The palate/presentation metaphor returns at that point so that the broccoli is foregrounded, tweening once again into the woman's silhouette as the following line is both spoken and written: "I'll learn to present myself." The young woman must learn "to present" herself according to the father's wishes, which is metaphorically shown through the perfectly placed broccoli becoming (tweening into) the woman's image. Throughout the text, the figure of the woman remains hunched, as if she cannot ameliorate her situation so long as the father is there.

The text ends with the words "a firm handshake/ a straight back" floating by the hunched figure. Then the woman's figure fades from screen, replaced by a pepper being sliced on a cutting board and the background fading to black as the final words are 
heard: 'I'll chop my peppers thick, for my father/ from whose kitchen I'll later move/ a thousand physical miles from." As these lines are read, the cutting board with the peppers and knife move toward the front of the text's frame, disappearing from view at the bottom of the screen so that the screen becomes black. The imagery and text of this ending suggests that the young woman removed herself ("a thousand physical miles") from the father to get away from the tension and the stress of living under his watchful eye. Her desire for removal is visually signaled by the peppers' movement out of sight.

Using what I know about poetic techniques and applying that knowledge to the visual and aural elements (as well as to the written elements), I interpret "While Chopping Red Peppers" to be a text that communicates a daughter's anxiety over her father's unwanted interruptions into her life. The designer used the central element of the red pepper in multiple modal contexts (as well as graphic representations of other produce) as a metaphor for the control the speaker's father had over her. The text is filled with multimodal clues that reflect the on-going tension in their relationship. If we use the five modes that the New London Group (Cope \& Kalantzis, 2000) suggested was possible in a multimodal text, some of the elements I've mentioned above that display a tension in "Red Peppers" would include,

- (linguistic) the line "the way vegetables are silent under water" is spoken and not written, which ties into its being a metaphor for the silence the daughter must endure under her father's emotional control;

- (audio) the voiceover signals that the speaker is a young-adult female (or at least not a child or an old woman, given the quality of the voice);

- (spatial) the churchgoers' (i.e., men in hats) change in size and rotation;

- (gestural) the hunched silhouette of the daughter; and

- (visual) the red pepper that contains the silhouetted faces of the speaker as a young girl and the father as an old man. 
While I can categorize these elements according to their modes of communication, the modes themselves don't necessarily help me to make meaning from the elements. I made meaning by applying my knowledge of reading poetry to reading the written text and the visual elements and the audio (and later going back and looking at how elements worked in modes I was less familiar with, like gestural and spatial). What the bulleted list above doesn't show is how these elements interact with other modal elements to compound the tension in the poem. For instance, labeling the churchgoers' change in size and rotation as a spatial quality of a multimodal text doesn't cause me to interpret that transformation as a metaphor for the speaker feeling like she is under pressure to live a life acceptable to her father (which seems to include going to church in addition to cutting her peppers an appropriate width). That meaning comes from my juxtaposing all of the elements in that scene together, as I did in the full reading above, as well as making connections between that scene and those that surround it.

As I said before, my reading wasn't intended to show how to help readers new to new media make meaning from a text; its function was to provide a sample reading to compare to those that the rubrics of Manovich (2001) and Kress and van Leeuwen (2001) provided. For instance, the reading that used Kress and van Leeuwen's four strata showed readers what process a designer might need to go through to compose a multimodal text - that is, that the designers of "Red Peppers" needed to consider

- (discourse) how to incorporate cultural and social contexts of familial relationships, cooking, religion, and poetics;

- (design) which semiotic elements to use to represent the above discourses, and which modes to use for each element (they settled on elements such as a voiceover, a graphic of a red pepper, a hunched figure, etc.);

- (production) which software program to produce the text in and, subsequently, how to use FLASH to bring the design together; and

- (distribution) how to get the text to potential readers (via Flash Player). 
Kress and van Leeuwen's model allows readers to break down the process of design and to consider how larger issues like discourses can be used to produce multimodal texts. Thus the four strata are still useful for determining design strategies that inevitably flesh out readings of new media texts, but only if readers are aware of the technological discourses that play out in many such texts (e.g., the examples of how the text works according to the FLASH timeline that I described above). Kress and van Leeuwen's rubric isn't intended to help readers determine why designers make the choices they do, which limits its usefulness in helping readers new to new media interpret the juxtaposition of so many modes of communication in these texts.

It is a similar story with Manovich's (2001) five principles, as the reading using those terms showed. What readers would walk away with by using Manovich's units of analysis in a new media text would have them wondering why it matters

- (numerical representation) that "Red Peppers" is digital;

- (modularity) that its elements can be edited;

- (automation) that the tweening process in FLASH is transparent to the designer;

- (variability) that the elements can be exported to and used in a different text; and

- (transcoding) that the file-naming conventions of "Red Peppers" as a FLASH file are being followed.

Perhaps that last one is obviously important to readers because if the text weren't transcoded as a SHOCKWAVE file, it wouldn't be readable and the point would be moot. But, otherwise, Manovich's five principles leave readers with a "so what?" For readers who are more familiar with new media texts, questioning a text using this rubric might be interesting in that it would uncover some (again, technological) features that the reader might have overlooked. Or, the rubric could be handy to provide a cultural-historical understanding of a new media text. But neither Manovich's five principles, nor Kress and 
van Leeuwen's (2001) four strata, offer support to readers who are still struggling with interpreting a text they've never encountered before, a text that uses multiple modes of communication that the reader is unaccustomed to having to interpret.

\section{Conclusion}

Not surprisingly, when I show "Red Peppers" to readers who've never seen it before - or anything like it - they either dismiss the text as technological/visual fluff (either response is typical) or, after I explain to them my reading of the text (the process of reaching it occurred over the period of four years), they simply do not understand how I could have gotten that much out of it. After all, my reading of "Red Peppers" was based on understandings I brought from reading and composing poetic, visual, and technologically rich texts - a mixing of design processes and reading strategies that helps me understand the text in ways that readers who approach this text with attention only to its alphabetic literacies (or even oral literacies) may not. I purposefully shifted my known reading strategies to accommodate an analysis of a text with an overtly visible design.

My reading shows that the multimodal and new media principles posited for understanding design processes of such texts don’t offer broad enough reading strategies. At the same time, my reading doesn't yet help other readers become able to form an interpretation of this or any new media text. The question still remains: What would a reading strategy useful for interpreting new media texts look like? How, in other words, can readers become able to recognize and make meaning from multiple modes used in overtly designed texts when they often cannot even recognize those design choices as being relevant to the text? Literary reading theories, such as Wolfgang Iser's (1978) process of reading described in The Act of Reading, is useful to understand why readers aren't yet able to or willing to shift their current reading strategies (based in written/ print communication with which they are familiar) to accommodate texts and modes with which they are not familiar (such as new media texts like "Red Peppers"). In the 
next chapter, I explore Iser's reading process to see how designed elements in a new media text like "Red Peppers" may only cause confusion in readers not familiar with interpreting overt designs. 


\section{Using literary theory as a framework for understanding readers' interactions with new media texts}

\section{Introduction}

While most multimodal and new media theories at present are concerned with describing the materialities of texts, literary theory describes at how readers interpret texts. Typically these texts are written works of fiction or poetry, but the same reading processes can be applied to any kind of text, as Louise Rosenblatt suggested in The Reader, The Text, The Poem (1994). In this chapter I focus on the work of Wolfgang Iser (1978), specifically his description of a reader's potential reading process in The Act of Reading: A Theory of Aesthetic Response.

Iser's (1978) text might seem to be a dated choice on which to base this chapter, but I argue otherwise. Its usefulness is that Iser's theories continue to provide a solid framework for teachers/readers to understand reading processes. Patricia Harkin (2005) argued in "The Reception of Reader-Response Theory" that reader-response criticism fell out of favor because "discussions of reading have been so thoroughly conflated with discussions of teaching literature...[the] decision not to teach literary texts in writing courses became or entailed a decision not to teach reading" (p. 421). However, as her article addressed, reading and reading theory should be reintroduced to the composition classroom because of its usefulness in applying phenomenological experiences to the reading process, which can help readers understand many genres of texts. Of the reading

theorists Harkin outlined in the article (including Louise Rosenblatt, Stanley Fish, and David Bleich, among others), she wrote of Iser that his "elaborate descriptions of the processes by which consciousness constructs meaning as readers encounter gaps and build consistencies in literary texts provided perhaps the most elaborate account of reading processes to emerge during" the mid-1970s, when reader-response was at its 
zenith (p. 412). Because of Iser's thorough treatment of reading processes_of how readers make meaning from texts that, as Harkin said "need not dwindle into sets of restrictive instructions in what particular texts mean" (p. 422) - his theories are useful to explore in regards to new media texts. I hope to show that while reader-response- and especially Iser's notions of blanks, which I will detail next — can help to describe how readers interact with new media texts, his reading theory provides a framework, but no details, for how readers can make meaning from a text that communicates in modes unfamiliar to them.

\section{Iser's reading process outlined}

In describing how a reader performs what Iser (1978) called a consistent interpretation or gestalt, he stated that a reader "finds himself directed toward a particular view which more or less obliges him to search for the one and only standpoint that will correspond to that view" (p. 38). That "one and only standpoint" is the reader's consistent interpretation. In order to teach a consistent interpretation, Iser suggested (like Umberto Eco, 1984, and Rosenblatt, 1994) that there are elements in the text that guide the reader toward making meaning. Iser (1978) continued, "The reader is situated in such a position that he can assemble the meaning toward which the perspectives of the text have guided him" (p. 38). The reader, then, creates mental images based on the elements that are represented in order to make sense of the text, but "the actual content of these mental images will be colored by the reader's existing stock of experience, which acts as a referential background against which the unfamiliar can be conceived and processed" ( $\mathrm{p}$. 38). This description of the initial stages of forming a consistent interpretation suggest that a reader might encounter "unfamiliar" elements in a text and make meaning from them based on the varied experiences that a reader brings to the text. Iser called a reader's "existing stock of experience" the repertoire.

He continued to describe how a reader finds a consistent interpretation, saying that the reader is "obliged to work out why certain conventions should have been selected 
for his attention" (Iser, 1978, p. 61). This process is perhaps the most difficult part of performing a consistent interpretation because, Iser said, many times the importance of certain elements is implied, rather than a stated given for the reader to interpret (p. 59), which would make a text's use of unexpected or nontraditional elements (such as an overtly visible design in a new media text) difficult or impossible for a reader to interpret. Iser suggested, however, that readers who are able to provide consistent readings do so because they learn to keep elements they previously dismissed (as not fitting with their consistent interpretation of the text thus far) in a mental background as they explore the rest of the text. If the need arises where a dismissed element becomes necessary, the reader can bring it back into play. Or, if a reader realizes that the interpretation she had formed based on a previous element is no longer useful (based on newly uncovered elements), she can shift her interpretation so it will be more consistent (p. 93).

Iser (1978) reminded us, however, that “There are, of course, limits to the reader's willingness to participate [in the process of uncovering a consistent interpretation], and these limits will be exceeded if the text makes things too clear or, on the other hand, too obscure" (p. 108). To invoke the inverse of Eco's (1984) model reader, some readers are not able to perform consistent interpretations of certain texts, whether from lack of knowledge or lack of desire. Iser, too, acknowledged that there are readers who are unable or unwilling to form a consistent interpretation. There are "those who do not share in [the] particular code" of the text (p. 190) because the reader doesn't know how to determine the meanings of elements within that particular text. (This inability to determine meanings of elements becomes evident in the example reading of a new media text that I provide in the next section.)

Iser (1978) described a reader's lack of understanding a text and its elements as a dysfunction in the transaction between a reader and a text. This dysfunction is caused by an author's use of "abrupt juxtaposition[s] of segments" that break "the expected order of the text" (p. 195). Iser termed an author's use of a break in expectations a blank, which 
"arise[s] out of the overprecision of representation," such as (to invoke Berkenkotter \& Huckins' [1995] take on genre theory momentarily) insider use of language - that is, an author's use of language in a way that only readers who are familiar with such usages can interpret. These blanks in a text "cause the reader to become more and more disoriented" (Iser, 1978, p. 207). Iser stated that "as the blank gives rise to the reader's projections, but the text itself cannot change [e.g., because it is a set design], it follows that a successful relationship between text and reader can only come about through changes in the reader's projections" (p. 167). If, however, the reader is unable to change her projections about a text because, say, the reader is unfamiliar with the elements or modes used to design the text and thus has no prior experience interpreting them, then failure to make meaning and to reach a consistent interpretation occurs (p. 167).

An author's inclusion of blanks in a text happen more frequently in "modern novels," Iser claimed, compared to the novels of $18^{\text {th }}$ or $19^{\text {th }}$ century tradition, because those early novels used generic conventions in more expected ways. (This is not surprising given that many early novelists were likely still working through the conventions of the genre and had, perhaps, not yet fully found the boundaries of the form.) I argue that even though Iser referred to modern novels as unexpected texts, the notion of blanks and the juxtaposition of elements is a useful way to describe how readers have to make meaning in new media texts. Such texts are often unexpected places of meaning for readers not used to engaging with overt designs. In the next section, I demonstrate how blanks caused by the juxtaposition of elements used in unexpected ways for one reader hindered her from achieving a consistent interpretation of the new media text Lexia to Perplexia (Memmott, 2000).

\section{Lexia to Perplexia: A blanked-up reading}

Lexia to Perplexia (Memmott, 2000), the new media text I discuss in this section, presented problems for one reader whom I observed; she could not fill the blanks created 
by the designer's overt use of nontraditional web design elements. The designer, Talan Memmott, used dynamic hypertext markup language (DHTML), HTML, javascript, and Macromedia FLASH to combine written text (both standard English and an HTML creole) in unexpected ways. The elements are, in many cases, animated and overlapping, caused by a reader's movement of the mouse. The cause-and-effect relationship between mouse movements and the text's reactions aren't always clear, as evidenced by the reaction of the reader discussed below. The purpose of Lexia to Perplexia is to argue for and demonstrate the cyborg relationship humans and computers share when they interact. Celia (the reader's pseudonym) believed that instead of sharing that interaction, she should be able to control it. In this section, I compare my reading of Lexia to Celia's reading to highlight how some readers who try to interpret a text are hindered by their expectations and understandings of how elements should function within specific kinds of texts.

\subsection{My reading of Lexia to Perplexia}

My reading of Lexia to Perplexia, although more in-depth and coherent than Celia's (which follows), is similar to N. Katherine Hayles' (2002) of the same text. My reading is mostly a literary one, but it also incorporates some knowledge of graphics and visual design where Celia's (and sometimes Hayles') did not. I point this out before I start the reading to prove that it is difficult (even for readers with experience interpreting new media texts) to move beyond a reliance on traditional (i.e., print-based) reading strategies. These strategies do, however, fall short of providing a coherent interpretation, especially for readers who are unaccustomed to changing their use of those strategies, as I did with "Red Peppers" (Ankerson \& Sapnar, 2000) to fill in a designer's purposeful blanks. I should also point out that my reading of Lexia is limited in that when I encountered the text in early $2001 \mathrm{I}$ was not so skilled in filling those blanks myself. I offer this reading, then, as an interpretive touchstone against which I compare Celia's reading later in the chapter. 
Lexia to Perplexia posits that a cyborg relationship is created when humans interact with computers; this relationship remediates both the person (in taking on technological characteristics) and the computer (in taking on human features). The title screen of the text contains a graphic that reads "Lexia to Perplexia" and includes the author's name in gold writing on a black background. Below that is a small rectangle containing a picture of a person's face (from nose to eyebrows). It is as if the face was in the computer monitor looking out at the reader, serving as an introduction to a cyborgian experience. After clicking the title, I encountered an index screen with title, subtitle, author, and four items in a menu (see Figure 3.1).

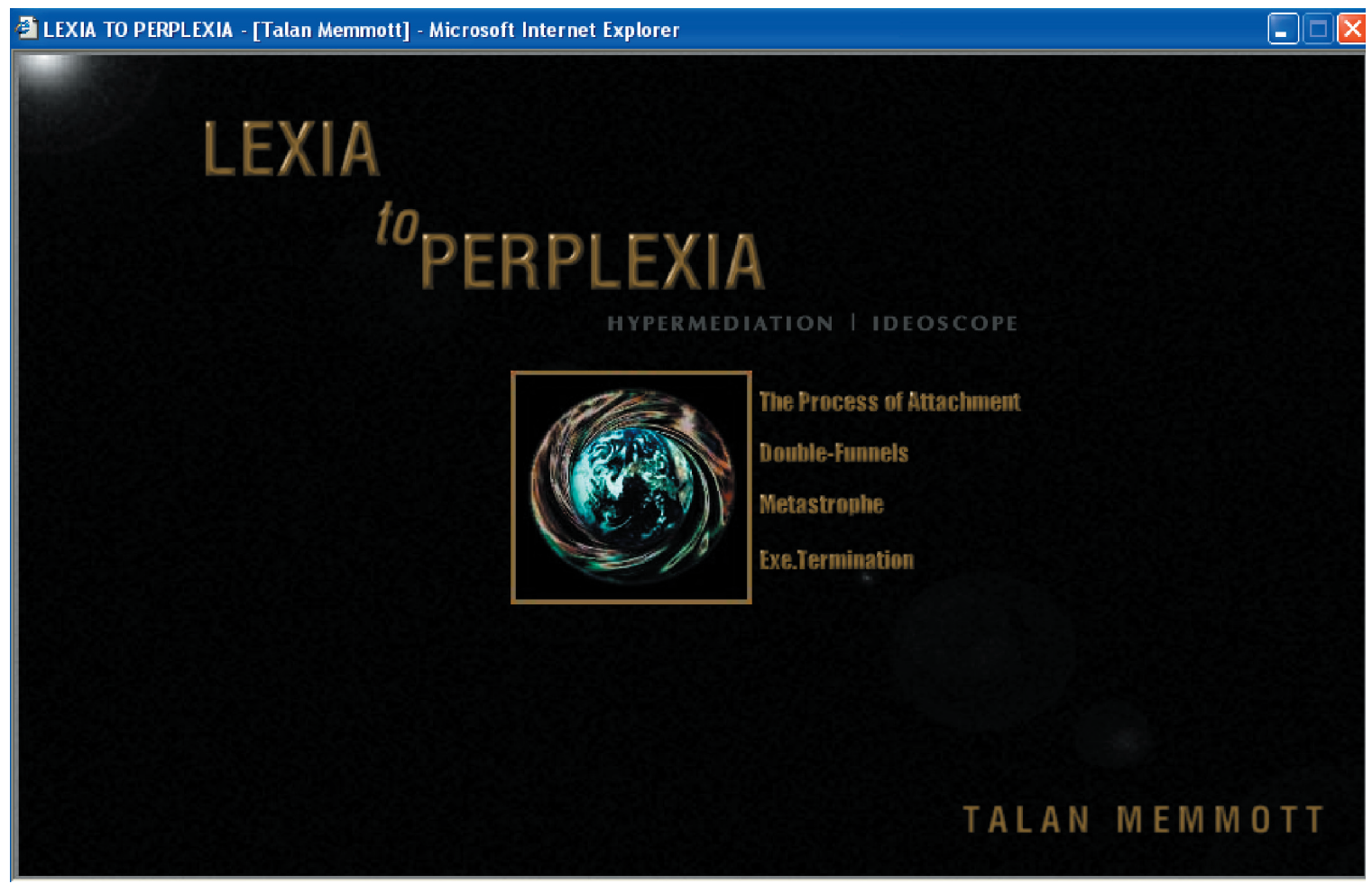

Figure 3.1. The index screen for Lexia to Perplexia

The black background appears to have a light source, like a star, shining from the upper-left corner, half out of sight. I suggest that the light is a star because this metaphor would relate to the graphic that resembles the Earth, which is situated at the center of the 
screen. The inclusion of the outer-space-like graphics and the distant view of a swirling Earth suggests that I am viewing the text from a distance-even from space. This text, it seemed, placed me outside of what I was familiar with; a more surreal interaction would be needed to interpret the text.

I moved my mouse over the title, which in literary hypertexts of the time usually offered an alternate navigational structure to the one a menu would offer; the word "PERPLEXIA" changed to "PER( $p)[\mathrm{L}(\mathrm{EX})]] i a "$ (see Figures 3.2 and 3.3). This design element - small in size but large in impact - held several meanings for me. Before its change, I interpreted the title as a jab at contemporary literary hypertext design and

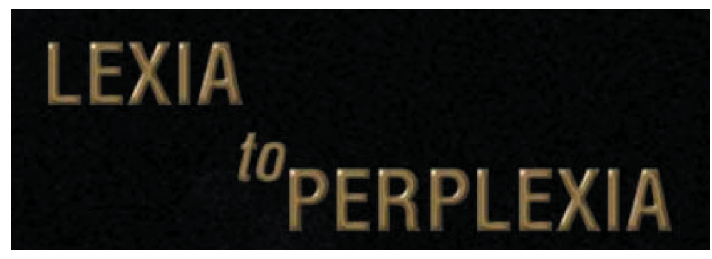

Figure 3.2. The original title

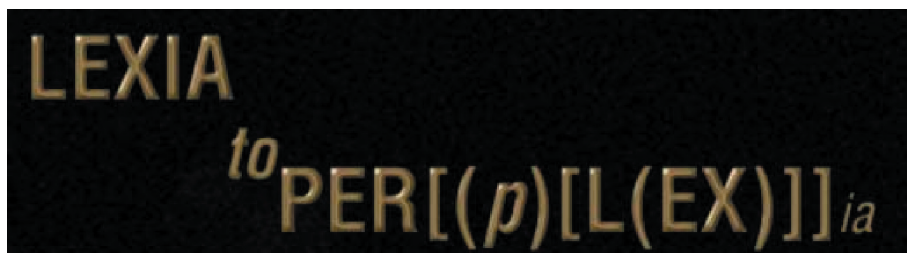

Figure 3.3. The moused-over title theory. To wit, several years

earlier George Landow (1994, 1997), in his edited collections

on hypertext theory, had propagated use of the term lexia to indicate a single chunk (or node or page...) of text on a single web page, which linked to other related lexias. Planning the links and connection between lexias in literary hypertext was a top priority in these works. In the early stages of hypertext, the possibility of linking was exciting and offered authors and readers countless ways to write, read, and theorize literary hypertexts. However, linking soon got out of hand, as several author-designers have commented to me including Ingrid Ankerson and Megan Sapnar (2000), who created "While Chopping Red Peppers" as a reaction to overly hyperlinked texts. The possibility of making a cohesive (if still hypertextual) reading from convoluted link structures became more perplexing in the 
late 1990s than pleasurable. Thus the jab on Memmott's part; he seemed to acknowledge hypertext authors' overindulgence on a reader's willingness to endlessly click.

And then, when the spelling (if one can call it that) of Memmott's title changed to "PER $[(\mathrm{p})[\mathrm{L}(\mathrm{EX})]]$ ia," an entirely new interpretation was made available — one that further supported the jab on lexias. Suddenly readers are confronted with nonlanguage, or rather, a creole of made-up, English-language-based wording combined with mathematical phrasings represented by brackets and parentheses, as one might see in an equation. This combination of languages or codes suggests another method of representing what Memmott called cyborganization, or the co-mingling of human (as malleable-language, analogic being) and computer (as strictly coded, digital thing).

I need to step back and say that until this point, I had been trying to classify this text according to a sub-genre of hypertext: hyperpoetry or hyperfiction. But with the unexpected change in wording - and to words that didn't exist in the English (or any other) language - I had no idea what genre I was trying to read. It wasn't unusual for electronic works to cross genres and include poetry, fiction, essay, dialogue or other alphabetic text and also to cross into nonalphabetic modes such as photos, graphics, video, and music, but such crossings were not typically presented as unexpected designs. Before Lexia, I had low expectations of the use of overt design elements in literary hypertexts because most such texts didn't draw attention to their designs [e.g., Joyce's (1989) afternoon; Moulthrop's (1992) Victory Garden]. However, Lexia's unexpected attention to design to convey meaning shifted my expectations radically. Because of this initial, unconventional move, I wanted to see more new and unexpected uses of design, and I wanted to figure out what those designs might mean in relation to the whole text. I returned to the menu and chose the top option ("The Process of Attachment") mostly because it was listed highest in the order, and I recognized that the last/bottom choice, "Exe.Termination," might take me out of the site given its visual pun situating it close to Exit, Termination, extermination, and executable (.exe) file. 
In "The Process of Attachment," a gray box with italic text filled center screen. The color of the typeface changed from black to green as I moused over it. It partially read:

The inconstancy of location is transparent to the I-terminal as its focus is at the screen rather than the origin of the image. It is the illusory object at the screen that is of interest to the human enactor of the process....

This initial statement reinforced notions that the meaning of texts is dependent on a reader's interaction with its elements rather than solely from the text (via the designer) having to provide a single, conveyable meaning. Memmott suggested to readers (i.e., the human enactors) that they might have to engage with the computer (i.e., the screen, the illusory object on the screen) in order to bear meaning in Lexia. The second part of the written text read,

- the ideo-satisfractile nature of the FACE... $<H E A D>$

$[F A C E]<B O D Y>,<B O D Y>F A C E</ B O D Y>$ rendered now as sup|posed other.

Cyb $\mid$ Organization and its Dys $\mid$ Content(s)

Sign.mud.Fraud

In this second section of the written text, Memmott played with the signs that made up the English language, transforming Standard English into creoles that connected human culture with technology. For instance, one creole example, based on HTML code, could be seen in references such as " $<$ BODY $>$ FACE $</$ BODY $>$," which, for readers familiar with raw code, would translate into a notion similar to the body contains the face, represented by the opening and closing body tags. In this case, body tags are the actual names of HTML tags that contain information represented in the "body" of a web page. But here, they also suggest that there is a connection between HTML tags and the human body because the (human?) "FACE" is contained within those tags. Hayles (2002) also examined this section of Memmott's text, suggesting that the HTML-human creolization, "allude[s] to the mind/body split in which the face, the most intensely signifying part 
of the human form, is first associated with the head or mind and then read as part of the body" (p. 52).

There is also a second creolization at work in this section, combining English with a higher level of technological language. While code creates a language readable by machines, words such as "Cyb|Organization" suggest a commentary on the interaction between machines and the language that humans use by compounding cyborg with organization. Hayles (2002) argued in regards to this quote that, "parsing body parts as textual components initiates a connection between flesh and electronic materiality that is further underscored" by electronic creoles like "Cyb|Organization" and "the electronic signature 'Sign.mud.Fraud" (p. 52). It seemed that Memmott meant to compare or, rather, combine the human with the machine.

I clicked on the gray box because that appeared to be the only link that would allow me to stay within this section of the text. The same black background remained, suggesting that this section of the text was self-contained because the design was similar to the screens I had been on so far. There was a gray box with arrows pointing to the left and right, resembling a timeline. The chunk of written text had been replaced with a fragment "f...f" (see Figure 3.4), which related in appearance and meaning to $f 2 f$ or face-to-face communication. Small, circular, gray graphics

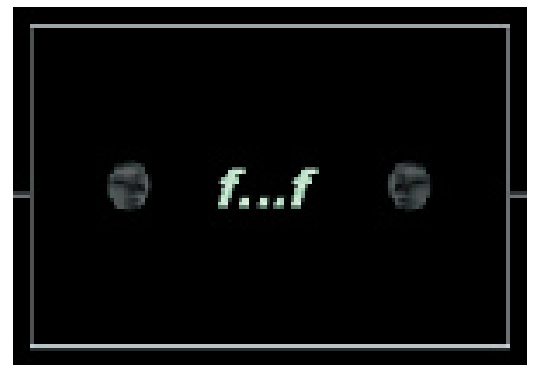
Figure 3.4: Section of "f...f" screen shot containing partial human faces on either side of this written phrase also suggested that "f...f" meant $\mathrm{f} 2 \mathrm{f}$. $\mathrm{f} 2 \mathrm{f}$ is a typical email or online communication shortcut that signifies any communication that is made when two or more people communicate within physical proximity of each other. This phrase is often used in comparison to virtual, synchronous, a-synchronous, or any other form of online communication such as email or chat that must be sent through the computer (or phone, 
terminal, etc.). Memmott seemed to be suggesting through these elements that $f 2 f$ communication could occur in actual physical proximity. But, a likelier interpretation would have the reader engaged in communication with the computer - a real face with a virtual face - or even two virtual faces communicating, as the two facing images (of faces) on screen implies. Either way, the text suggests that a close relationship between computer and human is necessary when each thing interacts with the other.

When I clicked on the "f...f" graphic, the black background was overlaid with a dark blue grid. The text within the box disappeared, and a curly bracket started to move across the screen from left to right. A sentence, broken into lines like poetry, appeared at the top left of the screen:

The FACE, drawn to the FACE, enters mostly through the FACE.

This sentence reinforced the notion that the face is the focal space of communication and is compounded by the repetition of the word "FACE," possibly signifying the multiple faces of the human and the computer. The sentence was a link, so I clicked and the following sentence appeared below the first, "Echo emerges/ and the world goes dark" accompanied by two human eyes - one in negative in the ever-present, gray box and one in positive at the far left of the timeline. On the right of the timeline was a plus sign (see Figure 3.5). The eyes created a blank in meaning for me. I had originally skipped over both the "FACE" sentence and the use of eyes in this screen because I didn't understand, and/or didn't recognize, their use. Instead, I had moved quickly to another section where I could make more sense out of other design elements. Hayles' (2002) reading of this screen, however, adds much insight to my blank-filled reading. She argued that the gray box is a terminal screen and that the face-like graphics can be read either as interiorized eyes looking out at us through the screen or reflections of our own eyes looking at the screen, thus positioning the reader 
as Narcissus gazing at an image that he failed to recognize as himself. By implication, this narcissistic doubling positions us inside the screen as well as external to it, intimating that we too have become techno-subjects. (p. 53) Hayles' interpretation here supports the cyborgian theme of Lexia and also fills in the gaps in my reading.

To move forward, I clicked the plus sign and a series of punctuation marks including

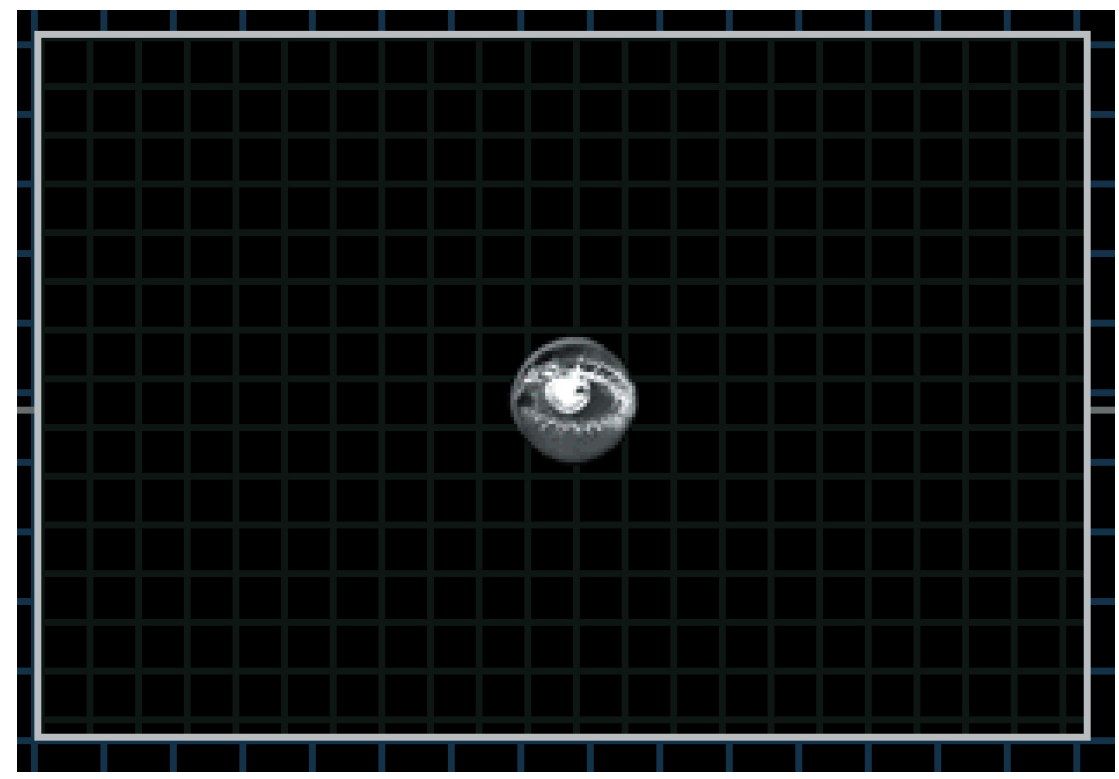

Figure 3.5. An example of the negative eye.

parentheses and upright slashes ( | ) appeared, imposed over the timeline. The plus sign changed into an outline of a small white square. When I moved my mouse away from the square, the upright slashes disappeared. I could mimic a feeling of animation in this graphic by moving my mouse in and out of the square, creating what looked like a sound wave when the upright slashes appeared and disappeared as quickly as I moved my mouse. It reminded me briefly of electromagnetic waves, something technical in nature. Here, my human body was interacting with technology through the text's design to produce a cross-genre, cyborgian event. 
The positive version of the eye had disappeared, so I moused over the negative eye inside the terminal. The sentence at the top of the screen changed to "I exit the exo/ taking fingersteps into the apparatus" along with another terminal with black, bold, sanserif text inside. Wordplay included the phrases "NO.where," "solipstatic," "Narcissus. tmp," and "exe.change." (see Figure 3.6)

These last two examples were more creolizations, combining Standard English (and the mythology of Narcissus) with computerese. By using the period to join the compound words while also showing their distinct origins, the words reminded me of file types including .exe as an executable file and .tmp as a temporary file. This design reinforced Memmott's purpose to juxtapose human and computer, to signal that humans were partly computer when they interacted with them, and vice versa.

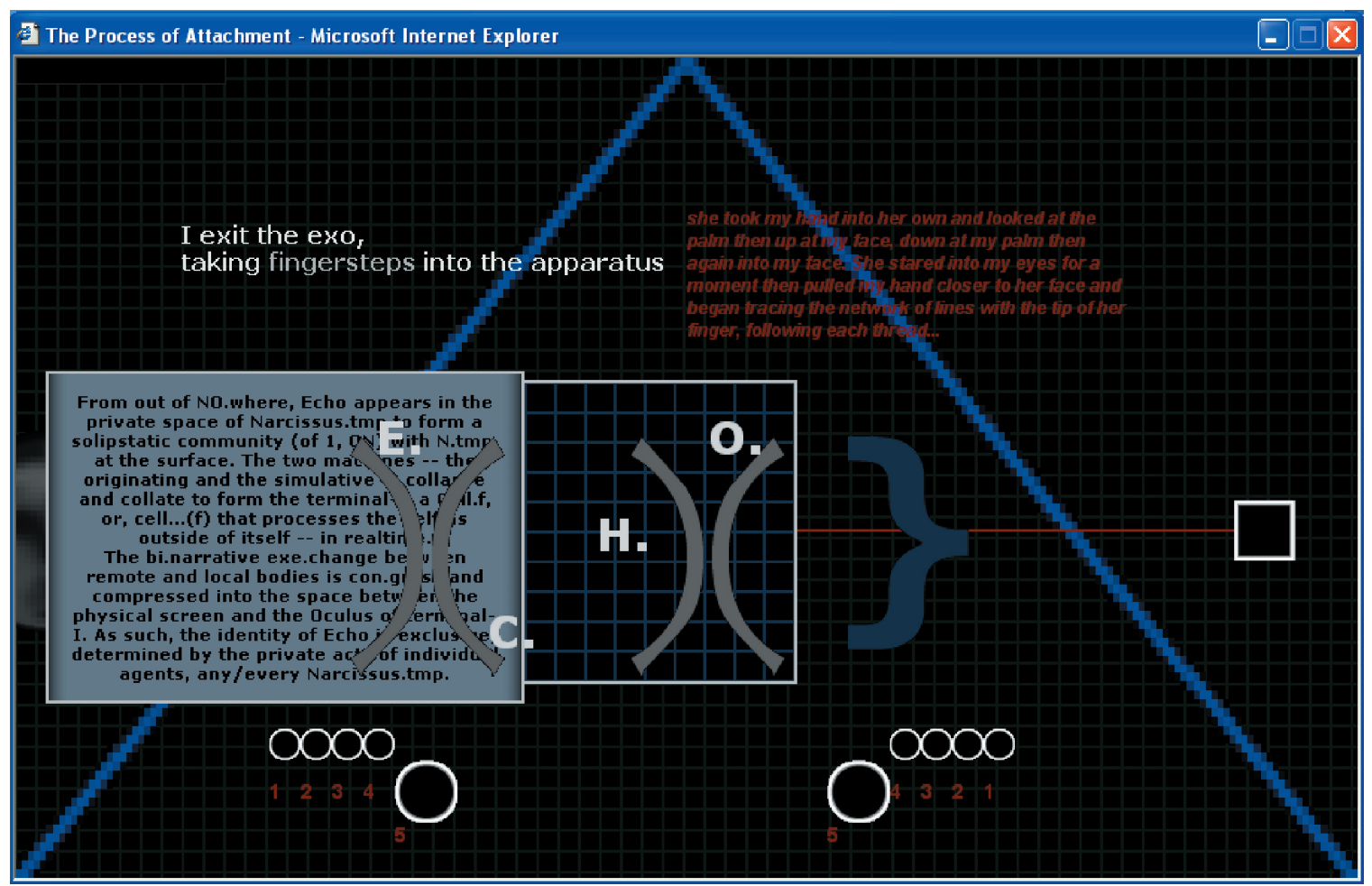

Figure 3.6. In the terminal (gray box), creolizations such as NO.where, N.tmp, and exe.change appear. (NOTE: I need to get a screenshot of this on a PC -- the piece doesn't work on Macs.) 
At this point, my reading strategies began to shift dramatically. Part of the written text on this screen is covered by large, grey parentheses, but I did not struggle to read the written text because I assumed that reading the individual words would not help me make meaning from Lexia as fully as if I made connections between the terminals and other elements on this and other screens. But there were large segments of the text that I skipped or dismissed on first (and subsequent) readings because I could not overcome the blanks in my own experiences to make meaning from the gaps Memmott presented in his design. Without Hayles' (2002) reading as a supplement to my own, my reading would have been on course toward a coherent interpretation but could not have reached the level of gestalt her reading did. My reading suggested that when users interact with technology, each take on traits of the other so that a cyborg being, a combination of human and computer, is the result. Memmott's use of the term cyborganization seems to best describe this process.

In comparison, the example of Celia reading Lexia to Perplexia, which I offer next, shows her inability to make sense of its design. Lexia was unexpectedly different from the kinds of web sites she was accustomed to reading, and she could not fill in the gaps created by the text's designer.

\subsection{Celia's reading of Lexia to Perplexia}

Celia, my sample reader, agreed to do a reading protocol of Lexia to Perplexia the same year the text was published-2000. To do this, she had to read through the text while verbalizing her thought processes and forming viewpoints so that I could capture what strategies she was using to make meaning from the text's elements. I chose her for this reading because she said that the only type of online reading she'd done was for school - texts that related to her masters degree in rhetoric and technical communication. Without fail, she said, she would print the web sites or other digitized documents to read them at her leisure, away from the computer. Rarely would she read onscreen because her frustration and impatience would mount in having to navigate through a text that needed 
horizontal or vertical scrolling. When I asked if she had ever read a literary hypertext or a new media text, she said no - she wasn't too sure what a literary hypertext was. She did, however, use the Internet to research information.

Celia was an organized person who did not like getting lost on the Web. She told me that she would not allow herself the time or luxury to browse through sites to discover something and instead searched the Internet according to pre-thought plans - $\mathrm{a}$ procedural way of learning - rarely using the Web for entertainment. Based on her selfcharacterizations and her Internet reading strategies, I guessed that reading Lexia to Perplexia would annoy and irritate her. Although she was a graduate student who had much experience using computers and searching the Web, she was similar to the students I described from my Revisions class who only used the Web as an informational and commercial tool. Celia was heavily interested in the arts, specifically dancing and music, and I therefore wondered if her artistic interests would help her make meaning from the elements in Lexia to Perplexia, a text that, from the start, she expected would be different from anything she had encountered.

Once Celia clicked on the main link to open Lexia to Perplexia, she questioned why she could not maximize the size of the screen. The edges were not draggable to fit the full size of her 17-inch monitor in the school's computer lab where we were. Memmott had set the screen size to remain constant, no doubt so that the design he'd intended wouldn't shift out of place. When Celia moused over the title and it changed from "Perplexia" to "Per(p)[1(ex)ia]]," she laughed out loud, but was frustrated that it would not change back to the original title when the mouse had left the area of the image. She did not want to click on the name of the author on that index page because she sensed that it would take her farther away from starting what she felt should be the actual "reading" of the text. Celia decided to click on the first entry in the menu, as I had done, revealing the black background and gray box filled with written text. However, once she started to read the text, she immediately encountered difficulties, remarking that the second word 
in the text box - according to her expectations that the written text would be Standard English—should have been "inconsistency" but was "inconstancy." In apparent disbelief that the text could contain such early obstacles to her making meaning, she blurted out, "It's only the second word! Agh!" Also, Celia was not too familiar with HTML coding and, therefore, didn't recognize the creolization in the text. She found herself trying to understand the words instead of the meaning of the sentences, or its design. She was trying to decipher individual word-meanings, trying to make every element in the text hold equal importance, rather than understanding them in connection to the whole.

Celia began to reread the text and was not clicking anywhere to see where else she could move within the piece. She was insistent on trying to decipher what Memmott meant by using the word variations. After several minutes, she realized the tags were similar to HTML, causing her to remark not that Memmott must have intentionally done so to suggest the connection between humans and machine as I had inferred from the text, but rather to exclaim that "the text has shit in it!" She assumed that the inclusion of HTML-type tags was in error, a mistake. Perhaps, she said, it meant the text was poorly designed, as in when readers encounter missing or broken links such as 404 errors when trying to navigate through web-based texts - a reading experience with which Celia was more familiar. This "error" discovery caused her to stop trying to interpret the screen aloud for me. She noticed, instead, the word "Freud" (which is actually spelled "Fraud," but she didn't say she noticed the difference) and decided to look for a link to move her away from this initial screen. She wondered, however, if there was "more than one link" or if the reader had to "go where it [the text] wants." She debated for a few moments what it was she thought the text wanted her to do; she was looking for a proper sequence, similar to how the Revisions students searched for a right reading path in Hypertext Gardens (Bernstein, 1996) even though there were multiple options. Celia was not familiar with texts that didn't have a "right way" to read. To her, there was only one 
sequence or direction to read a text, even though Lexia to Perplexia offered uncountable sequences, including some that were hidden to readers.

Celia continued to focus on the written text, trying to determine what words would take her farther down the right reading path even while the screen changed continuously with each mouseover on a word or graphic. She didn't comment on the non-alphabetic modes in the text such as the graphics resembling mathematical equations, the eyes, or the changes in color. She noticed these changes at times, such as when she moused over the word "dark" and the screen went dark, but she didn't realize that mousing over the word was what had triggered this reaction. Instead, she wondered what she had done to cause this change. She moused over other areas, but none produced the same effect as that initial reaction, and her frustration mounted in trying to determine the right way to read the text: "What do I read?!" she exclaimed. "Is the grey box all one link?"

Celia was not unlike many readers approaching new media texts for the first time. Commenting on readers' interaction with texts whose designs are instrumental to their meaning, as with Lexia's shifting and changing elements, Hayles (2002) suggested, “These actions often surprise and frustrate a user" (p. 57). Hayles' sample reader, Eugene Thacker, concurred:

A first-time reader of this work is, among other things, struck by the activity of the work: like many hypertext and net.art works, it seems to be alive, sometimes frenetic, sometimes frustratingly inert, and usually hyper-sensitive to any action on the part of the reader/user. (p. 57)

These statements seem to be all too true; Celia was unaware of the text's meta-level design and so she tried repeatedly, unfruitfully, to simply make the text work for her.

She clicked on numbers that appeared on screen and noticed they were links because the cursor changed to a pointing finger, typical of hotlinks in Internet browsers, but she said there was no URL displayed at the bottom of the browser like she was used to seeing with other kinds of web sites. She was referring to the links that appear in the status 
toolbar at the bottom of Netscape COMMUNiCATOR, Microsoft InTERNET ExPLORER, and similar browsers. She was using Netscape for the reading protocol, but because Memmott created the piece to appear in a browser window of his specifications, there was no status bar. Celia wondered aloud why some systems were different, chalking up this unusual instance of the link not appearing to her unfamiliarity with the system. I was unsure whether she meant her unfamiliarity with the software or hardware systems or with the text itself. She used a PC for this study, which she normally used (the lab had both PCs and Macintoshes), so it may be that she was referring to the browser preferencesalthough she did not, or could not, articulate the differences to this degree of specificity.

Even though many of the design conventions in Lexia perplexed her, there were some that she recognized from other designs, including the compound word, "solypstatic," which made her cringe because of its unusual combination of letters. Yet it also reminded her of two distinct words - solipsistic and static. Being able to distinguish the individual words within the creolization helped her recognize that Memmott was trying to play with words, even if she didn't understand their purpose. She also noticed his use of file extensions like .tmp and .exe, which reminded her of the .doc and tif extensions she has seen in Microsoft WoRD and graphics programs. Her limited knowledge of computer lingo was at work, although she was unfamiliar with how these extensions made meaning in the text.

When Celia reached what appeared to her as "the end" of this section (based on a lack of movement, links, etc.), she asked, "What the hell was that? Does it make sense? Is it me or it?" It seemed that she had tried to categorize this new media text into one genre - to classify it in a way that would allow her to make comparative readings from it based on similar texts. She had never interacted with a new media text and had never been required to pay attention to a text's design to make meaning from it. Considering this lack of experience, her questioning of the text and the confusion it instilled in her was warranted. But even the linguistic mode of the written text was presented in a way 
that made her comprehension of it difficult. "If it's a story," she said, "I'm not following it." Although she had come to appreciate the wordplay, calling its use "cool," she couldn't articulate its meaning. She said she didn't like the unexpected, exploratory experience of trying to interpret a new media text compared to her experiences with educational and informational web sites. She declared that she "sucks" at reading this kind of work and that it annoyed her.

She ended our session by asking me some pointed questions: Who was this site created for? And what genre is it? She offered the categories of poetry or art. In the editing class she taught, she wondered how a work like this would relate to an audience or how she would ever try teaching a piece like Lexia to her class. She asked the same questions she would ask of her students in trying to get them to determine the genre of a piece, and the same questions I asked myself when I first started reading new media works. How accessible is this piece to anyone who isn't already in the field of new media? Is Celia supposed to be part of the audience? If so, she said, the author had not reached her in this reading and, she reiterated, "He will not reach me," implying that she might never understand what Memmott was intending with Lexia to Perplexia. The gaps Memmott designed were chasms too big for Celia to cross. She wasn't able to recognize that the elements were juxtaposed in the text's design according to her actions with the mouse, which controlled many of the movements. In some cases, the text didn't allow her to control such movements, but she repeatedly insisted that she should be able to, based on her experience with other web sites, and this frustrated her and kept her from forming a coherent interpretation.

The complexity of Memmott's design hindered Celia's and my reading, although I was able to make rudimentary meanings from many of the design elements that Celia couldn’t grasp. Celia knew enough about reading texts to understand that the written text was more important in making meaning than, say, the background color of the web site. Although both of those elements are important to the overall design, the written 
text is more significant to the text's meaning and thus to performing a coherent reading. However, even within the mode of written text — a mode Celia was familiar with — the creolized elements are, perhaps, more significant to the text's meaning than the sentences with standardized language. For Memmott's purpose of showing how computer technology and users interact in ways that allow — nay, require - each of them to take on characteristics of the other in cyborgian ways, it is more important that readers recognize the juxtaposition of creole against standard English in order to highlight the cyborgian emphasis in the text's design. Celia was never able to make this connection in meaning between juxtaposed elements because she wasn't able to choose which elements were the most important ones to make meaning from. (And neither this example, nor Celia's reading, accounts for bringing nonwritten elements into that reading process.)

It is telling of an element's importance when it becomes central to the meaning in a text. It was the appearance of the creole that, for me, shifted my viewpoint of the text to understand it solidly as enacting cyborganization. Differing phenomenological experiences help readers choose important elements and also help readers reach different stages of understanding and interpretation. In the next section, I address the problem of reading a new media text based on Iser's argument that readers have to choose which elements are significant in a text in order to make a consistent interpretation.

\section{The need to choose significant elements}

Iser (1978) suggested that it is neither the sole responsibility of the reader nor of the text to make sure that the reader can understand which elements are the most important to interpret. Although the author/designer must initiate this exchange through her choice of elements, the success of a reader's interaction with a text relies on "the extent to which the text can activate the individual reader's faculties of perceiving and processing" ( $\mathrm{p}$. 107) and the extent to which the reader can process these individual interpretations of elements into a larger meaning for the whole text. It is this search for a coherent reading, 
this grasp at gestalt, that readers reach toward. Without "some potential correlation between" the elements in a text, "gestalt would not be possible" (p. 120). This potential correlation and the subsequent correction of interpretations that happens when newly discovered elements are introduced to the reading is called autocorrelation, a term Iser borrowed from E.H. Gombrich (see Iser, 1978, p. 120). Iser further stated that

The reader's part in the gestalt consists in identifying the connection between the signs; the "autocorrelation" will prevent him from projecting an arbitrary meaning on the text, but at the same time the gestalt can only be formed as an identified equivalence through the hermeneutic schema of anticipation and fulfillment in relation to the connections perceived between the signs. (p. 120)

In other words, the reader cannot assign any meaning to the elements that she wants because the author's intended combination of and connection between the elements would be ignored, and this would produce an inconsistent reading. Iser suggested that elements are reciprocally modified in their meanings, depending on "the extent to which expectations are fulfilled" by their use in the text (p. 124). So, a reader must take into account all possible elements in a text-foregrounding some while placing others in the background, depending on their importance to the overall "schema of anticipation and fulfillment" that the author has set up. From the meaningful juxtapositions of foregrounded elements, a reader creates a consistent interpretation.

It is possible to have a text in which a designer has juxtaposed elements in ways that (a) the reader cannot make sense of because of her lack of phenomenological experiences, (b) the reader cannot make sense of because the signs simply do not fulfill the text's expectations (i.e., rhetorically poor design choices), or (c) the elements are clichéd uses according to the reader, and she dismisses the text, not wanting to read it. But if, as Iser may have intended, the elements are chosen wisely by the designer and the reader has the knowledge to interpret them, then it is up to the reader to choose and make meaning from the elements upon which a consistent reading is to be based. "Consistency-building," 
Iser (1978) said, "is the indispensable basis for all acts of comprehension, and this in its turn is dependent upon processes of selection" (p. 125). So a reader must be able to select which elements are most significant to the text in order to create meaning from it.

"The constitution of meaning," Iser (1978) stated, "gains its full significance when something happens to the reader" (p. 152). For instance, when a reader's viewpoint has changed because he has been "taken outside his own experience," then gestalt, or a consistent interpretation, has happened (p. 152). Once this significance in meaning has been ascertained, and the "tensions between the signs" are resolved, the reader has reached closure on the text (p. 123), having performed a consistent reading. Thus, a consistent interpretation might be summed up as one in which a reader is able to make significant connections between the disparate elements of a text (having resolved any tensions in her selection of elements) and creates new meaning through the formation of a unified reading of the text. Additionally, failure to reach a consistent interpretation can occur when a reader who is not necessarily lacking in understanding designs, but who instead fails to want to interact with the blanks in a text in order to form a consistent interpretation dismisses the text. In this sense, being unable to read a text and being unwilling to read it are separate qualities in readers. A text, after all, can only stimulate but not "demand completion" from a reader's "existing store of knowledge" (p. 177).

If readers look back to the first reading example from chapter 1, the students were unable to form a consistent interpretation of the online version of Hypertext Gardens (Bernstein, 1996). In the second example, Celia's reading of Lexia to Perplexia showed how the unexpected blanks in the text caused by nontraditional web design elements prevented Celia from understanding the text. To reach a consistent interpretation, these readers, as Iser suggested, would have had to be able to choose which elements in the text significantly contributed to its meaning. But this is where Iser stops. Iser did not suggest how readers should choose significant elements — only that they must — in order to have a consistent reading of a text. Readers new to new media often focus on 
the written text, ignoring or dismissing the design. This seems to happen because the design of a text creates gaps in meaning that readers are not accustomed to having to fill. This necessity — the requirement of determining meaning from significant elements in a design — is a process that many new readers of new media texts are unable to do, mostly I suppose, from not having had to do it often. In the three examples I've given (Hypertext Gardens by Bernstein [1996], "Red Peppers” by Ankerson \& Sapnar [2000], and Lexia to Perplexia), readers could potentially pull a significant amount of meaning from the written text, disregarding (or backgrounding) the importance of the design, but such a reading cannot be considered a consistent interpretation of the text because it ignores most of the modes of communication the designer included.

Reader-response provides a framework for understanding reading processes, but as Celia's reading (and the readings of Hypertext Gardens provided by students) showed, readers are generally accustomed to reading - to having to interpret — written text and not much of any other mode of communication. Iser's reading theory doesn't suggest how readers can shift the same processes they use to make meaning form words to make meaning from visual or audio or interactivity. Yet, the accomplishment or breakdown in reading a new media text can still be described with Iser's process. However, in order to help readers reach a consistent interpretation of a new media text, they need to be made aware of the necessary shift in reading strategies from interpreting words-as-elements to modes-as-elements. In the next chapter, I demonstrate how some forms of rhetorical criticism can help readers begin to make this shift in recognizing modes in addition to writing as potential meaning-making elements in new media texts. 


\section{Rhetoric and new media texts}

\section{Introduction}

Rubrics provided by some multimodal, new media, and literary theories assume that readers have a base of knowledge from which they can make meaning in a text. For instance, to produce a consistent interpretation, literary theorist Wolfgang Iser (1978) assumed that readers would be able to identify the significant elements in a novel (i.e., plot, characters, themes, etc.) — elements that are situated firmly in the realm of print-based narratives. However, as I showed in Celia's reading of Lexia to Perplexia (Memmott, 2000), new media texts require a different, expanded assumption of knowledge - one that encompasses print-based (and narrative) reading strategies and one that also addresses visual and interactive elements in a text. I demonstrated how Iser's theory can account for phenomenological interpretations of a new media text in my own reading of Lexia when I was able to apply the process of choosing significant elements more broadly than to the words of the text only. My literary reading accounted, in part, for some of the visual and interactive elements but only because I had prior knowledge of interpreting new media texts which suggested that I should pay attention to these elements in addition to the written ones.

In this chapter, I turn my attention to a set of reading strategies_-Sonja Foss's (2004) methods of rhetorical criticism - in an attempt to show that rhetorical reading strategies, while also assuming readers' base of knowledge lies in print-based texts, have begun to shift the ground on which readers are able to approach a text by offering strategies that move readers closer to being able to interpret new media texts. I focus on methods highlighted in Foss's Rhetorical Criticism: Exploration and Practice-including generic, cluster, and generative criticism - because of the author's detailed and practical guide to finding and analyzing a rhetorical artifact (both discursive and nondiscursive) in a way 
that would be applicable in most composition classrooms. I examine one text, "Digital Multiliteracies" (Miles \& Taylor, 2003) in light of these three methods of criticism to show that it is possible to use Foss's take on rhetoric to analyze a visual text (as the book's examples of the family photographs and the Hay-Wain painting suggested), even though these reading strategies also assume a visual understanding/knowledge of texts that readers may not yet have. As I will show, Foss's methods do not quite reach as far as suggesting how readers understand the connections between their phenomenological interpretations and the significant multimodal elements in a text. It is also important to note that the readings of "Digital Multiliteracies" below are only one possibility —my own - that occur from using Foss's methods. I use these readings as examples to show how I would have tried to justify my reading of the text to my co-editors, not to suggest that they are the only possible readings of the text.

\section{2. "Digital Multiliteracies": An example}

In the context of composition classes, the move to attach rhetorical criticism to reading new media texts is appropriate. Such a move allows us, as Foss (2004) wrote, to "engage in a process of thinking about symbols, discovering how they work, why they affect us," and being able to articulate those answers to others (p. 3). Like Gunther Kress and Theo van Leeuwen's (2001) theories of multimodal discourse in which multimodal texts are designed with attention to multiple semiotic modes of communication, rhetoric involves interpreting signs given for a particular purpose. Those signs can include a range of modalities, not just written or verbal ones. As I have shown in previous chapters, however, readers situated in composition or English studies programs are not always likely to know how to interpret modalities other than written (or spoken) ones. Let me give an example that addresses the need for reading strategies that take into account visual, verbal, and interactive modes. 
In the fall of 2002, as CoverWeb co-editor of Kairos (the scholarly journal I discussed in chapter 1) I initiated a call for texts for a special issue on new media. (I did so because there were few texts at the time that used design elements as part of their arguments, and I wanted to provide an opportunity for authors to publish works that did.) One text that was submitted for that issue presented a particularly difficult challenge for my co-editors and I because it required reading strategies for which we were unprepared. This particular text, Violence of Text (Miles, 2003b), was a self-proclaimed "online academic publishing exercise" containing six scholarly texts composed with a combination of sound, video, and written text (in various forms including visible coding) to present their arguments. The overall purpose of the text was to demonstrate that scholarly meaning can be made from modes of communication other than written-text-as-linear-argument. The authors argued that violence may need to occur to the alphabetic-as-artifact in order for that learning, and subsequent composing, to take place. They demonstrated this violence by undermining the importance of written text in the document and privileging its visual, verbal, and interactive modes of communication. Often the written text was completely obscured because it was presented in ways readers wouldn't expect to encounter-such as when the written text was embedded in HTML code so that the code was more visible (and recognizable) than the writing buried within.

I want to focus on one text out of the six for the purpose of this section: "Digital Multiliteracies" (Miles \& Taylor, 2003) relied the least on written text to communicate its meaning. Instead, it incorporated a video-editing software interface and three selections of multimodal clips from which to choose: still photographs, audio, and written text. Unlike the other texts in this collection, "Digital Multiliteracies" didn't move or scroll or do anything until the reader selected random clips to drag to a corresponding timeline and the sequence was played back. That sequence would play all three of the modes of clips at once so that readers had to decipher the clips to understand what their "movie" meant. The argument that the designers of this text made was that multiple modes of 
communication need to be taught in digital environments so that students can become digitally multiliterate. "Digital Multiliteracies" required readers to find a meaning-making strategy that differed from those they used to read traditional "scholarly" publications; in other words, readers needed a strategy that accounted for "Digital Multiliteracies"" overtly visible design. In the case of my co-editors, a strategy that took design into account was different from any they had previously encountered, which according to their initial responses to the text favored its written elements. When they read this piece, they were unfamiliar with the value of its design and could not categorize it as not scholarly.

Both of the co-editors' experiences reading digital texts, including new media texts, varied greatly from my own. The co-editors - one of whom had a $\mathrm{PhD}$ in composition and another was working on her $\mathrm{PhD}$ in composition-were well-versed in reading printbased, academic articles as well as scholarly hypertexts that had appeared in previous issues of Kairos. (Although their degrees were in composition and not rhetoric, the crossover in research and teaching that happens in these two fields suggests that these two readers should have been familiar with rhetorical criticism.) The editor with a $\mathrm{PhD}$, with whom I had worked for over a year, was an online writing center scholar and had read texts under review at Kairos with a wonderful, developmental eye.

As editors of this special section, it was our responsibility to review the text and decide whether it was worthy of sending to the editorial board for possible publication. We were all invested in seeing quality pieces published in the section, and although the new media issue was my idea originally, I had been in conversation about it with my co-editor for over a year. We wrote the call for texts based on a conversation about what new media meant to both of us. We took a broad approach in defining new media, in line with the kinds of scholarship that had been published in the field of computers and writing already. We agreed to consider written, text-heavy pages with added multimedia components (like Gossett, Lamanna, Squier, \& Walker's [2002] webtext mentioned in chapter 1), which the other editor was more familiar with, as well as texts that I felt 
would really push the boundaries of what new media scholarship could be (for me, Violence of Text turned out to be a perfect example of this, which is one of the reasons I focus on it here). We also discussed what we could feasibly, technologically, publish given our server setup. We had not discussed any of this with the assistant editor because she had not been assigned to work with us at that time. Below I refer to them both as co-editors rather than highlight a rank in editorships because the assistant editor, once on staff, participated fully in the process of reviewing texts.

We divided the responsibilities of the editorship, and much of the technologyintensive work fell to me whereas the line/word editing and communication with authors went to other co-editors. I worked more fluently on the copy-editing of accepted manuscripts and on technology matters, such as cleaning up poorly written code, making sure table widths in author's webtexts were set properly, and transferring the final versions to the journal's server. She had little web design experience and so she handled much of the email communication with authors. She was an excellent writer and had published several articles in print and in online venues since getting her $\mathrm{PhD}$. Yet she acknowledged to me that she'd received help putting the online texts into HTML so that we were able to divide our tasks and roles in the editorship accordingly. The assistant editor, who joined our team half-way through the year, said she had some technical experience with HTML, but little knowledge about the breadth of possibilities in new media texts. From their descriptions of the amount and level of experience that each of these co-editors brought to the table, it became apparent that neither had a lot of experience understanding why a text might highlight its use of technology (like Lexia did, in chapter 3). As I discuss below, my co-editors read Violence of Text based on printbased reading strategies, seeing the design elements, they said, as technological tricks to cover up poor argumentative structures.

We each reviewed Violence of Text (Miles, 2003b) on our own time, planning to meet in an instant messaging program afterwards to discuss our thoughts. None of us had 
previewed it, and so none of us knew what we were heading into until we got there. Like Lexia to Perplexia (Memmott, 2000), where the reader had to mouseover areas of the text to find connections and potentially make meanings, a reader of "Digital Multiliteracies" (and its surrounding collection, Violence of Text) had to interact with the text to make it perform. Miles and Taylor's (2003) text contained options for incorporating photos, audio, and written text into a timeline that would play back the reader's choices like a movie clip. Unless a reader chose a clip to preview or drag to the timeline, the text remained static (see Figure 4.1). It wasn't until we met online to discuss our readings of the text that I realized the extent to which our differing understandings of the importance of design had invoked drastically different readings.

In "Digital Multiliteracies" (Miles \& Taylor, 2003), there were no print-based, alphabetic clues on the opening screen suggesting how to read the piece, as some hypertexts offered (although the separate introduction to the entire edited collection did have such instructions). A reader unfamiliar with video-editing interfaces would have found this text unusable, or, as it turned out with my coeditors, "broken" (personal communication). Each of their readings of "Digital

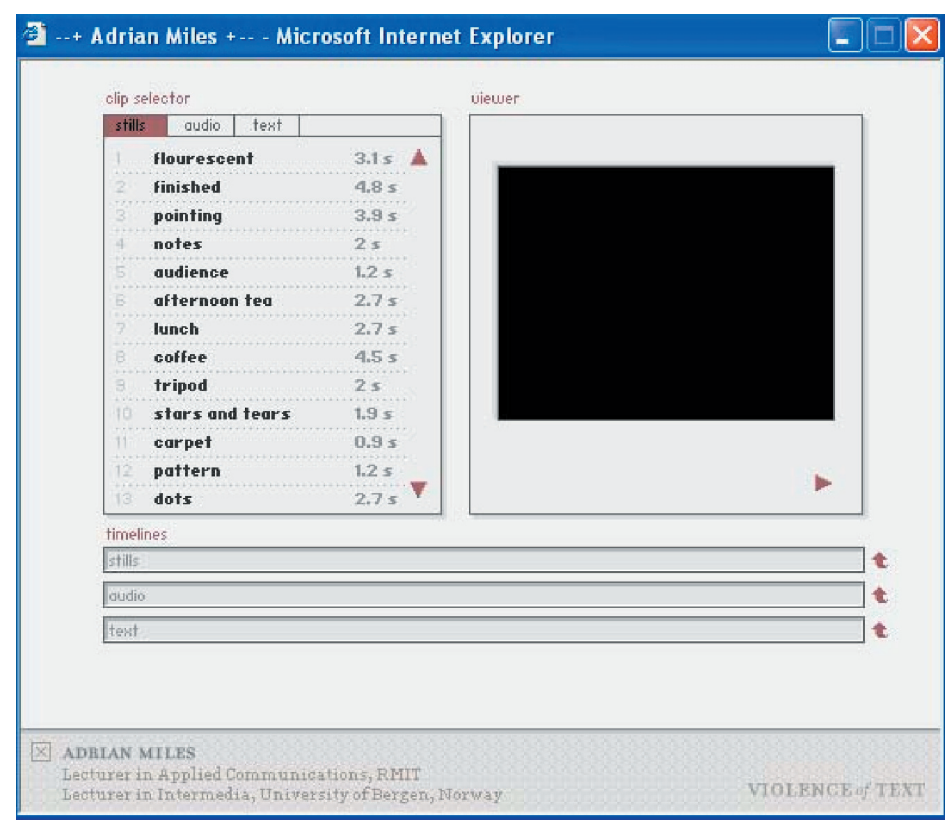

Figure 4.1. The opening screen of "Digital Multiliteracies"

Multiliteracies" provoked

a similar response: They felt the text was not working, and one of them suggested that Violence of Text (Miles, 2003) as a whole used technology for its own sake, not for the 
sake of the text's argument. Both editors weren't sure if the text had an argument: One editor said that the text was too "artsy" (the other agreed) and said that it didn't live up to the publication standards of a scholarly journal. These interpretations show that they were looking for a traditional, rhetorical argument based in print conventions. When they could not find one, the text became unusable for them. Their interpretations did not allow for understanding the potential of design to make meaning (to persuade, even) in new media scholarship. They had never seen it done before and had no experience on which to base such a reading. What they expected was a traditional, linear argument, so the seeming confusion of a designer using multiple modes as part of an overtly visible design — a design that required them to interpret it in order to understand the text's argument - caused them to dismiss the text altogether. This kind of interpretation that causes a reader's dismissal doesn't only happen with scholarly texts. I refer back to Iser's (1978) argument that readers become disoriented when they cannot make meaning from the blanks caused when texts break from traditional expectations. Readers who are solely comfortable with the print traditions of any written genre, as my co-editors were, might face difficulty in trying to understand the purpose of multimodal elements in any kind of text even when they want or need to understand it. Megan Sapnar (2002), co-editor of the site Poemsthatgo, said that readers reacted similarly to the new media texts displayed on that site:

We have received many comments from "traditional" readers of poetry and fiction who express reservations about the New Media format and who see images as "visual tricks" that may give poorly thought out writing an appealing wrapper. One visitor commented, "Our attention may become distracted by the visuals thus making us less critical and more acceptant of anything, regardless of quality." But it's my hope that this will give us an opportunity to raise the level of critical discourse regarding textual, aural, and visual literacy. (pp. 90-91) 
It's not surprising that readers who expect to find poems on the site (after all, the web address has the word "poems" in it) are surprised and even frustrated when the texts they find aren't just poems, but new media compositions. No matter the genre of a new media text — and with "Digital Multiliteracies," I argue that it draws on multiple genres to create a new kind of text - readers who are schooled in rhetorical analysis are not always capable of transferring that knowledge to interpreting designs.

Kress and van Leeuwen (2001) suggested, however, that readers who are familiar with some semiotic modes can adapt to understanding new modes so that "what is or is not a formally, officially acknowledged mode in a given domain of practice can change over time" (p. 54). For instance, on the Poemsthatgo site, a reader who is willing to make meaning from the visual and aural elements in nearly any of the site's texts would discover that those elements weren't there to trick readers into accepting doggerel as good poems, but function as significant layers of meaning in the text. If my co-editors were going to take "Digital Multiliteracies" seriously as new media scholarship_rather, to begin to understand it at all-I had to find a method that would help us all to see beyond the written word as mightiest mode and show how readers could draw on their rhetorical skills to make meaning from the design.

\section{Foss's methods of rhetorical criticism}

Compared to my co-editors, I could see a way of reading of "Digital Multiliteracies" that was more cohesive, as I will show later. What I discovered was that even though I could convey my interpretation to them, I wasn't sure how I had reached that reading myself. And until I could explain the meta-analysis aspect to them, they could use my interpretation but not build on it (or reject it) to create their own. I turned to rhetorical criticism in the hopes of finding a way to describe my reading of "Digital Multiliteracies" meta-analytically. 
There are several scholars who use rhetoric to interpret multimodal or new media texts (see, e.g., Gruber, 2003; Hocks, 2003a, 2003b; Wysocki, 2001, 2004b). The purpose of such scholarship has been to demonstrate that rhetoric can be applied to a broad range of texts. Although this work is important in expanding the field of rhetorical and visual or new media texts, I wanted to trace my understanding of "Digital Multiliteracies" back to a basic rubric (of sorts) within rhetorical criticism in order to show how metaanalytical approaches might help my co-editors make sense of "Digital Multiliteracies." In other words, I was looking for a scholarly text that demonstrated a process of analysis unencumbered by its direct application to a text. For that reason, I turned to Foss's (2004) work on rhetorical criticism. Although there might be criticism against her work for being too abbreviated or simplistic - it reads as though its audience is an introductory rhetoric class - its step-based process is exactly why I chose to use it. It would be easier to convey my reading strategies to my co-editors using an introductory approach, especially since we were all interacting with "Digital Multiliteracies" as beginners of sorts.

In a short chapter entitled, "Doing Rhetorical Criticism," Foss (2004) outlined four steps in "the process of producing an essay of criticism" (p. 11), listed as such

a) formulating a research question and selecting an artifact;

b) selecting a unit of analysis;

c) analyzing the artifact; and

d) writing the critical essay. (p. 11)

My artifact was already selected_-'Digital Multiliteracies"—-so let me speak briefly about my research question. Foss argued that "a research question is what the critic wants to find out about rhetoric by studying the artifact" but also that a research question "may generate new theories about how rhetoric operates" (p. 12). I wanted to know if "Digital Multiliteracies" contributed to scholarly knowledge in the field of new media enough to publish it in a scholarly online journal. On a more basic level, I just wanted to see what 
the text did-how it worked, what meanings it conveyed. This research question drove my initial readings of the text.

Let me skip steps (2) and (3) momentarily to remark that I won't be treating step (4), writing the critical essay, as part of this process because for the purposes of helping us understand the text, this step (at this point in discovering a method of meta-analysis) is mostly irrelevant. We did write about our interpretations, but informally, through emailed WORD attachments roughly outlining our thoughts or through instant messaging programs. So, let me return to step (2), selecting a unit of analysis.

Units of analysis, Foss (2004) said, are the lenses by which a critic examines a text to answer her research question. For instance, Foss provided examples of units of analysis including types of evidence, components of an argument, word choice, and metaphors to name a few (p. 15). Foss included ten methods of criticism, each relying on a different unit of analysis (although she did suggest that these methods weren't the only ones available - just some of the most common). In looking to Foss's work on units of analysis in rhetorical criticism, I knew that my reading of "Digital Multiliteracies" would only make sense through specific lenses such as generic, cluster, and generative criticism. Other units of analysis that didn't seem appropriate to my reading of the text included fantasy-theme, ideological, feminist, and so on. Even metaphoric and narrative criticism provided a print-centric, word-centric strategy that proved too limiting for reading new media texts. I will now provide an overview of these three units of analysis and suggest how beneficial they might be to my reading of "Digital Multiliteracies."

\subsection{Generic criticism}

Generic criticism can be used to "discover commonalities in rhetorical patterns across recurring situations" (Foss, 2004, p. 225). The reasoning behind generic criticism as a useful tool for interpreting texts is that there are ready conventions for distinguishing similarities and differences between genres. This "process of classification is central" ( $p$. 226 ) in determining how and why a text fits a particular genre, or breaks from that genre, 
for a specific rhetorical situation. Lloyd Bitzer (1968), the rhetorician who first discussed rhetorical situation, argued that recurring rhetorical situations demand specific texts, out of which genres or "rhetorical forms are born and a special vocabulary, grammar, and style are established" (p. 5).

In most rhetorical situations a text can be analyzed to see if it fits/meets the conventions of a particular genre and to determine whether those conventions are followed or subverted. Foss (2004) provided the example of body art as a rhetorical form that purposefully breaks away from generic, artistic conventions "to encourage viewers to question the definition of art" (p. 234). If viewers of such art are not already familiar with its conventions (of breaking from convention) then, Foss said, "the audience tends to be confused and reacts negatively" (p. 234). This reaction is the same as that of Iser's (1978) readers who are unable to fill in the blanks of a text, and the same as the sample readers I've presented throughout this dissertation who were unable to interpret the new media texts I've discussed. Unless readers are able to analyze a text in relation to similar genres, generic criticism is not a useful analytical tool.

For this reason, generic criticism is not the best method to provide a meta-analytical language of reading "Digital Multiliteracies." It could be partly useful since "Digital Multiliteracies" is composed of several genres - photography, audio recordings, conference papers, and software interfaces to name a few. I referenced each of these genres when explaining my reading of "Digital Multiliteracies" to my co-editors, but at least two major problems remain with using generic criticism as the main unit of analysis for a new media text like "Digital Multiliteracies": (a) there are too many potential genres by which to analyze the text and thus "Digital Multiliteracies" doesn't fit neatly (or even messily) into a single genre for comparison, and, more over, (b) most uses of design elements in "Digital Multiliteracies" break generic conventions in ways that my co-editors would have been unable to fill with meaning. I will discuss this in more depth later, but let me provide an immediate example: The co-editors had never used 
video-editing software before, whereas I had. Thus, "Digital Multiliteracies"” use of that genre to provide its interface and major navigational elements - let alone how "Digital Multiliteracies" broke subtlety away from that form - was not as familiar to my coeditors as it was to me. Nevermind the theoretical implications of using such an interface as a design feature and how that usage helped form the argument of the text. Even if I had told them which genres to use in analysis, nearly all of the forms would have appeared antithetical in regards to their (and other scholars') expectations of online scholarly conventions.

\subsection{Cluster criticism}

Foss (2004) wrote that a cluster analysis provides "insights into the meanings of key terms" (p. 72), which are "discovered by charting the symbols that cluster around [the] key symbols in an artifact" (p. 71). Foss suggested that looking at the key symbols and terms - or in the case of nondiscursive, visual texts, visual elements that appear significant due to repetition, size, and/or placement, and so on - can provide readers with insight into the rhetor-designer's worldview (p. 72), or rhetorical purpose. She outlined three steps to performing a cluster analysis of a text: "(1) identifying key terms in the artifact, (2) charting the terms that cluster around the key terms; and (3) discovering an explanation for the artifact" (p. 72). Cluster criticism is useful here because, in Rhetorical Criticism, Foss (2004) specifically addressed how this analytical method can be used to interpret artistic texts. One essay included as an example of the cluster-criticism method is Kathaleen Reid's (2004) analysis of Hieronymus Bosch's fifteenth-century painting, The Hay-Wain (see Figure 4.2), a triptych depicting "the medieval story of the creation, the fall, and the potential redemption or destruction of humankind" (p. 78).

In Reid's (2004) essay, she argued that cluster criticism is useful in visual texts because, as Foss suggested, the method of clustering key terms can also be used to identify clusters of key visual elements, from which meaning can be inferred. The HayWain, Reid argued, is a particularly useful text to which to apply cluster criticism because 


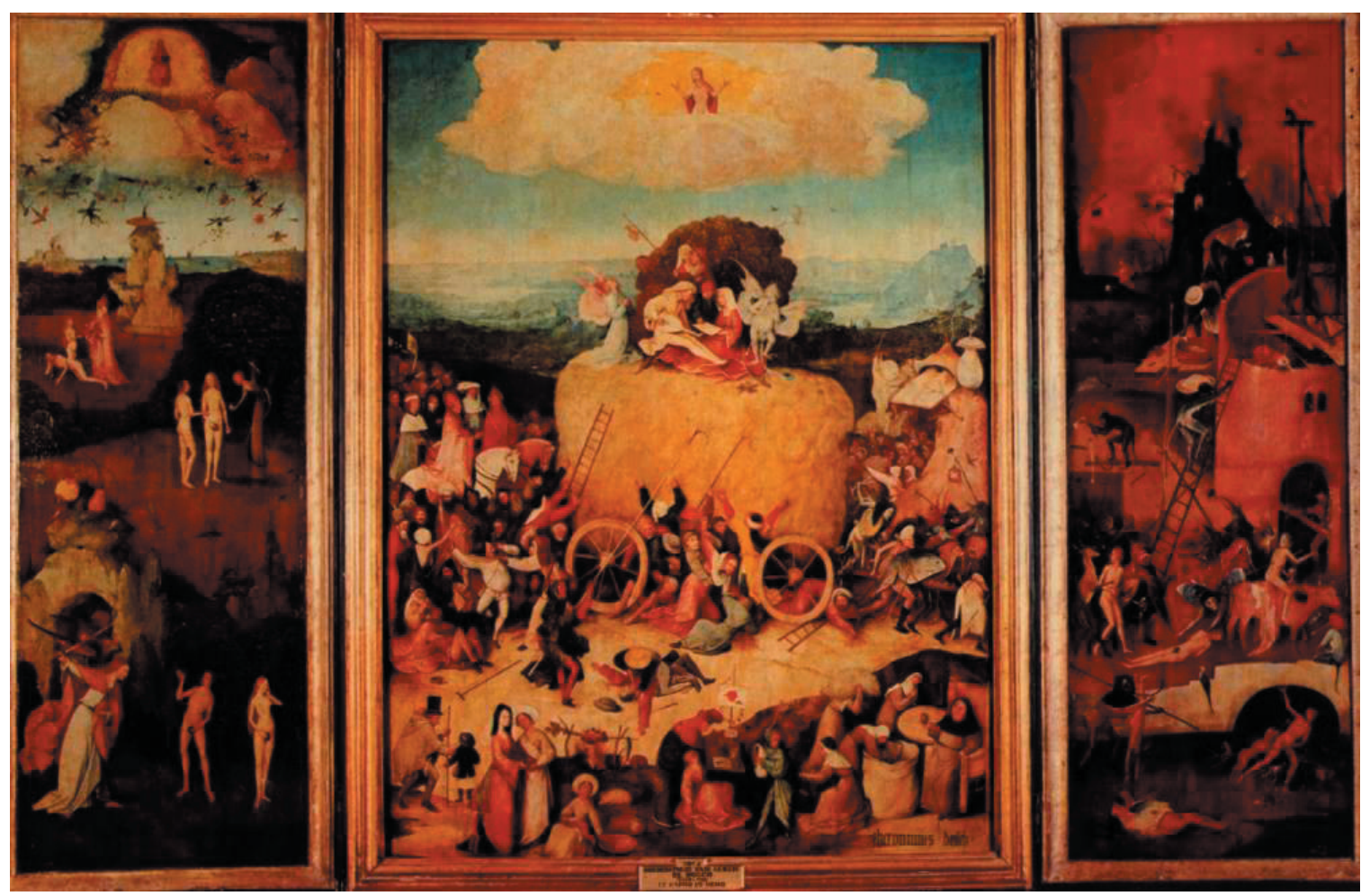

Fig. 4.2. The Hay-Wain painting by Bosch.

its meaning has been repeatedly contested, and many critics suggest that the painting is "so idiosyncratic that its meaning must remain a mystery" (p. 79). Reid then went on to demonstrate that using cluster criticism can provide a consistent reading of the painting by helping her to identify the key visual elements in the text. These elements included the intense use of the color gold as well as the graphic elements of the "arch shape, ladders, clerics, couples, fish, and the boar" (p. 83). These items were selected, she said, "because of their high frequency and/or high intensity of use (Rueckert, 1963, p. 84). Frequency refers to how often the term is repeated, and the intensity refers to how significant the term appears to be in the work" (Reid, 2004, p. 82).

By analyzing each of these key elements in relation to the cluster of visual elements that surround them, Reid (2004) concluded that Bosch's painting intends to show the theme of transition - both that of transition of life from good to bad and "transition of power from the humans to outside forces," which will end badly for humans (p. 87). The painting, Reid claimed by analyzing the clusters of key elements, is Bosch's attempt to 
"persuade individuals to consider the transitions of their lives," most especially spiritual and moral ones (p. 87). In providing this consistent reading of the key elements in The Hay-Wain, Reid suggested that cluster criticism is useful when examining a visual text for meaning and, thus, shifting the use of some forms of rhetorical criticism to reading nonwritten works is possible.

Reid (2004) did, however, bring up several issues as potential stumbling blocks in using cluster criticism for visual texts. One issue in using cluster criticism for visual texts involves choosing an artifact to which to apply this method. Reid suggested that using cluster criticism for large-scale or animated/moving texts might prove especially difficult. For large-scale texts there may be too many key elements (and thus too many elements that cluster around those items) to attempt a meaningful analysis. She (and subsequently Foss) suggested choosing an artifact from which no more than five or six key terms or elements could be used. For fleeting communication, as she called artifacts such as film and audio recordings, the necessity to freeze frames or stop tapes might prohibit a thorough cluster analysis from being performed. Reid also commented that smaller artifacts such as short poems and photographs — and even smaller paintings than the 3-panel Hay-Wain - might not provide enough key terms to analyze the artifact (p. 91), leaving a critic to wonder when, or if, she has chosen an artifact that will provide a decent sample size of key terms. Is five or six terms enough? Will I be able to successfully use cluster criticism on a new media text the size of Violence of Text or even on a smaller text such as "Digital Multiliteracies" with all its fleeting communication and interactivity at work (in addition to the written and visual components that cluster criticism can accommodate)?

Another issue that Reid (2004) acknowledged is that the clusters she chose "may be the result of the critic's biases" (p. 90). In other words, what the critic chooses as key elements is subject to that critic's (or reader's) prior knowledge of and experience with analyzing, for example, an artifact within that same genre (and thus is familiar with that 
genre's conventions; e.g., a medieval work of art that deals with religious imagery) or an artifact produced by a rhetor with which the critic is familiar (e.g., an expert on Bosch will, perhaps, choose elements that differ significantly from the elements a first-year art student will choose - and each of these critics will surely have different interpretations of those elements). Reid explained this issue by saying that "cluster analysis is based on the assumption that the connotative meaning of a term can be known by examining the context of that element" (p. 90), and while that process may hold true, it assumes that readers share the same contextual knowledge of key visual elements.

This issue of a critic's knowledge is related to another issue Reid (2004) mentioned: interpretation. She wrote that

A major problem here concerns the high level of reflexivity found in visual communication. While written and spoken language is reflexive, it expresses as much by what is between the words as by the words themselves; there is even more reflexivity in visual communication, since elements such as those found in paintings are not always as specific as words for describing the communicator's intentions. (p. 91)

The problem, she argued, is that the reflexive nature of visual communication "allows for more multiple realities than do words. The extent to which the visual communicator and viewer have similar interpretations is based on the extent of their shared knowledge and understanding of the elements" (p. 91, emphasis mine). This quote supports exactly the point I want to make-if a reader wanted to use cluster criticism to interpret a usable artifact (i.e., one that renders an appropriate number of key terms and clusters), that reader needs to share similar understandings of the visual (and other) elements in a text with what the rhetor-designer understands them to mean in order for the reader to know which elements might be key and why. To have the reader, as Foss (2004) said, "discover an explanation" based on the cluster of terms around the key term/element implies that the reader will be able to determine what those key terms mean. Although cluster 
criticism seems, based on the example analysis of the Hay-Wain painting, to be useful for visual texts, I want to complicate that idea by asking the following: What groundworkwhat knowledge - is necessary for a reader to be able to successfully use cluster criticism (or generic criticism or literary criticism, etc.) on a text like "Digital Multiliteracies"? To help me answer this question, let me look for a moment at the artifact.

As I look at "Digital Multiliteracies" to see if I can determine what its key terms are, I find that I don't know where to start. I could use key terms in reference to written text, in which case, I might focus on the written text I can see within the design — that is, my list of key terms might only include (because of their intensity of color and placement) the words clip selector, viewer, timelines, as well as (because of their frequency) stills, audio, text. Oddly enough, these six terms places are placed not in relation to other written text (as in a sentence) but as navigational or placement elements. For instance, if I understand that the cluster of elements around the term "stills" at the top of the screen includes a list of still photographs (which, by the way, I can't possibly know without interacting with the text by clicking on the clustered term names in the list), then I might recognize the key term of "stills" as akin to a menu header. Unless I click on the "audio" term, also at the top of the screen (i.e., not the terms near the timelines), then I might not be aware that the usage of stills, audio, and text at the top of the screen signals their context as navigational elements. If I didn't click on anything on this screen, I would have to be familiar with the conventions of web design and new media texts to recognize that those items functioned contextually as menu items. If I wasn't familiar with these design conventions, I would be hard pressed to interpret these key terms in any meaningful way because cluster criticism doesn't ask me to physically interact with the text.

Knowing that I have to click somewhere to have this text make meaning is based not in cluster criticism but in my prior experiences with similar texts, experiences that were unfamiliar to my Kairos co-editors. As I stare at the key terms I came up with using cluster criticism, I re-imagine how this text must have stymied them initially. Although 
such criticism has been shown as useful for visual texts such as Hay-Wain, it assumes that readers are able to shift their analytical skills to visual elements and then to interpret those visual elements. That is a fine use of cluster criticism, but what happens to readers' interpretive abilities when they don't know, for instance, that they have to click? How can rhetorical methods of analysis help readers who are new to new media texts, who don't yet know that they need to click? In the next section, I use generative criticism to suggest that it might allow users to more fully explore a text, gaining knowledge about the text, whereupon using cluster criticism to extrapolate key terms from that reading might suggest a possible new media reading strategy.

\section{A generative reading of "Digital Multiliteracies"}

Generative criticism doesn't outline a specific unit of analysis that a critic can use to interpret a text; instead generative criticism offers critics a way to form unique "units of analysis rather than selecting them from previously developed, formal methods of criticism" (Foss, 2004, p. 484). Foss suggested that critics could generate units of analysis in two ways: (a) pulling units from already established concepts or theories, or (b) creating units based on a research question (p. 484). In the case of "Digital Multiliteracies," the latter strategy seemed to be the most useful. I didn't have one specific theory or concept to attach to my reading of "Digital Multiliteracies." In fact, an endpoint for my analysis would be to generate a reading theory or concept to apply to new media texts such as this one.

“Digital Multiliteracies" presented itself as a reading challenge, and so I needed to know how readers might be able to choose which elements in the text were most significant in order to make meaning from it. But, the question that preceded this step was more general than that: "What does this text mean?" With this question as my starting point, my reading didn't necessarily focus on which elements were the most significant to the overall meaning, but focused instead on the larger issue of interpretation. Using 
a generative analysis, I would be "carefully and thoroughly examining" the text from which "insights gleaned [would] emerge from the artifact itself" (Foss, 2004, p. 486). From those insights, a unit of analysis would emerge. Following this process with "Digital Multiliteracies," I needed to thoroughly understand the text first, and then formulate a unit of analysis to apply to that text (and others) when conveying those results to an audience. In the next section, I demonstrate a generative reading of "Digital Multiliteracies" and, in doing so, offer an overview of the elements that played the most significant role in my understanding of the text.

\subsection{Getting started}

The main point I gleaned from "Digital Multiliteracies" was that English teachers should offer room in their curricula for students to design multimodal texts with digital media because students need to know how to think critically about modes in addition to writing and about the technologies they use to compose those texts. The author of the text, Adrian Miles, called this implementation a pedagogy of digital multiliteracies. The text was designed in collaboration with one of Miles' students, James Taylor, who designed it to resemble the interface of a video-editing program. In the text, they argued through modes including still photography, audio clips, and written text that teachers should have students compose multimodal texts like video blogs, or vogs (short, videobased texts), as a way of teaching students to be digitally multiliterate. The text was designed to enact its meaning because a reader must choose multimodal clips (still images, audio, and written text) to play back simultaneously on a timeline, creating a vog that is based on the reader's selections.

Upon opening "Digital Multiliteracies," readers see a clip selector with three options, a viewer, and three timelines. The three options in the clip selector-stills, audio, and text - offer a list of timed clips that readers can view or hear. By choosing which clips to drag to the timeline, readers "interpret through implementation," as Miles (2003a) stated in his introduction. There are three modes of clips, and a reader can drag any 
number of each into the corresponding clip timeline and play back all of the chosen clips simultaneously. A reader can rearrange the clips, or choose different clips, as many times as she likes. The reader designs a version of the text, and in doing so, enacts a pedagogy of digital multiliteracies. However, not all of the clips — or other design elements - make sense at first glance, but they can still be incorporated into a consistent reading, as I show below. In the rest of this section, I examine the five major groups of elements that I found to be useful in forming a consistent interpretation of "Digital Multiliteracies."

\subsection{The interface}

The interface of this text is similar to video-editing programs like iMoviE (see Figure 4.3) or Final Cut Pro. In such programs, as in "Digital Multiliteracies," there is an area to contain clips waiting to be edited, a timeline where an editor arranges clips in the order

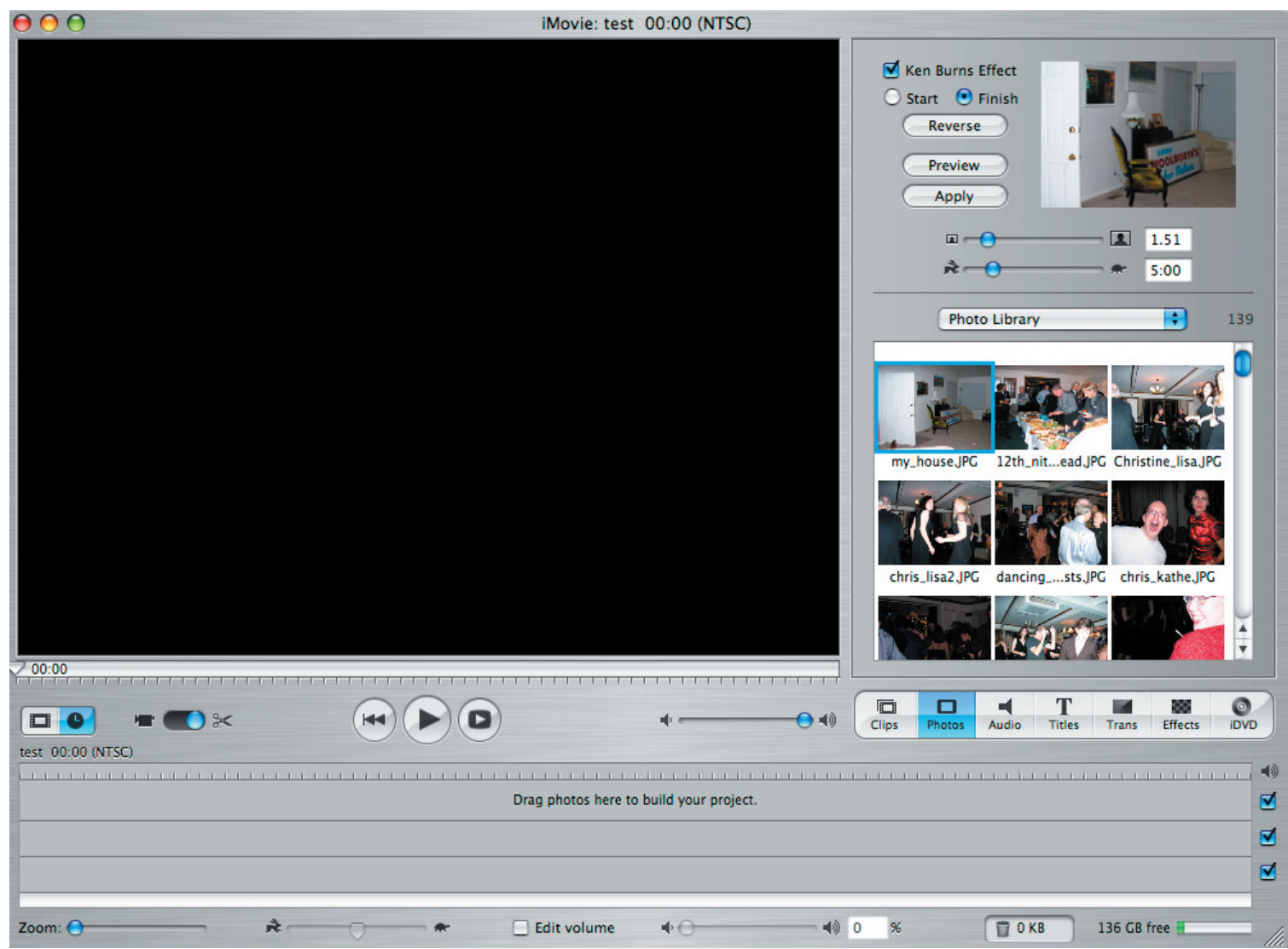

Figure 4.3. An example of the iMovie interface. The viewer is on the left, the clip selector is on the right (represented by thumbnail-size photos), and the timeline is on the bottom. 
desired, and a preview window to view the movie as it is being edited and before it is exported. The video-editing interface of "Digital Multiliteracies" is only "evoked" (Kress \& van Leeuwen, 2001, p. 73) because even though it resembles video-editing programs, a reader can only place clips on the timeline and play them back; readers cannot edit, rearrange, or splice clips as would be available in a real version of such software.

In "Digital Multiliteracies," the video-editing interface is used only to select clips and view their combinations in producing a vog. Vogs are similar to other video-based genres including music videos (with quick cuts and changes), television news (with its incorporation of text and video on screen at the same time), and film (because vogs juxtapose selected clips in cinematic ways), among others. I drew on this knowledge of video-based genres and video-editing work to form an initial interpretation from which to start my reading: I understood that as the person interfacing with this text I had to perform the role of video editor. My next job as reader-editor would be to choose those clips that I wanted to include in my vog.

\subsection{Starting with what readers know: The alphabetic}

Instead of examining the still clips, which are located in the first clip selector readers see, I want to start with the third clip selector, the text clips, because it will be the mode with which English-studies readers are most familiar. It is my guess that the designer set the text clips as the last option in this multimodal presentation to encourage readers to try the other two (and perhaps unfamiliar) modes first. Because Western habits of reading are in a left-to-right pattern and the Web's typical organizational and hierarchical navigation patterns are left-to-right (and top-to-bottom), the text clips are the least important of the three modes because they are placed last in a line of choices for the reader. The text clips would normally be the last ones readers would encounter, after they have read and made meaning from the still clips and audio clips. Because the text clips are the third option in the navigational hierarchy, this placement suggests that the text clips are the least 
important group of elements, reinforcing Miles' and Taylor's argument to pay attention to multiple, alternate modes of communication.

Each text clip is labeled with a one- or two-word title, like a filename or a summary of the quote within. The text clips in "Digital Multiliteracies" are quotes taken from Miles' paper version of his presentation. (Miles teaches at RMIT University, Melbourne, where in Fall 2002, he asked students in his advanced media course to attend a symposium on digital literacy. Their assignment was to remediate the linear papers of six presenters [including Miles' (2002) own text], to conduct interviews of the presenters, and take photographs and audio of the presentations. With these multimodal materials, the students created new media versions of the presenters' arguments - texts that enacted their arguments through their new media presentation. The still, audio, and written clips in Miles' text "Digital Multiliteracies" come directly from that symposium. This information was located in the introduction to Violence of Text.) In the text clips section, readers are offered short segments — usually a sentence or less — of Miles' paper-based argument. I browsed through several of the clips before tackling them all in order. (Aah, I just couldn't resist reading them all, nor the linearity of the top-to-bottom list in which they were organized).

I clicked on the second clip in the list, labeled "reading \& writing," and it appeared in the viewer. The text read, "However, it is apparent that to be literate includes reading and writing, that reading by itself renders us consumers of literacy but that consumption, of itself, is only half of what constitutes a proper literacy" (see Figure 4.4). This clip suggested that literacy is more than interpretive skills; it must include production of texts. Based on what I knew from the introduction of the text, the sentence in this clip supported Miles' argument that students needed to produce digital, multimodal texts. But it wasn't just the words themselves that helped me reach this meaning. After 10.1 seconds - the number listed as " $10.1 \mathrm{~s}$ " to the right of the clip. The designer had specifically timed each clip according to how long or how short the written text within 


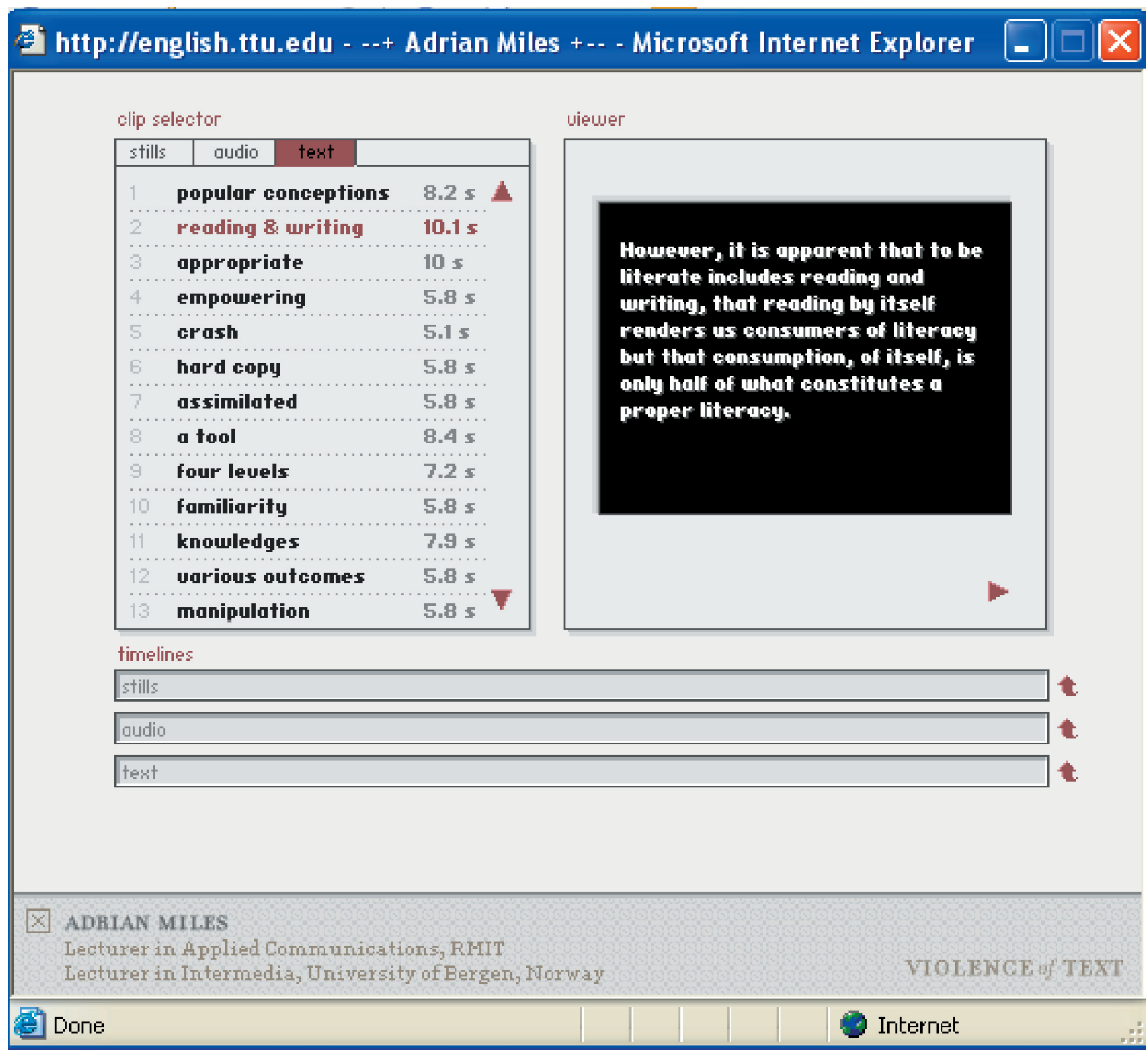

Figure 4.4. A screenshot showing the clip "reading \& writing" in the viewer.

each one was, as if he had read through each of them out loud (or to himself) to see how long they should last. The timing suggested that I should pay attention to the length of the clip (and in some cases, that I needed to read more quickly) because it would be an important factor in how I constructed my vog. I held on to that interpretation as I moved to another text clip.

The clip called "hard copy" said, "there [sic] are some aspects of hard copy [printbased texts] that we have maintained in relation to 'soft' forms such as the World Wide Web." By using this quote, Miles summarized his argument that the Web was too much 
in this (print) world and that readers and designers did not take enough advantage of technological capabilities and reading strategies that moved away from single-moded conventions. This clip lasted 5.8 seconds; also, it began with a lowercase letter. Normally I wouldn't think a distinction between upper or lowercase would be important to a text's meaning. I point it out here because some clips begin with uppercase letters, signaling, perhaps, that these lowercased phrases were only parts of sentences - parts of larger meanings - taken from the paper version. Or, the designer intended to put some sentences into lowercase because this meant that the importance of grammatical correctness in written language is not always necessary. It wasn't that I didn't understand the sentence because the first letter was lowercased. Yet, it was only after going back to the text several times that I even noticed the difference. Although I can make a case for the importance of recognizing that some text clips were lowercase and some were not, it didn't seem to play a huge role in furthering my consistent reading. I couldn't determine a pattern among these clips, and so I felt this element of the design wasn't as necessary to foreground in my reading. But because I noticed it, I became aware that it might be useful later in the reading.

The "materiality" clip, the next clip I read, said, "what we think we want to do but can't is not recognized as productive resistance but misrecognized as only ever the deferral of that which will be overcome tomorrow." This written text suggested a connection between the other two clips I'd chosen, "reading \& writing" and "hard copy." "Reading \& writing" discussed the need for production-based learning, and "hard copy" discussed the continual production of print-based texts in digital formats. In comparison to those two clips, "materiality" discussed how people don't want to see inabilities (or failures) in production as part of the learning process. The title of this clip also suggested that Miles considered this learning process a material aspect of design. It may also be that one's inability to create "what we want to do but can't" represents the struggle a student or teacher has in trying to design (or read) the material components of a digital text. 
This clip held significant meaning for me when viewing it in light of my co-editors' first readings as well as the other sample texts I discuss in this dissertation, for in each of these instances the readers had failed to make meaning from their texts.

I chose each of these three clips based strictly on the clip title and how I thought, as a reader, I might connect with what the quote would say. And, yet, their combined meanings, even as somewhat random selections, connected readily to support my initial reading of this text-Miles argument for increased production of digital texts that use multiple modes of communication, even if that process is difficult. This last part - the difficulty part—was perhaps only an underlying factor in Miles' argument. As he stated the need for a pedagogy of digital multiliteracies, he no doubt also knew the struggles that teachers would undergo, both pedagogically and technologically, to enact such a curricular move. Given the strategies he used to convey his message, this process of understanding the need to be (and to teach students to be) digitally multiliterate is even more difficult. Thus it was with my co-editors' struggle to understand his argument because the design - the overt attention the designers paid to using multiple modes of communication as part of their argument — was beyond anything they'd ever encountered, even in only considering the written text clips.

\subsection{The meaning of sound: Examining the audio clips}

The audio tracks in "Digital Multiliteracies" were recorded during the question-andanswer session after Miles' physical presentation at the conference. Each track-there were 34 including a blank one that lasted 2 seconds - was listed alphabetically in the selector using a key word or phrase spoken during the clip. The audio tracks presented a sonic sense of the symposium via the speaker's Australian accent, which provided immediacy to the text (see Bolter \& Grusin, 2000). This voice-of-immediacy combatted the "nonplace" feel of the Internet (p. 179) by providing reference to a physical, actual, vocal space in which the original presentation occurred. I had an immediate connection to the text through that voice (and, later, in the still clips, through a face), which I assumed 
to be Miles' because he is Australian. I will return to what meanings his voice provided me in a moment. Let me stay now on the theme of linguistic modes by discussing some of the spoken text in the clips.

\subsubsection{Transcribing the oral text}

The first audio clip, called "against something," said in part, "writing is always against something." Given that the text clips suggested Miles was taking a stance against only teaching print-based texts, it should be no surprise that this audio clip pitted writing as a mode in opposition to other modes. This clip situated writing as an antagonistic practice. The clips are listed in alphabetic order, placing this clip first in that list. It is useful for readers to encounter this clip first, which is so firmly situated in relation to Miles' argument for digital multiliteracies.

Another clip, "be literate," seemed to be a call-to-action: Be Literate! The full audio-'OK, there's an awful lot of variables that we can put in there that we actually have to be literate about" - demonstrated to me, foremost, that these clips were taken from the question-and-answer session because of the stumbling inclusions such as "OK," as well as informal language like "an awful lot" and "we can put in there," suggesting that Miles was responding off the top of his head and using whatever language came most quickly to him. Secondly, this clip suggested (in the context of the other clips I'd read or heard to that point) that "we" (teachers, I guessed) need an expanded notion of literacy because there are many "variables" that have to be taken into account when one is teaching students to be digitally multiliterate. One variable, for instance, might be teaching students to use technology critically or to use modes other than that which are traditionally considered part of literate practice.

A third clip, called "english teacher," said, "If you talk to an English teacher, it's like it's almost more important that we can understand Shakespeare than it is if we can write a shopping list." The words Miles' used are somewhat accusatory, and the tone in his voice 
added to that indignant representation-Why should Shakespeare be more important than a shopping list? he seemed to be saying. Miles questioned, briefly and succinctly in this six-second clip, a literature-based approach to critical literacy. He used this question to support the overall purpose of his argument — that is, that teachers should expand their pedagogies to include digital multiliteracies. He reinforced this argument by repeating similar statements in several audio clips. It was the "english teacher" audio clip, however, that I foregrounded in my reading; it was memorable because of its traditional Englishstudies reference to Shakespeare.

So far in this reading, I have focused on the written text of both the text and audio clips - a mode that most English teachers are familiar with, even if they are unsure (as my co-editors were) of forming meanings out of these bits and pieces. However, it was more so the other modes of communication - the other overt design choices in "Digital Multiliteracies"- that prevented those readers from forming coherent readings of the text. At this point, I turn from the familiar to the unexpected, from written text and transcribed oral text to nonwritten modes in the text's design. If readers associate Miles' and Taylor's text with the theoretical tradition of the New London Group's (Cope \& Kalantzis, 2000) theory of multiliteracies, then as a reader I have to pay attention to the text's audio, spatial, gestural, and visual design (p. 26) as well as to the linguistic design elements. For instance, I can make meaning from the design elements of Miles' vocal tone and pitch. Even though those elements are considered part of the NLG's breakdown for linguistic design, how a reader hears the audio elements in "Digital Multiliteracies" affects the interpretation of the audio design because the audio clips function as a soundtrack that accompanies the written and still image clips in the timelines. Thus, I continue my generative reading by exploring what meaning the delivery of the audio tracks brings to the text. 


\subsubsection{Hearing the oral text}

Although the transcribed phrase from "english teacher" repeated in my head, Miles' voice - its tone, pitch, accent, and so on — helped me extend the meaning I made from the audio clips. For instance, Miles' voice covered a range of tonal qualities, from being loud and in medium-pitch range to having a higher pitch and a slight stutter. These vocal qualities related directly to what he was saying and, thus, to his meaning. In a thematically related clip, "shopping list," in which the clip picks up part way into a phrase, Miles' said "and it's much more significant to a literate culture that you know how to pick up a biro [pen] and an envelope and write your shopping list on the back than it is to read Shakespeare." Besides relating in theme to "english teacher," it also related in how it was delivered: strong and loud, a tone that signaled Miles' confidence in making the statement. There were no significant pauses between words, and the beginning of the clip, which started with "and," was delivered softly and quickly as if it were simply a connector between the phrase that was spoken and one that had immediately preceded it, albeit one not captured as part of that audio element. The direct, loud voice qualities in "shopping list" suggested that Miles was sure of his argument, which made me confident of him as an authoritative speaker.

In comparison, his voice pitch is different in other clips such as the one titled "de de.” In this clip, Miles stuttered, “de...de..de...de...de.....qualitative change...what's this?" as if he had lost his place or forgotten what he wanted to say. I interpreted his high-pitched voice and stuttering (which I've represented here with ellipses) as a lack of confidence, especially when I compared it to his confident tone in "shopping list." A third example, "against something," which I mentioned earlier, falls somewhere between the pitch and breathiness of the other two examples. In this clip, Miles said, "It seems to me that writing is always....against something." (Again, the ellipses show where Miles pauses while speaking.) His pitch is slightly higher than "shopping list" and lower than "de de," and he hesitates before saying the words "against something," as if he isn't quite 
sure how he wants to phrase his statement, or perhaps, he isn't sure how the audience will react. By including that slight pause between words and raising his pitch to a less dominant, more questioning level, he demonstrates that he is trying to find the right words to uphold his argument.

Although the pitch and tone of Miles' voice may not seem a substantial element to make meaning from in this text, it did contribute to my reading in that its differences allowed me to react as I would to someone speaking. I did not mind that Miles' voice evoked confidence (if not a little arrogance) in the "shopping list" clip because I agreed with his argument. The mental connection I made to his tone and pitch was useful for my reading because it made me feel that those vocal elements in his text supported his argument, if only because they sounded like they should. For a reader who, on the other hand, didn't agree with Miles' argument from the outset, such emphatic language could cause a reaction opposite to mine, where the reader would dismiss those particular elements as not holding significant meaning in her reading. For most academic readers, voice quality would probably be not an explicit factor in whether they were persuaded by the text. However, if those readers called forth their experiences in listening to conference presentations - agreeing or disagreeing with speakers based on how the speakers phrased and delivered their talks — readers might be more able to accept or dismiss such elements in a new media text.

Another vocal factor that helped me make meaning from the audio clips was Miles' Australian accent. Although I can only base a reading of Miles' accent on my own cultural standpoint as a White, North American woman in her 30s, even this angle showed cohesive meanings from the vocal element of the text. I brought certain cultural stereotypes to hearing Miles' accent, one of which was my inability to determine at first whether he was Australian or British, a mistake I often make when hearing an accent for the first time in a while. (I've been told by several Australians and British that North Americans make this mistake all the time.) So, I tried to place the accent in relation to 
others I knew, which I did by comparing Miles' accent with famous Australians with which I was familiar. A comparison of this kind is not always beneficial in meaning making, but, as Kress and van Leeuwen (2001) said, the provenance of a mode - a reader's understanding of a semiotic mode based on other contexts in which she has heard that mode - can be understood with a positive or negative affect. In the case of Miles' accent, both effects were possible. A negative connotation could be made based on my connecting Miles' accent with Steve "Crocodile Hunter" Erwin, the lovable guy who searched out dangerous species such as poisonous snakes and spiders on the North American cable channel, Animal Planet. There was also Paul Hogan, from the 1980s Crocodile Dundee movies, who wielded a foot-long knife to protect himself in the “outback" of New York City and Los Angeles. Both of these people/characters represent a silly, Americanized, stereotypical view of Australians. I could have attached these base stereotypes to Miles' accent, devaluing him as a person of authority (thus devaluing his argument). (It is possible that some readers may equate Steve Erwin and Paul Hogan with positive connotations, but I do not share those sentiments and, thus, cannot offer a reading based on that.)

On the other hand, Miles' accent may benefit him and could produce a positive connotation. For instance, I associated Miles' accent (perhaps because I heard it within the context of an argument for digital multiliteracies) with The New London Group (Cope \& Kalantzis, 2000), several of whom are from Australia. Because the NLG was the first group of scholars to promote a pedagogy of multiliteracies, I equated Miles' accent with them, which lent authority to his digital multiliteracies argument. Additionally, although it may be a minor point, Miles' accent could establish his authority based on another North American provenance-infomercials. The recent trend in infomercials has been to hire spokespeople with British or Australian accents because it is thought that North Americans respect and like the mellifluous British tone. The producers of these shows believe that people trust someone with a British accent and will, therefore, want to 
buy whatever product is for sale. This connection may work to Miles' authorial benefit. These examples may seem somewhat trivial to point out, but it is important to remember that a reader's understanding of a text is based on what meanings each element conjures depending on her prior experiences. Thus, even an element like the tone and breathiness of Miles' voice in this text can make meaning based on a reader's knowledge of similar voiced texts.

However, none of this explains why I kept the "de de" clip foregrounded as part of my meaning-making repertoire. When I first heard the clip, it simply made me laugh. Then it confused me: Why would a designer choose to include an audio clip that so obviously did not further the persuasiveness of the text? Unless it did in some way that I had missed. At first, the clip didn't make sense to me in relation to the author's intention to persuade readers to enact a pedagogy of digital multiliteracies because the clip didn't really say much of anything. But, it wasn't so much what the linguistic elements meant within the individual clip or within the context of the larger work. What was important was that the clip functioned as a blank for me, a minus function Iser (1978) called it. The clip so determinedly broke away from how I expected a scholarly text to make meaning, especially in relation to the other audio clips, which made some coherent meaning as sentences on their own. By choosing to include this clip as a possible selection in the audio clip selector, the designer pushed me in a direction I wasn't expecting where I had to take the time to think about the clips he had incorporated as more than just forming small bits of a larger, coherently linear text. I chose to incorporate the use of the "de de" clip as significant to my reading because it symbolized the attention readers and designers need to give to every element they use.

In the end, the gap that this clip produced in my reading made me want to figure out why it was there. Different than my co-editors' interpretations, in which this clip was seemingly viewed as an insignificant element or a pointless inclusion that offered little to the meaning to the text-I was willing to examine this clip to determine why it was 
important. Although other readers would not see the significance of the clip because they might interpret it only on its own as an individual element and dismiss it as gibberish (much as Celia had done in trying to interpret the individual words of Lexia (Memmott, 2000) rather than seeing them in relation to the whole text), I recognized that the designers had paid much attention to the text's overt design and deduced that they would not have thrown in an unneeded element. Thus, it was not that I thought the "de de" clip was an inattentive use of audio on the designer's part. Instead, the clip was highly significant to me for two reasons: Its inclusion reinforced Miles' argument for a pedagogy of digital multiliteracies in which texts that use clips like "de de" should be and can be critically interpreted. In other words, a clip like "de de" can be interpreted as a significant element in the text's design. Secondly, as I read the text and tried to analyze the use of this clip within it, I became more and more aware that "Digital Multiliteracies," and its encompassing collection Violence of Text (Miles, 2003b), enacted its own argument to be critically aware of digital technologies while using them to produce multimodal texts. In retrospect, this clip is perhaps the most overt use of a designed element — and the most unexpected element — in "Digital Multiliteracies." Other readers, however, might consider the still images that I discuss in the next section even more unexpected and uninterpretable.

\subsection{The still clips: Reading photos}

The still clips presented in this selection-37 plus one blank clip - appear to be photos taken during the symposium, as they range in subject matter from images of coffee cups and carpet to out-of-focus pictures of Miles yawning. I should remind readers that the still clip selector is in the front position when "Digital Multiliteracies" is opened. That is, the still clips are presented as the first choice among the three selector-modes. For readers accustomed to making meaning from written text, the stills don't stand out as the best way to understand the text. For instance, the first clip, titled "flourescent" [sic], is an upward, angled shot of metal squares with light shining through, which appears to 
be the kind of fluorescent lighting covers one finds in an office or school building (see Figure 4.5). At first, this clip seemed totally unrelated to the argument of becoming digitally multiliterate. So, I clicked on several other clips including ones titled "finished," "pointing," "audience," "afternoon tea," "coffee," and "stars and tears." (See Figure 4.6 for

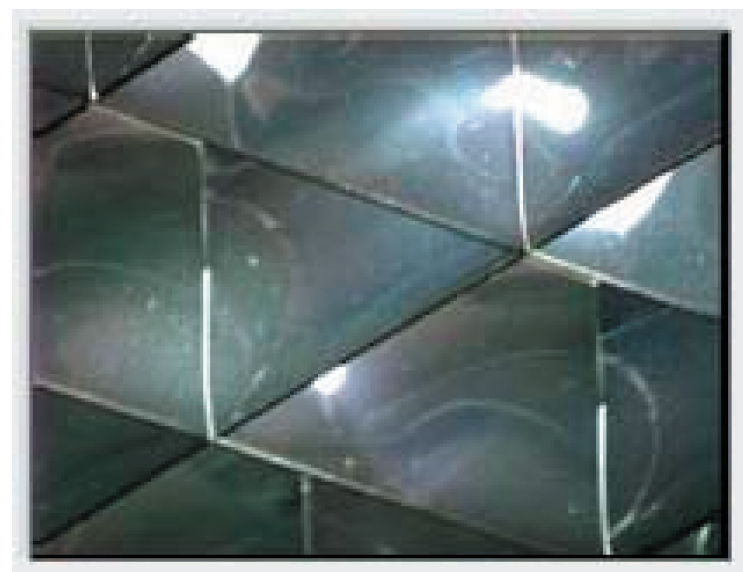

Figure 4.5. The fluorescent lights in the first still clip. a compilation I have constructed of these still images; in the original text, they appeared at separate times in the viewer.)

Some photos were blurry shots of Miles, where part of his arm was out of the frame as he pointed to something outside the viewing area; focused and out-of-focus partial shots of coffee and tea cups; and random computer projections, which aren't large enough to read the written text. The general sense I gained from these photographs was that rather than functioning as illustrative examples or supporting visual evidence for
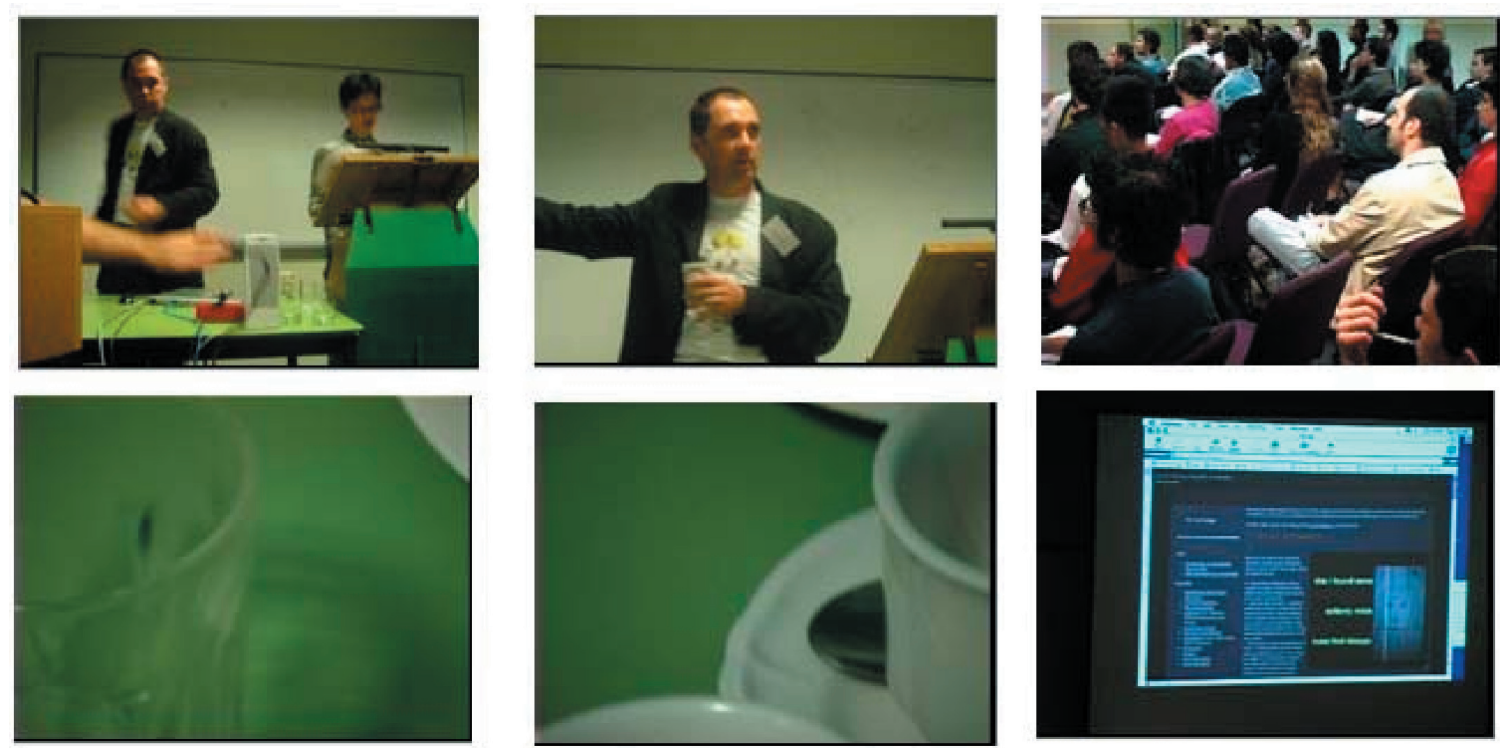

Figure 4.6. A compilation of several of the still clips. 
Miles' argument, they showed the physical symposium space. And in blurry, poorly framed photos, at that. Why, I thought, had the designer chosen to include photos of the presentation, monitors, audience members, and coffee cups, half of them out of focus and hard to see clearly? What purpose is served? What meaning could be made?

When I looked through these stills, what I began to notice was a strong sense of the location, place, size, and atmosphere of the conference-not something easily or typically conveyed in a scholarly text, let alone one distributed in conventional forms on the Internet. For that matter, how often had I, as an audience member of a conference presentation, noticed the color or texture of the carpet, kept track of the style of water glasses the hotel used, or paid attention to what the presenters were wearing? Not often. However, the time-space of the conference at which Miles' presented was explicitly shown to readers of "Digital Multiliteracies" through the use of physically locating photographs. This physicality did have meaning and could be related, similar to the audio clips, to what Bolter and Grusin (2000) called immediacy in new media texts:

A photograph may be either an expression of the desire for immediacy or a representation of that desire. The photograph that represents itself to be viewed without irony expresses the desire for immediacy, while a photograph that calls attention to itself as a photograph becomes a representation of that desire. (p. 110) In other words, the designer had chosen to represent a reader's desire for immediacy by using photos that called attention to themselves. Thus, a reader would have to negotiate the still clips on at least two levels: (a) understanding the meaning of each still clip she chose to read, and (b) understanding the designer's overt choice to use photos in unconventional, scholarly ways.

Much like the function of the "de de" audio clip, these still shots helped me understand Miles' argument even better. Although, at first, I felt their inclusion in the text was useless to form a consistent reading, I realized in reviewing the clips-especially in relation to the meanings I garnered from the other clip selectors - that their blurry, 
odd compositions forced me to think about their materiality as photographs as well as the materiality of the symposium space. In having to think critically about the photos in this way, I was enacting a pedagogy of digital multiliteracies, reinforcing Miles' argument through my own readerly actions. In addition, the photos personalized the text by showing readers the physical space that included images of Miles, breaking the text out of traditional conventions of web-based scholarly texts. "Digital Multiliteracies" showed me what it felt like to be there at the symposium. It is rare (if ever) that a scholar would choose to include the parts of a presentation that were spontaneous or off-thecuff remarks into a conventional scholarly publication. But here, the designer included those rare, lived moments as if to remind readers that "Digital Multiliteracies" was presented as part of a conversation on digital literacy, that the ideas were informational and sometimes informal, even fun. By using still photos, the designers helped me engage in a hyperconscious reading of the setting of the symposium and the medium of photography by arguing that montage-as-mode should not to be overlooked as a strategy for making meaning (see, e.g., Bolter \& Grusin, 2000, p. 38). The still clips became one more collection of design elements through which I made meaning from Miles' text. The timelines I discuss next brings the three designed modes of audio, written text, and images together.

\subsection{Composing a vog: Argument in action}

Although readers can make connected meanings by playing each clip by itself, the full impact of "Digital Multiliteracies" presented itself when clips are placed in their respective timelines and viewed. The creation and playback of a vog requires a reader to make sense not only of the individual and accumulated meanings of the selected clips (as suggested in the sections above) but also to make sense of them while those clips play back simultaneously. This simultaneity is seen in the overlapping of whatever clips a reader has dragged into the stills, audio, and text timelines. I cannot show a compiled 
version of selected clips in this paper format, but I want to discuss what meaning I gained by using the clips I discussed above if they are compiled into a vog.

If combined in the three timelines, the clips I've been discussing so far-three stills ("flourescent," "coffee," and "stars and tears"), two audio clips ("english teacher" and "shopping list"), and three text clips ("materiality," "reading \& writing," and "hard copy") — would form a vog (in essence, a secondary new media text within the larger text of "Digital Multiliteracies"). In playing these clips simultaneously, the viewer window would show the still clip "flourescent" as the background, the written clip "materiality" superimposed over the still, and would play the audio clip "english teacher" at the same time, and so on. Also, because each clip is timed, the written text clips would transition before the audio clips do. These transitions would create juxtapositions between the clip changes within each mode/timeline as well as between the three modes/timelines at once. Regardless of which clips a reader has chosen to include on the timelines, the combined text in the form of a vog requires a completely different reading strategy than understanding the individual clips did. A reader would have to pay attention to all three sets of clips at once and also to each of the clip's design elements. Or, more likely, readers would have to determine which element (or elements) are the most important in order to make meaning from the combinations.

What did it mean, for instance, to have the "english teacher" clip play at the same time as the "flourescent" clip while "reading \& writing" was shown on screen? (Although I cannot provide the sound here, see Figure 4.7 for what the two visual elements look like.) When I looked at the timeline with just these three clips in it, I noticed that the written text, at 10.1 seconds, lasted three times longer than the still clip (at 3.1 seconds) and a third longer than the audio (at 6.1 seconds). This meant that as I viewed these clips together, the fluorescent image would disappear before the audio of "english teacher" ended and well before the written text in "reading \& writing" concluded. A black screen 
replaced the fluorescents, so that the white words of the written clip were superimposed over a black background for the remainder of the audio clip and beyond.

By paying attention to what I could pick up anew from the clips as they played altogether (rather than relying on what I remembered of what I thought they meant when I looked at them individually), I could form readings that supported Miles' argument to be digitally multiliterate. For instance, if I thought about the fluorescent lighting in relation to the words that struck me as most important in the audio clip_-"English teacher," "more important," "read Shakespeare," and "shopping list" — along with the written text I could catch"to be literate includes reading and writing," "consumers of

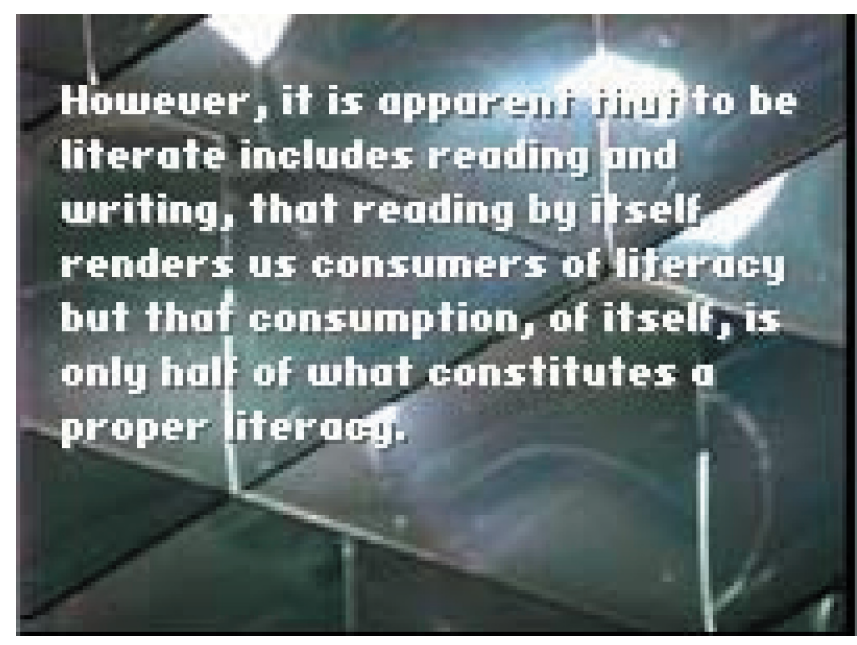

Figure 4.7. The "reading \& writing" and "flourescent" [sic] clip combined.

literacy," "half of a proper

literacy"-I was reminded of sitting in class in twelfth grade under those glaring lights, trying to decipher the tiny typeface in which Sonnet 42 had been printed on nearly transparent paper in my Norton Anthology. What I missed from those experiences, and what Miles' argued teachers needed to include in their curricula, was the production of texts that don't mimic traditional forms of literacy practice.

\section{A generative, clustered meta-analysis: Paying attention to significant elements}

Stepping back from my analysis of "Digital Multiliteracies" momentarily, I can show how using generative criticism - how a close, exploratory reading of this text - helped me determine which modes and elements were most significant in my reading. The 
subsections of the generative reading offer the first clue: Some of the design elements I focused on included the still, written, and audio clips; the timelines, which facilitated playback; and the interface as a whole. In addition, I focused on other clusters of elements including the viewer as a way to see individual clips; the clips' separation within the selectors; and the clips seen together in the viewer as a result of using the timelines. In seeing these design components highlighted in my reading — one of many possible readings, I reiterate-I can suggest which elements were most important to my coherent reading of the text.

Looking back over my generative process, which I have summarized in the above section, I note that I started small-looking at the clip selectors, playing with individual clips, and, eventually, using the timeline to make those clips interact. I paid attention to the fact that the design purposefully used not just written text - the mode readers most often and easily recognize as scholarly_-but also still images and audio text. I had fun at first, combining these modes together in the timelines; fun seeing what seemingly bizarre combinations I could come up with. The performative aspect was enough to intrigue me and to consider this text worthy of exploration. Analysis came later when I had to justify that play as making meaning within scholarly contexts; when I had to get my co-editors, thousands of miles away, to interact with the text in a way that helped them see its point. I needed a way to show them what I was seeing. The description I give below is perhaps as close to providing a meta-analysis as I could have given them.

Although I still believe that this text's meaning can be extrapolated from any number of clips played on the timelines, I kept returning to several that I thought emphasized the argument to teach digital multiliteracies more than others. These are the clips I discussed in the previous section. But, I need to explain what concepts kept me returning to this selection of significant elements. Much of this choice relied on my being nearly the perfect fit as a reader for "Digital Multiliteracies" at that particular time. Before I started reading "Digital Multiliteracies," I was interested in finding a new media text that 
stretched the boundaries of digital scholarship, a text that followed in the tradition of Anne Wysocki's (2002) A Bookling Monument. I was also already invested in teaching students to be multiliterate in digital environments. Plus, I was always looking for scholarship that was written or designed with a performative aspect. For instance, when I read any of Geoffrey Sirc's work, I imagine how he might deliver his text as a speech, following the rhythm of the writing, and often I am delighted by his insouciant arguments that typically fly in the face of traditional scholarly tones. "Digital Multiliteracies" fit my needs in all three of the above areas: (a) It made arguments I agreed with; (b) It pushed the boundaries of meaning making using technologies; and (c) It did both of the above points in fun and different ways. Because I was an ideal reader of "Digital Multiliteracies," I was able to recognize how the blanks that the designers chose to include made sense within the context of their purpose. That is, I recognized their use of the three modal clip-groups interacting to create a video within a video-editing interface as a performance of their argument to be digitally multiliterate. So, once again, I return to significant elements.

As I pointed out during the audio clip analysis, some clips contrasted in pitch, volume, and tone - the color of Miles' voice, so to speak. Comparing these differenceswhat Miles' emphasized and what he didn't—corresponded directly to which statements held more weight toward the overall meaning of the text for me. Vocal color isn't often a topic discussed in English classes, but I found it a useful way to describe the linguistic delivery of the audio clips, especially when describing how his delivery affected my interpretation of those design elements. Of course, color is more easily seen (rather than heard) in the visual elements of the text, from the soothing, muted green and white of the coffee cup photo to the lack of visual emphasis in the beige background of the whole text. This background color never makes an appearance in my analysis, and I only notice it at all because the frame of the Flash Player focuses my attention inward to "Digital Multiliteracies" rather than to the backgrounded windows on my computer screen. 
But color is only part of what's drawing my attention in this text. The beige break of color helped me see the three distinct sections in "Digital Multiliteracies"selectors, the viewer, and the timelines - each of which has its own hierarchy, its own organizational pattern. The audio is listed alphabetically, which seems to be rather arbitrary in its design, while the organization of the written text follows that of Miles' paper version, paragraph by paragraph, (practically) thesis statement by thesis statement. And yet, the still clips (again, the first selector that readers see) doesn't seem to have a recognizable organizing principle. It is as if the designers intended readers to move from least recognizable mode to most recognized, least organized to most. It seems unlikely, given the purpose and argument of the text, that Miles wants readers to understand the most organized as a best-practice example or even something to work toward; only that it is one option among many from which readers (and also producers) can choose to make meaning within texts.

When I stated earlier that I recognized three distinct sections or larger groupings of elements in the text, two design principles helped me to see that: alignment and proximity. The clip selectors and viewer are left- and right-aligned respectively. When I clicked on a clip, it appears centered in the viewer window (although the written text is left-aligned with equidistant margins, making it appear in the middle of the viewer window). The timelines are justified under the selectors and viewer. Because all the elements are framed within the Flash Player frame, I recognize them on one level as being a single entity — in the form of a video-editing interface — but there is also enough space between these three sections to suggest that each group has its own particular purpose within the text. The elements that made up those groups were placed in close (or overlapping) proximity to each other, further suggesting that I needed to interact with each one on its own. That is, I needed to understand the purpose of the selectors and then the timelines; the viewer functioned in relation to both of those elements. And, finally, I 
created a sequence of chosen clips on the timeline and played them back in the viewer, giving me an overall meaning from the significant elements in the text.

What this meta-analysis suggests is that there are recurring and useful concepts present when I read a new media text like "Digital Multiliteracies." A reading like the one above comes out of many areas of expertise, not just rhetorical or literary or multimodal. If I pull out the conceptual (key) terms I used to get to this reading, the list looks something like this: text, element, audience, purpose, context, emphasis, contrast, color, framing, organization, proximity, alignment, and sequence. In this meta-analysis, I have only narrowly shown how I applied these concepts to pull out the significant elements from which I formed a consistent interpretation; but I use these emergent concepts to show that it may be possible to help readers gain an understanding of what is important to recognize and interpret in new media texts, putting them on their way to achieving consistent readings of new media texts. In the next chapter, I detail these concepts in relation to their theoretical trajectories and apply them to another new media text to show the portability of this proposed rubric as an effective strategy for reading new media texts. 


\section{A reading strategy for new media texts}

\section{Introduction}

In each of the previous three chapters I provided a reading of a new media text to demonstrate that other given the strategies readers can use to potentially interpret new media texts, these strategies only help readers understand some aspects of new media texts. Because these strategies don't yet help readers see how to make meaning from multiple modes of communication, I suggest that a strategy that helps readers shift their available reading methods so they can begin to understand new media texts is necessary. In this chapter I show how concepts that readers might already be familiar with in relation to written texts can be applied to new media texts. This shift from understanding written elements to understanding multimodal elements will help readers rely on what they already recognize - the terms - to shift their reading strategies and help them to interpret new media texts. The terms that I will describe in this chapter include text, element, audience, purpose, context, emphasis, contrast, color, framing, organization, alignment, proximity, and sequence. As I said, some of these terms will be familiar to compositionists, such as audience, purpose, and context, which are taken from rhetorical theory. Other terms such as proximity and alignment, are taken from web and graphic design. Sequence and framing originate from other visual theories, such as cinema studies. In this chapter, I will define each of these terms and show how they can be applied to reading a new media text.

\section{An e/merging new media reading strategy}

As I demonstrated in the previous two chapters, a reader must be able to choose which elements in a text are the most significant and juxtapose the meanings of those elements to interpret the whole text. If readers have a ready vocabulary for understanding 
how and why elements of a text work, then they will be more likely to perform a consistent reading of new media texts. In this section, I outline thirteen terms-text, element, audience, purpose, context, emphasis, contrast, color, framing, organization, alignment, proximity, and sequence - that can help readers pull out the significant elements of a text to make meaning from it. In applying these terms, readers can accomplish four things: (a) make explicit the meanings she has attached to elements, (b) choose which elements are significant to juxtapose in order to form a consistent reading, (c) articulate what that juxtaposition means to form an interpretation, and (d) learn how to shift terms for reading texts that readers are (mostly) already familiar with to make meaning from new media texts. I demonstrate these terms by showing how I make meaning from a new media text called "Murmuring Insects" (Ankerson, 2001).

\subsection{Text}

I start with the term text to suggest that, unlike Gunther Kress's (2003) argument that multimodal texts be labeled according to their dominant genres, new media texts do not always have a dominant genre to which readers can apply strict reading conventions. Also, following Umberto Eco (1984) and Louise Rosenblatt (1994), both of whom used text to refer to the object a reader interacts with, this term seems more suited to new media. For instance, although some readers might label "While Chopping Red Peppers" (Ankerson \& Sapnar, 2000) a "new media poem" because of its use of written poetry as one of its modes, I argue that such classification by genre (a) undercuts the value of the overwhelming number of other genres at work in that text, and (b) puts readers in the position of thinking about the text as a poem, rather than as a text that requires a much different reading strategy. So, in using the term text as part of a new media reading strategy, a reader can describe some of the general qualities of the overall text. Using text in this way doesn't mean that readers have to know what the text means yet, or how it makes that meaning; it simply provides them a term with which they can describe what's going on in the text-a summary of sorts. 
Although readers new to "Murmuring Insects" (Ankerson, 2001) would use the terms below to interpret the text, let me summarize its purpose here, to provide context for the rest of the section. "Murmuring Insects" is a text designed to evoke remembrance about the events of September 11, 2001. The text combines Eastern and Western design elements to juxtapose a sense of calm and fear, much as the actual tragedy and its surrounding events did at the time. "Murmuring Insects" was published online shortly after September 11 as a way to express sorry and also to remind readers that they have to move forward, move beyond fear.

In further summarizing the text according to the terms, "Murmuring Insects" is a Flash-based text because it requires the Flash Player plug-in. When I open the text, there is a picture of the World Trade Center (WTC), showing one tower as it was collapsing on the morning of September 11. A portion of the New York City skyline can also be seen (see Figure 5.1). I hear what might be frogs or crickets and a soft rainfall.

The WTC images fade into

a gradient of colors, and the words "murmuring" and “insects" appear on screen. The sequence of words appearing and disappearing loops while the sound of insects fades after several measures. The numbers “9.11.01” appear in a soft white color at the bottom right of the screen. That date is the only navigation link so far.

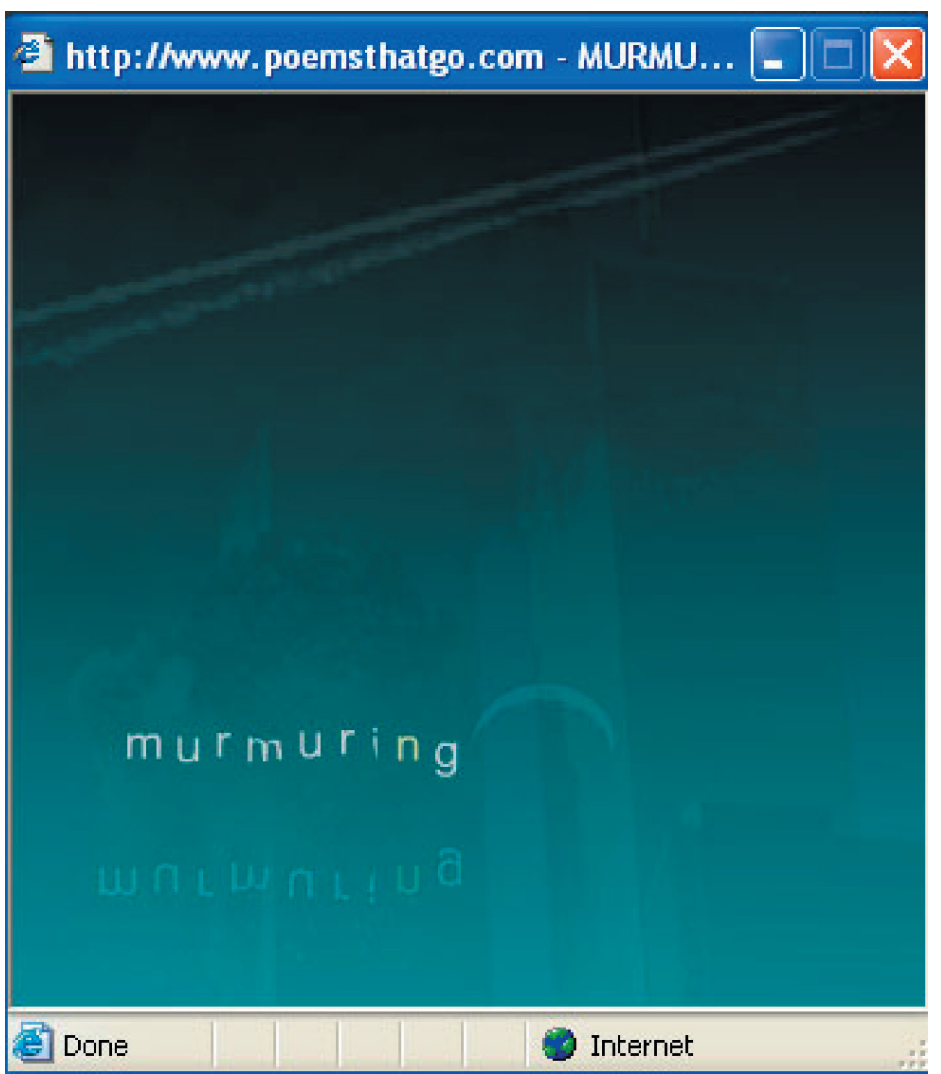

Figure 5.1. The opening scene of "Murmuring Insects" 
When I click, an index screen appears in the same gradient color with the words "air," "earth," and "water," in white. All three words are links. In the air scene, the contrails (which appeared in the introduction) reappear; the background becomes a blue-green, and a Japanese violin song plays. The outlines of animated geese fly off screen and written text appears: "In the sky/flocks of departing geese." A woman's voice says, "and then we saw the people jumping. We saw what we thought was debris, and we realized it was people jumping." The scene fades back to the index screen. In the earth scene, the contrails appear again, but the background is a soft green. The violin solo plays along with audio clips of street noises. Written words appear and fade: "In the weeds/ murmuring insects." The screen fades to the index screen. In the water scene, there is an image of a person's face over a deep blue background. Written text appears line by line, "tears like dew/ well up in my eyes." The soundtrack for this scene is of a man's voice reading what sounds like a poem and choking up. Each scene fades back to the index screen after the sequence of words, images, and audio has played.

This is a simple description of the text - just the basics of what happened, what a reader sees, what some of the elements are that occur and a general idea of how those elements relate to each other (as in which scene they occur). What I haven't done yet is be specific about significant elements or suggest what this summary might mean - that analysis will follow with the other terms. Such an informal description of what a new media text is and does gives readers a summary to keep in mind as they conceptualize how the rest of the terms might work within the text.

\subsection{Element}

In the last two chapters, I argued that a consistent reading of a text required that a reader be able to choose the most significant elements from which to create meaning. Of course, being able to choose which elements are most significant necessitates that a reader be able to name the elements in a new media text. Elements are individual instances of modes and media in a text, and are often remediated texts themselves. They 
can be explored for meaning on their own, but to perform a consistent reading, a reader must be able to combine certain elements' meanings together.

The elements used in "Murmuring Insects" can be made explicit by a reader in several ways. First, elements can be categorized according to different media, such as audio, animated graphics, photographs, and written text. (Or, in a text like "Digital Multiliteracies" (Miles \& Taylor, 2003) elements included stills, audio, and written text, as well as the timelines and the video interface, etc.) Second, each of these media can be further categorized by mode. For instance, if I were to account for all of the audio modes used in "Murmuring Insects," I would include the following, grouped by scene:

- Air: violin music, night-animal noises (crickets, frogs, etc.), and a woman's voiceover;

- Earth: night-animal noises and street noises; and

- Water: night-animal noises and a man's voiceover.

I can do the same kind of breakdown for the animated graphics, photographs, and written text. But relying only on media doesn't help a reader fully describe the elements. For instance, color cannot be classified as a media, but it is a mode through which meaning is made. I highlighted some of the colors used in the background of "Murmuring Insects" in the text portion of this section, however, color-as-mode is not used only as a backdrop to other, more significant elements. Color is used as a meaning-making mode in relation to all the visual elements in this text (I will discuss how to make meaning from color later on).

In addition to color, other modes are at work within single elements of the text. The scene for air contains these elements (followed by the media in which each is conveyed):

- puffy white contrails [photographic],

- white, crescent moon [graphic],

- light blue background [a feature determined in FLASH],

- flying black geese [animated graphic], 
- words written in white [animated, alphabetic text],

- reflection of two, above-mentioned lines of poetry [alphabetic text, flipped],

- some characters of the above-mentioned written words in light blue [alphabetic text],

- violin music [audio],

- crickets and frog noises [audio], and

- a woman's voice [audio].

Further, the alphabetic text can be classified, based on the description of the text earlier and its overall use in "Murmuring Insects" as a poem, broken into lines for delivery, which makes each line, as it appears, a separate element. The audio tracks can also be further classified according to genres: soundtrack [violin], ambient noise/ soundtrack [night animal noises], and voiceover [woman's voice, which can also be associated with TV news genres because written elements on the title screen indicated that some clips came from NBC and ABC news sources]. These examples show that elements cross modal boundaries. Thus, a reader might consider how the alphabetic text (a) functions as lines from a poem, (b) is written in a certain color, (c) has some alphabetic characters written in different colors, (d) moves the way it does, and (e) relates, finally, to the other elements in the scene and text.

The purpose, however, of using element is to help readers describe what individual combinations of materials are at work in a given text, not to analyze what those elements might mean. While some readers might be able to suggest a meaning from the colors and animation of the written text in the air scene, others may need to first, simply, list what elements are being used. Being able to articulate most of the elements from the outset will help readers, as they apply the other terms, to decide which elements are significant enough to incorporate into a reader's consistent meaning of a text. 
At this point, it seems prudent to discuss the next three terms-audience, purpose, and context—-because these terms provide readers with a foundation for understanding the why and how of text and element as well as the rest of the terms. For instance, after a reader describes the text and its elements, as I have done above, then she would need to determine how the text and its elements make meaning. Without addressing audience, purpose, and context, the other terms would only allow readers to describe elements based on their characteristics within the text. Audience, purpose, and context provide readers with a way to rhetorically analyze the elements and, in performing that analysis, decide which elements are significant to a consistent reading. I am not saying that these terms are hierarchical—-readers do not need to first describe the text and the elements in order to figure out what the intended audience and purpose is. As such, I will address purpose next, and then discuss context and audience. I will skip the term audience momentarily to suggest that a reader can more easily determine a text's audience (or, rather, the audience that a designer had in mind) by examining the text's purpose and context. I will address purpose first, briefly incorporating context (in relation to the events of September 11, 2001) to show how these terms interact to help readers discover how a text makes meaning.

\subsection{Purpose}

The purpose of a new media text — or the designer's intention in creating it for a particular situation - isn't always explicit, unless the designer supplies that information. As with Violence of Text (Miles, 2003b), my co-editors mistook its purpose as being art when the designers intended it to be read as a scholarly text. Once Violence of Text was published in Kairos, for instance, readers might have been more likely to see its purpose as scholarly, since the context announced it as such. Readers of "Murmuring Insects," which was published on the Poemsthatgo site, might automatically assume that the text's purpose (because of its publication location on a website dedicated to aesthetic/poetic texts) is to be emotive. But what does it emote? The publication context only gets readers 
so far in determining a text's purpose. All texts have a specific purpose that the designer had in mind when she created it. For instance, a reader can uncover purposes of the text by analyzing its elements, researching for additional information about the text (or its modes), and making an educated guess based on those findings if, as is the case with "Murmuring Insects," the purpose isn't already announced on the title page.

In spending some time with "Murmuring Insects," I uncovered my understanding of its purpose - to remember the events of 9-11 — and how and why the designer fulfilled it. The written text in each of the three scenes is taken from one poem, which I will discuss more in a moment. In the poem, the speaker tells us what she (or he) sees surrounding her in nature and how that makes her feel. Because the written text is brief, I repeat it here:

In the sky

flocks of departing geese

in the weeds

murmuring insects-

tears like dew

well up in my eyes.

I assume that composition teachers can interpret meaning from this poem: The speaker is describing her own feelings to the reader by pointing out specific, naturerelated elements and her tears as a reaction to those elements. Readers may interpret the tears as being the product of variable emotions including sadness, happiness, sorrow, and so on. It's not important that readers know what emotion the speaker wants to convey yet, especially considering that the poem is only one element (and, in fact, is made up of multiple elements) in the new media text.

When I first realized that the poem was written not by the designer but by the person named in the byline, Otagaki Rengetsu, I did a Google search to find out more about this person and the poem. I discovered that the author was a Japanese Buddhist nun living in the 18th or 19th century and that the poetic form she used is called a waka (Women's 
Early Art, n.d.), which is a Japanese text written for ceremonial occasions (McAuley, 2001). One of the earliest descriptions of waka was written in the ninth century and is flamboyantly described the form's ceremonial purpose: "It is poetry which, with only a part of its power, moves heaven and earth, pacifies unseen gods and demons, reconciles men and women and calms the hearts of savage warriors" (McAuley, 2001). Although originally used in formal ceremonies, the waka, and later the haiku, were used in less formal gatherings when an occasional text was needed to commemorate an event. In an occasional poem, a reader is asked to think about the event, through the speaker's egopoetic voice, a voice which tends to be more rhetorical and telling than narrative or showing (Turco, 1986, p. 75). The purpose of commemorative retellings in poetic form is to pacify, calm, and reconcile. In the case of the eponymous written poem for "Murmuring Insects," its purpose seems to have been to calm (and perhaps inspire) readers by reminding them of the beauty (and power) of nature. Although differing readings of the text's purpose could exist for other readers, my analysis shows how my interpretation of purpose was affected by the elements that seemed most significant to this particular reading.

In addition to the calming effects of the written text, the designer of "Murmuring Insects" included elements of nature that would support the peaceful feeling of the waka. Ingrid Ankerson, the designer, used elements including the flying geese, the crescent moon, and the audio track of the night noises of animals to signify nature through materials besides the written text. But what is the purpose of all of these calming elements? In each scene, the nature-related graphics appear alongside voiceovers, which most specifically relate to the events of 9-11 (I will discuss how this context affects the meaning of the text in more depth below). If a reader were to consider the presidential rhetoric used to describe the groups believed to be responsible for the terrorist attacks of September 11 (i.e., "evildoers"), then a reader could potentially relate the elements that recalled the attacks (voiceover audio tracks and photographic images) as a reminder of 
what those evildoers did. In addition, by knowing that the original waka form was used to "calm savage warriors," readers could connect the "savage warriors" with current-day "evildoers."

Yet, in each scene, the voiceovers were connected to nature in a calming way. For instance, the cricket noises in each scene serve as a consistent reminder of nature throughout the text. In the air scene, the woman speaking about people jumping out of buildings is accompanied by the lines of poetry about departing geese and the animation of the geese. In the earth scene, the lines of poetry about the murmuring insects are accompanied by the street noises audio track - a metaphoric murmuring. In the water scene, the audio track is of Dan Rather reading from "America the Beautiful" and his tearing up is accompanied by the lines of poetry about "tears, like dew" that form into the shape of tears in an eye before dripping down the screen. So, in each scene, the calming effects of nature were presented to counteract the savage reminder of the voiceovers. Although readers might likely feel apprehension and unease when remembering the events of 9-11, more so with the immediacy of the voiceovers, most of the imagery in the text is intended to calm readers - to remind them, perhaps, that even though the terrorist attacks were an awful event, readers can memorialize those events in ways that are more productive and peaceful than simply by reacting with fear. Fear was a likely emotion during and after 9-11, and because the text was published shortly after the events, readers would need to know its historical and cultural contexts in order to determine how the text's elements fulfill its purpose. And, knowing the intertextuality of the FLASH text with the $18^{\text {th }}$ century waka further helps readers understand the text's purpose. In the next section, I discuss how the historical, cultural, and intertextual contexts (as well as other contexts) help readers interpret the text.

\subsection{Context}

Although a reader cannot know all of the contexts in which a designer composed a text, a reader can infer her own contexts-including those that suggest historical, 
intertextual, technological, cultural, social, economic, and other immediately available discourses — given the elements a text uses. Contexts such as these help a reader determine the text's purpose. Kress and Theo van Leeuwen (2001) used the term discourse to explain how social and cultural contexts help designers construct knowledges that they use to compose a text. Stuart Hall's (1997) work focused on readers of texts (rather than designers), suggesting that readers create meanings from texts based on contexts and discourses. He offered the notion of texts as palimpsests - objects that have multiple layers that can be changed and reinterpreted based on those changes - and said, "Viewing objects as palimpsests of meaning allows one to incorporate a rich and complex social history into the contemporary analysis of the object" (p. 167). Thus, readers can bring their own social history (i.e., their social context) to make meaning from a text but, as in a consistent reading, a reader has to apply her own contexts (her phenomenological understandings) according to what elements a designer incorporated. Contextual clues are similar to Roland Barthes' (1957) myths and Kress and van Leeuwen's (2001) provenance in that they are only half-evoked - the conceptual ideas for how elements in a text are related to contexts are only conjured by readers and are not likely to be explicit for all readers.

For instance, the elements that suggest that the historical, social, and cultural contexts of "Murmuring Insects" are based on the terrorist attacks of September 11, 2001, are explicit only if readers interpret elements in conjunction with one another. Individually, they may not evoke this context as strongly. The elements that signal this context include the title screen's indication of the text being "in memory" of something, the recurring image of the contrails, an image of one of the twin towers falling in the opening FLASH scene, the words "09.11.01" used as the entrance link into the body of the text, and the audio tracks that reflect on the events of the days and weeks around 9-11. Each of these elements help readers understand that "Murmuring Insects" is historically contextualized around these events. Because of this association, readers can interpret the text within 
their knowledge and feelings about 9-11. A reader's reactions to these events will vary, and, thus, her reaction to the text will vary. For instance, if a reader lives in New York City (or in close proximity on the eastern seaboard) and had close physical or personal ties or connections to the events, she might react more intensely (i.e., repulsively if she doesn't want to be reminded). Context provides readers an opportunity to analyze why the designer used these elements - what contextual relationships the elements have-in order to determine meaning and purpose. Although "Murmuring Insects" is intended to console, it may_-simply because of the subject matter and historical context — be rejected by potential a reader. At the same time, readers may be drawn to the text because of its relation to 9-11, as they look for a way to memorialize the event.

Reading a text with an eye toward intertextual contexts is another way readers can make meaning from the juxtaposed elements by drawing on their knowledge of other texts. For instance, seeing in the opening screen a photo of the twin towers, one as it starts to crumble, might remind a reader of when she first saw that image in newspapers, television, or the Internet. Having a visual reminder of what happened might evoke her feelings from that day. Many North Americans were scared, and the media portrayed a fearful and, later, angry nation. The media images from the 9-11 events served to bring those mixed feelings back to a reader. In addition to the images, a reader can explore the literary context, as I did earlier in describing the purpose of the waka form. One item to note that I didn't mention earlier is that waka, like haiku, are meant to invoke nature in a reverent way. This is most evidently achieved in the water scene of "Murmuring Insects" where the lines "tears, like dew, well up in my eyes" combined with the written text's graphical resemblance to tears in a person's eye provide a metaphor of humanity and nature becoming one through water. An intertextual application of context in "Murmuring Insects" makes this meaning possible for a reader.

In a final example of contextual readings, I apply Jean Trumbo’s (1997) description of physical space in a multimedia text, in which a designer must account for how the space 
of a text is determined in part by technological constraints. Readers can place a new media text within the context of its technology, which on a physical-human level may be the first determination as to whether a reader could even approach understanding a text like "Murmuring Insects." For instance, in order to access this new media text, a reader would need:

1) access to a computer

- with Internet access

- with a browser

- with FLASH 5 player installed

- with sound capabilities

- (memory isn't much of a problem considering the file is only 200k)

2) to know how to use a browser

- with a mouse

- by typing in a URL in the appropriate place

3) to know where to find the specific text, or similar texts, including

- that the text is archived on a web site

- and that, in the case of "Murmuring Insects," the text is only recognizable by the small icon of the crescent moon on the web site

4) to know how to open and navigate such a text just by looking at the icon in the web site's menu, as no instructions are given.

All of the steps in this process are necessary for a reader to even see the text. Next, I turn to discuss the term audience as a way readers can infer who the designer intended to reach with a text based on its purpose and context.

\subsection{Audience}

Traditionally, the rhetorical invocation of audience is intended to help writers envision a potential reader for their text and, thus, write a text that fits the rhetorical situation in which those readers react favorably. Readers can also infer backwards - as 
Kress and van Leeuwen (2001) suggested readers could do to discover how a designer thought about composing a text — from the meaning of elements in a text to whom they infer a designer's intended audience might have been. Choosing to read a text doesn't indicate that a reader is automatically someone that the designer had in mind when she created the text. Instead, a reader can determine who the designer may have intended as the audience by examining a text's purpose and context through its use of specific elements. For instance, if a reader of "Murmuring Insects" recognizes the abovementioned contexts on the text's title page, which contains elements such as a photograph of contrails in a blue sky and the words "in memory," then that reader is drawing on the same contexts the designer intended to use, according to the text's purpose. If there is an inarguable connection between how a reader interprets a text's elements and what purpose that reader believes the designer intended (i.e., a consistent reading, a gestalt), then that reader could be considered an audience member of the text.

Although I have concerns that audience is not that useful to readers because it doesn't really help them interpret the elements of a text, it could be useful in two ways in a new media reading strategy: First, readers might recall that, in chapter 3, Celia questioned whether she was an audience member for Lexia to Perplexia (Memmott, 2000). Audience provides a way for teachers to discuss not necessarily whole audiences but the importance of a reader interacting with a text to perform a consistent reading. Teachers can draw on their rhetorical knowledge to describe how writers think about readers - about what they know, what they bring with them to a text — so that an author can write a text that will fit a reader's needs and wants. Second, audience bridges the difference between reader and designer. Drawing again on a teacher's rhetorical understanding of audience, he or she can make a connection between how readers infer back to the design process through analysis to show students what processes they might encounter when designing their own new media texts. In this way, audience might be useful to apply in a new media reading strategy after meaning is made from a text so that students have a fresh sense of what 
choices they'll need to make regarding elements, modes, media, purposes, and the rest of these attending terms when they begin to compose. I turn to the next term, emphasis, to demonstrate how, in conjunction with the above terms, specific elements make meaning and how readers can choose which elements to juxtapose to perform a consistent reading.

\subsection{Emphasis}

Emphasis is one way a reader can determine which elements are the most significant in a text and, thus, it helps a reader choose which meanings to incorporate into her consistent reading. There are three components that readers can use to determine the emphasized elements in a new media text: contrast, color, and framing. At the end of this section, I discuss how emphasis helps readers choose significant elements, but first I explore how each of the components of emphasis works to make the function of elements explicit.

\subsubsection{Contrast}

Contrast is difference - the combination of elements such that a difference between them produces an emphatic effect. There are several fields of study where contrast is used to help produce texts, and if readers are familiar with how designers use contrast in nonwritten as well as written texts, then readers can bring that visual knowledge to understanding new media texts. For instance, Robin Williams' and John Tollett (1999) in The Non-Designers Design Book provided an example of contrast by using a large, black circle placed on a rectangular, white background (see Figure 5.2). The dark color contrasts with the white background, producing a difference between

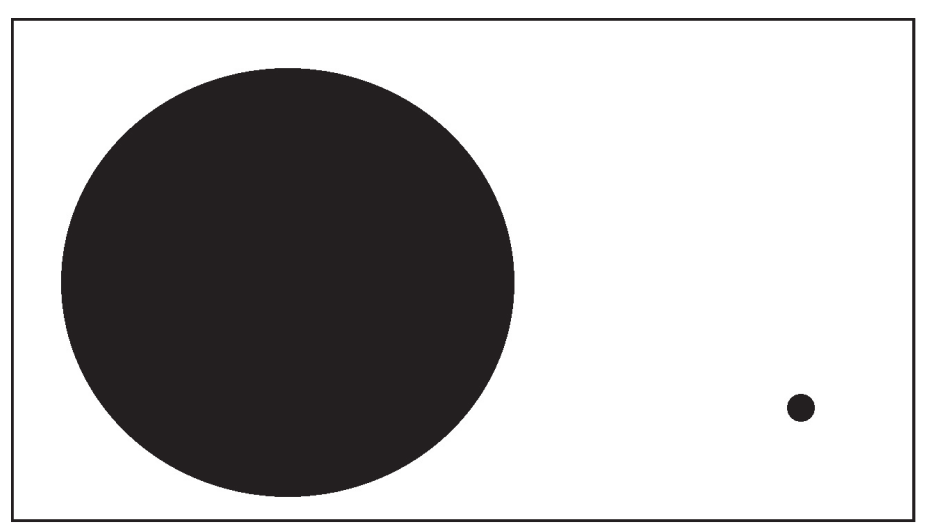

Figure 5.2: Contrast shown between black and white elements and size of elements. 
the elements. Should another element be added (like the small black circle), the contrast would then be between the large black circle, the small black circle, and the white background. Color, size, and placement can also be used to provide contrast in a text.

Bruce Block (2001), author of The Visual Story, also argued that contrast is helpful to show the intensity of the difference between elements, which "relates to the emotional reaction members of an audience feel" (p. 10). Contrast can affect many modes of communication including color (i.e., light versus dark), space (i.e., large versus small or background versus foreground), timing (i.e., slow versus fast), and the varied tone and pacing of a written or oral text, among others. For instance, the voiceover in the air scene "Murmuring Insects" is a good example of contrast: Certain words the woman says contrast with others - those she says slowly and loudly and those she says quickly and softly. Her entire phrase is "and then we saw the people jumping. We saw what we thought was debris, and we realized it was people jumping." Her emphasis is on the following words:

- "people...jumping," which contains a slight pause between the words (represented by ellipses), creating a contrast between the silence and her speech;

- "debris"; and

- "people jumping” again.

Consider how this phrasing might look on volume meter - there would be spikes rising above the normal speaking level as the woman punctuated each of these words. In this way, these four words contrast with the rest of the phrases, which she says in a more level speaking volume, and the significance of those contrasting elements becomes important when it comes time to make meaning from this scene.

For instance, the woman's emphasized words contrast with other elements on screen to produce an emotional disparity. The other elements of note include (a) the lines of poetry, "in the sky/ flocks of departing geese," the meaning of which (i.e., geese flying to depart) is evident; (b) the animated geese flying across the screen; and (c) the violin 
and cricket audio tracks - all of which are similar in theme in that they impart a sense of nature as a peaceful thing. Compared to those elements, however, the woman's voice stands out as a contrasting element thematically. These contrasting elements stand out within the scene because (a) the woman's loud words are the most easy to hear, (b) the geese are the largest element on the screen and move briskly, which would attract a reader's attention, and (c) the written text, which many readers will be drawn to as potentially the most direct way to make meaning explicit in this scene, commands a reader's attention because the words occur after the geese appear and they are in a central location (i.e., focal point) on screen. The violin and cricket noises may not seem to be a significant element in the scene because they, unlike the woman's voice, remain at a noncontrasting volume. However, that steadiness contrasts with the graphical movement and the frantic tone of the woman's voice, creating a subtle, calming effect through the use of the cricket noises.

Why does the contrast of steadiness or franticness matter? If a reader asks how these juxtapositions relate to the purpose of the text, she could create the following meaning: Although the geese, poetry, and violin create a sense of calm, the combination of those elements with the woman recalling how people jumped (we assume to escape the smoke and flames of the falling twin towers) offers a different interpretation of this scene. Her spoken words, juxtaposed with the other elements, ask readers to think of the flocks of departing geese as the people jumping but landing softly on the ground (because the words of the poem cascade gently down the screen). Now, let me turn to the second component of emphasis, color.

\subsubsection{Color}

Color also determines emphasis and can help readers point to how a change in hue, saturation, tone, and so on, affects meaning. Williams and Tollett (1999), in The Non-Designers Design Book, suggested that color doesn't have to mean the typical 
reds, oranges, or blues, but can also refer to black and white. Visual emphasis can be accorded to which color an element uses, or how much black compared to a white or grey background is used, as mentioned in contrast. Additionally, Williams' said that certain "warm" colors such as red and orange command more attention, and, thus, more emphasis, than "cooler" colors like blues and greens (p. 116). Molly Bang (2000), in Picture This, suggested that warm colors are more emotionally tense than cool colors, and that the shape of the element in which those colors are used can signal added emotional reactions for a reader. In her book, she used the story of "Little Red Riding Hood," retelling it visually through colored rectangles and triangles to show how principles of color, among other artistic framings, worked to create an emotionally tense text even without written words.

Color serves as a powerful way to demonstrate emphasis. For instance, the brightness of colors plays an important role on the index screen of "Murmuring Insects." The words "air," "earth," and "water," while all in white, are at varying degrees of transparency, which makes them more or less hard to read. But all of these elements stand apart from the background because they are brighter in color, drawing a reader's attention to them as significant elements. The word "water" is the most difficult to see because it is nearly the same color as that part of the gradient background. So what

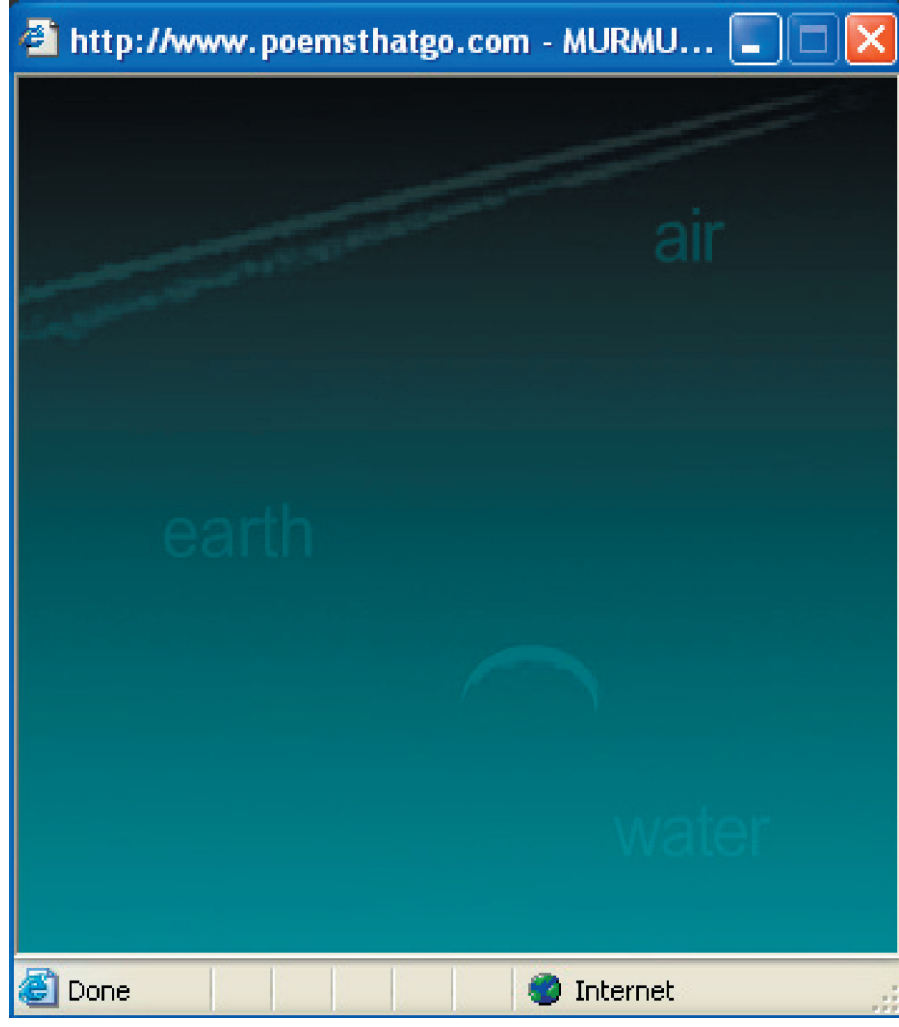

Figure 5.3. The index screen links compared to the gradient of the background color. 
does this mean? I interpret the color of the index words to be associated with their literal and metaphoric meanings. For instance, the word "water" blends in with the background, which makes me think that the word and the murky green-blue color of the bottom portion of the screen represents water conceptually. I can also imply that "earth" located in the middle of the screen and "air" located at the top of the screen also signal their respective literal connotations because air is found above earth (see Figure 5.3). I have read these meanings into these elements based on their color and position on the index screen.

I can further compare the color of elements to the meaning of other elements within the text as a whole. Although the background color is dark and thus fades into the background of a reader's attention, even it has significance that helps a reader make a consistent reading of the text. The background color for the index screen remains a

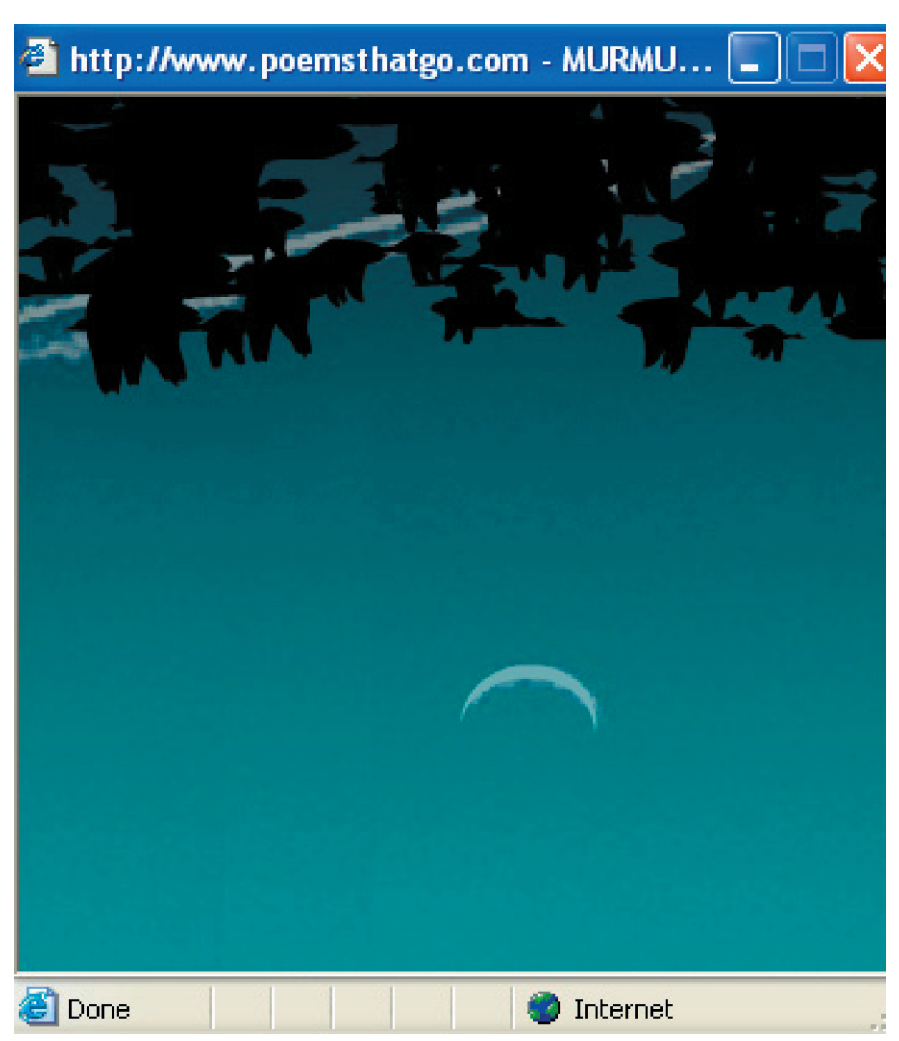

Figure 5.4. The background color in the air scene mimics the color of a daytime sky. gradient of black at the top, changing to a greenish-blue at the bottom of the screen. But each scene changes to signify a color relationship with the linked word it represents. Once clicked, the background of the air scene gradually becomes lighter, close to the color of a daytime sky (or morning sky, i.e., the time of the attacks). This change in color metaphorically represents the air around us (see Figure 5.4). 
The earth scene changes to a gradient of deep greenish-black at the top of the screen to a light, grassy or weed-colored green to match the meaning of the poetic line, "in the weeds/ murmuring insects." Finally, the water scene remains nearly the same color as the index screen — a deep bluish/ black, similar to the color of open water at night—-but it also adds the sheen of light reflecting off the water. This effect is created by the background addition of a person's face, whose nose and an eye is highlighted. The light reflecting off the side of the nose creates the illusion of light reflecting the water in that scene (see Figure 5.5).

In each of these scenes, the background color changes to metaphorically signal the space (i.e., air, earth, or water) tears likc dew

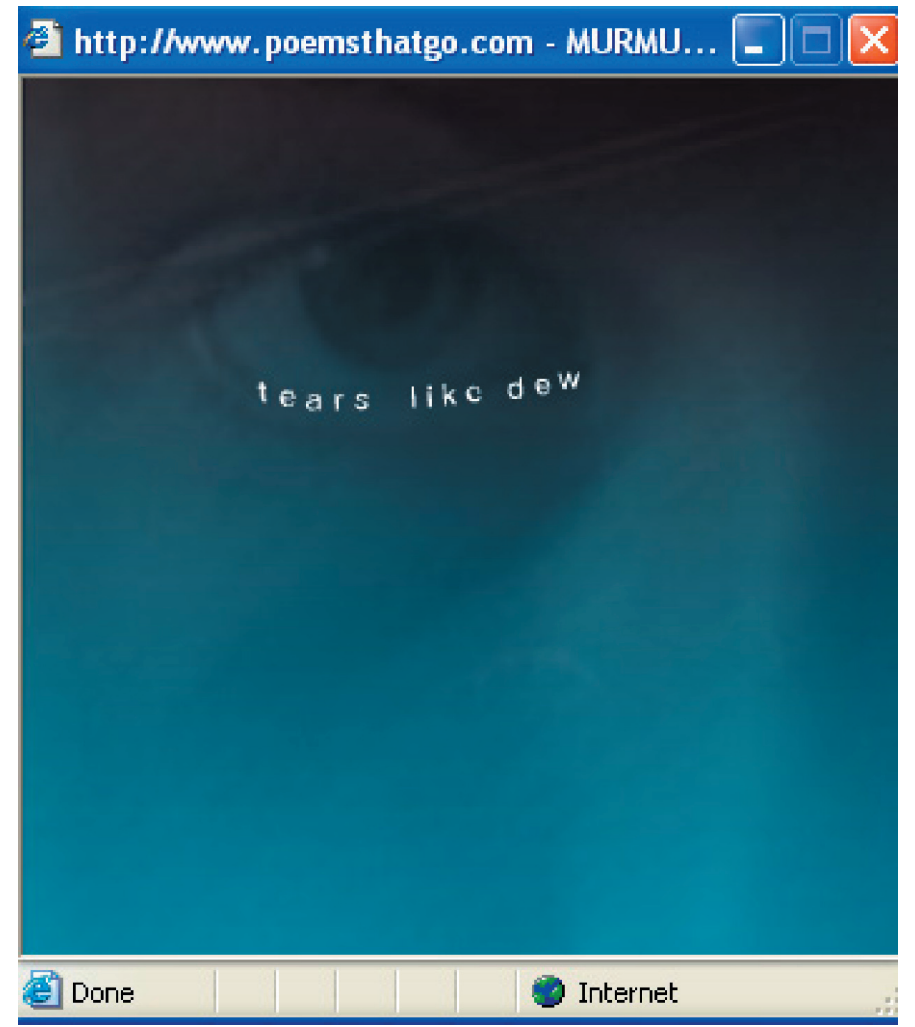

Figure 5.5. The nighttime lake with reflected light in the water scene.

of that scene. By initially pointing out the colors of individual elements in "Murmuring Insects," I can connect elements with potential meanings based on my phenomenological experiences of those colors and juxtapose ones I find appropriate to supporting a consistent reading. Although I've made some connections here, how these meanings work in an overall reading will come as I continue to explore the other terms in this new media reading strategy. 

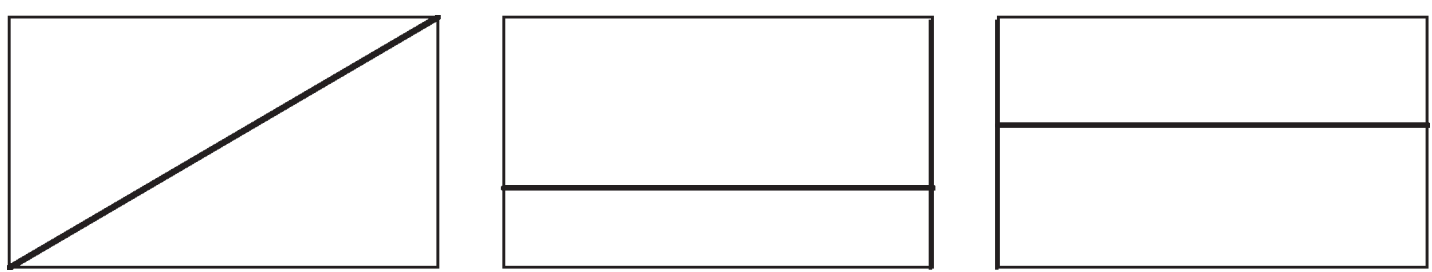

Figure 5.6. Examples of frames possible in screen-based texts.

\subsubsection{Framing}

Framing pulls together theories of photography, art, and film to show how a designer places emphasis on a particular section of a composition. A frame helps a reader focus on small groupings of elements within a text. Block (2001) discussed framing in film, $\mathrm{TV}$, and new media and described how the individual frames or series of frames can be divided to achieve certain emotional effects. Block offered several options for dividing frames to draw a reader's attention, some of which are shown in Figure 5.6 (p. 58).

The frame of a text is divided to emphasize certain groups of elements, which helps determine meaning. For instance, in the earth scene of "Murmuring Insects" the text itself is framed by the surrounding Flash Player window. Within this window, the entire new

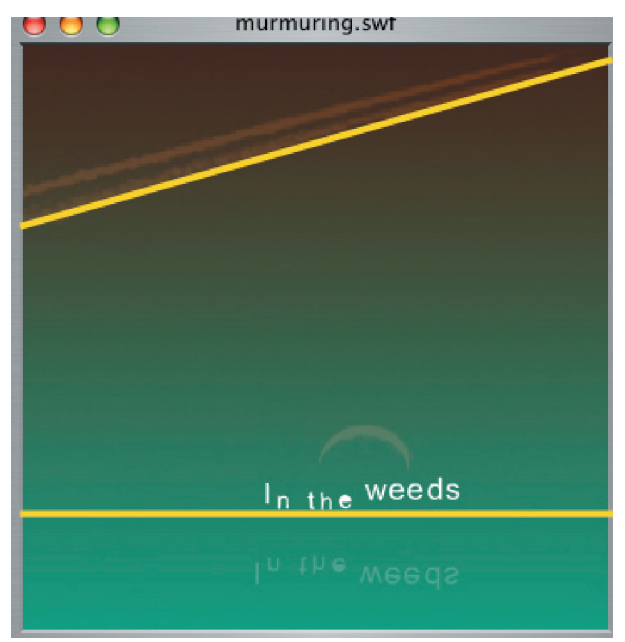

Figure 5.7. Yellow lines indicate where the frame is, created by the contrails and the invisible horizon where the words settle. media text is contained. Also, certain elements within the text are used to frame the focal area, or area of emphasis, for the audience. The contrails and the moon, for instance, appear (if faintly) in each of the scenes. These elements frame the action within the scene. Only the geese appear above (or, rather, over) the contrails. The only action that takes place below the crescent moon is the reflection of the written words. Thus, a reader's attention is directed to the center of the screen, where 
the most significant visual elements appear. The significant animation, and thus the focal point in this scene, occurs between these two elements, outlined in Figure 5.7. The same frame created by the contrails and the settled lines of poetry recur in each scene, providing the audience with a consistent frame within they can view the main visible elements of the text.

\subsubsection{Bringing emphasis together}

I've discussed so far how readers can use each of these components-contrast, color, and framing - to describe specific elements (and combinations of elements) in a new media text. So, how do they work together to create emphasis in a text? Here's an example: In "Murmuring Insects," some alphabetic characters in the lines of written text are a combination of upper- and lowercase (i.e., contrast), as in the air scene. By juxtaposing the contrasting letter-cases with (a) the meaning of the written lines, (b) the audio track of the woman seeing people jumping from the WTC, and (c) the animated geese, a reader could speculate that if the slowly descending motion of the lines represents people jumping from the buildings (but landing safely), then the different cases of the characters also represent the diversity of people who were present at the events of 9-11. This is a speculative reading on my part, as I search for an intended meaning for the different cases, but it is a plausible idea, and I cannot see any other elements that contradict this interpretation.

Readers may also notice that certain color-contrasting characters change cases as they descend on screen. The D, for instance, in "flocks of departing geese" changes from uppercase to lowercase as it nears the landing point. One possible interpretation of this element is that even though the people that these alphabetic characters represent as they float at different intervals down the screen land safely at the bottom in this new media text, they did not float nor land so softly after jumping from the twin towers. The $\mathrm{D}$, in this case, could be a visual metaphor for how the bodies of jumpers fell, tumbling 
downward, head-first as pictures of jumpers showed (see, e.g., the Richard Drew photograph of a man who jumped from the World Trade Center and the accompanying article, “The Falling Man,” Junod \& Drew, 2003). That image certainly invokes fear, and not calm, for me as a reader, even amidst the calming effect of the slow-floating characters in the text.

I've been describing what is emphasized in the text, but let me also suggest that not emphasizing an element can create significant meanings in a text. Several elements, such as the moon, contrails, and crickets, are emphasized throughout by remaining active elements in each scene. Yet, they are also periodically de-emphasized in scenes when they are covered over or masked by other elements. For instance, in the water scene, the contrails and the crescent moon are masked by the image of a face that appears. This is the only scene where these two elements are not prominent on screen. The designer could have masked the contrails to emphasize the face and lines of poetry for several reasons: First, this is the water section, which has a dark background, the color of an open lake at night. Perhaps readers are meant to feel as if they are close to the water (or under water), and wouldn't be able to see the contrails during the night from this vantage point. At the same time, the moon can still be seen (barely) beneath the surface of the face, which might indicate that a reader is meant to see only an obscured version of the moon in this segment. Second, being able to see the face with the lines of poetry acting as tears in the person's eyes has a more direct metaphoric connection to the audio track of Dan Rather stuttering over a contained sob than being able to clearly see the moon or contrails does. Third, in the air and earth scenes, the subject matter of the voiceover tracks is directly related to the noises and events of September 11 (air: people falling; earth: sirens and yelling) while Rather's audio track is a reflection on the events after the fact - his track is taken from the first live airing of the David Letterman show after September 11, nearly a week after the events. Because the contrails are covered (i.e., deemphasized) I interpret this water scene as a remembrance of the day, rather than a description of 
events during the day. This reading of the emphasized elements combined with the contrasting de-emphasized elements connects nicely with the purpose of the text. Even though this interpretation provides two different purposes for the text-description and remembrance - both potential meanings work within the purpose of memorializing the events of 9-11. Next, I turn to the final set of terms (organization: alignment, proximity, sequence) that are helpful to determine relationships among elements.

\subsection{Organization}

Organization, like many of the terms used here, is probably familiar to compositionists because of its use in analyzing and teaching written texts. Teachers are comfortable talking about how a written essay is structured, what the logos of a text is, and so on. Organization brings all of these associations together through terms including alignment, proximity, and sequence that help readers to also describe how the elements in a new media text function. Similar to discussing organization in a written text, a reader can apply the term to describe the overall order, structure, or reading pattern in a new media text. In "Murmuring Insects," for instance, readers find one organizational structure on the index screen: The three linked words — air, earth, water — are organized hierarchically from the top of the screen, which is typical of a Western reading style. The links are also listed from right to left, which is more typical of an Eastern reading pattern. The combination of both of these reading patterns suggests a melding between Eastern and Western habits. This idea is reinforced by the use of the waka (i.e., an Eastern form whose purpose is to calm) and the North American news and television voiceovers (a Western form whose purpose is to inform, but also to sell the news, which leads to overly dramatized accounts of events, which leads to fear).

However, returning to the three links momentarily, their organization suggests that the scenes can be read in any order and the overall meaning of the text won't change. The waka form of poetry helps in this pattern because the text is not narrative, meaning there is no plot or story line to follow. Rather (and not Dan Rather $(-)$ ), the text acts like a lyric, 
where each of the coupled lines that appears in each scene (broken up in "Murmuring Insects" as two lines each; six total) can be understood on its own or in combination with the other scenes. For instance, in Table 1, I have provided three possible reading patterns of this text. The readings created by following each pattern might differ slightly, but the overall purpose of the text will be similar. In the next three sections, I describe the components of organization: alignment, proximity, and sequence.

Table 1: Three possible ways to read "Murmuring Insects."

Reading Pattern 1

In the sky

Flocks of departing geese

In the weeds

murmuring insects

tears like dew

well up in my eyes
Reading Pattern 2

In the weeds

murmuring insects

In the sky

Flocks of departing geese

tears like dew

well up in my eyes
Reading Pattern 3

tears like dew
well up in my eyes
In the sky
Flocks of departing
geese
In the weeds
murmuring insects

\subsubsection{Alignment}

Where elements are placed along a horizontal or vertical axis in a text suggests relationships between those elements based on alignment. In "Murmuring Insects," for instance, each element of written text appears at the same point along an invisible horizontal and vertical axis, even though those elements appear onscreen at different times. Figure 5.8 contains one line of poetry superimposed on the other in one scene (done through screen captures and changing the transparency of one layer in РнотоsноР so that both layers can be seen). This consistent alignment allows a reader to focus on a certain area of the screen (much in the same way that the contrails and moon ask the audience to frame the action of the text by focusing on a certain space of the screen). Each line, once straightened, shares the same space on the screen, and each rests on the same horizontal alignment. (They would share nearly the same vertical alignment, on 
the left and right ends of the lines if the second line, "well up in my eyes" were shorter.) By sharing this alignment across the time-space of this scene, a reader can interpret that these elements share a common intention. In this case, the elements' shared purpose is to metaphorically represent a person's tears.

In the air scene, however, the lines of poetry don't align along a horizontal or vertical axis. The lines never come to rest on the same horizon, and they barely maintain a steady horizontal graphic line before moving, morphing, or fading from the screen. This scene seems to be the most scattered, both visually and emotionally, and the alignment of the words (or, rather, lack of alignment) shows the disparity between what the text is trying to convey and what the woman says about people jumping. It is an unsettling organization of elements, which reflects the unsettling feeling a reader might have when watching this scene.

I should note that it is odd, perhaps,

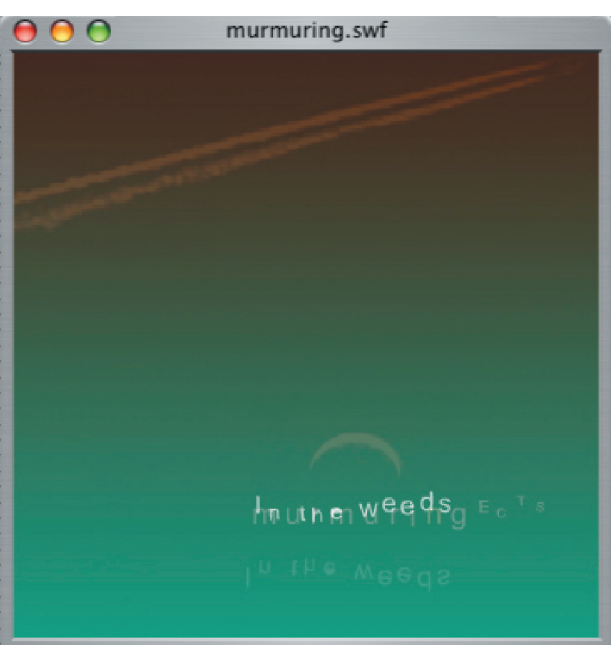

Figure 5.8. Two lines of poetry that I've superimposed to show the invisible horizon on which they land. that in "Murmuring Insects" the only elements that align are alphabetic. Alignment doesn't only refer to written text, since graphics, animations, and other elements can create (or break) alignment. It is just that this text doesn't exhibit any examples of it. Instead, "Murmuring Insects" is a useful counterexample to Williams' and Tollett's (1999) prescriptive design principles because the text is well designed (as evidenced through the elements' thorough connection to the text's purpose) despite its lack of aligned elements. 


\subsubsection{Proximity}

Proximity refers to the relationships created by the space (or lack of space) between elements. How close or far apart elements are from each other determines what connections in meaning can be made. In the air scene of "Murmuring Insects," for instance, proximity works to create a relationship between the geese (to act as a barrier that becomes open) and between the geese and the contrails when the latter are masked. In Figure 5.9, I have included a sequence of screen shots taken from the air scene, showing how the geese, at first, nearly cover the contrails, then separate to show the sky with the contrails visible. Although it is difficult to make out what the geese are in the first few sections of the scene because of their close relation to one another, they soon have enough space between them to distinguish their individual forms. If a reader came to this scene first in her reading pattern, she would not necessarily notice that the contrails remained on screen from the index screen. The geese's proximity to each other and to the contrails (because the geese are placed on top of the contrails) masks the contrails from view, as if the geese should be the focal point. However, they soon divide and the contrails become visible, reminding readers (by invoking the memory of the planes) why the geese, as a metaphor for the falling people, are there. The animated division of geese prompts me to turn to the final term in this new media reading strategy: sequence.
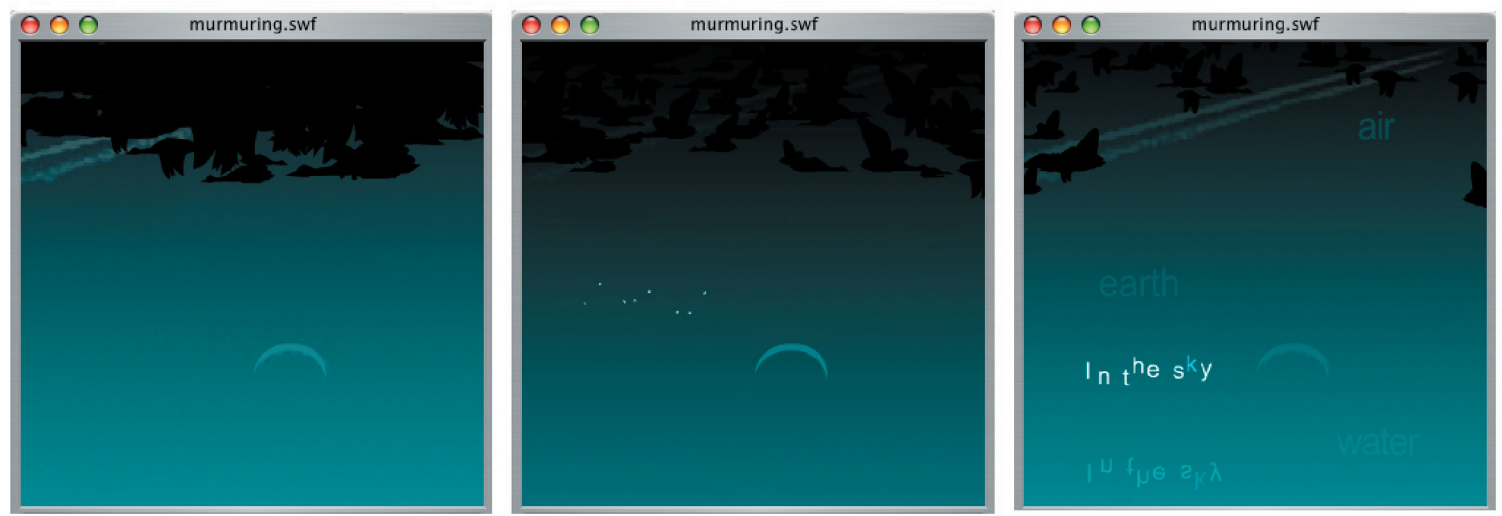

Figure 5.9: A sequence of screen shots showing the geese covering the contrails during the air scene. 


\subsubsection{Sequence}

I discussed earlier how paths chosen by readers affect the overall organization of "Murmuring Insects." But in more subtle ways, sequence affects the organization of elements within those reading paths by providing a way to discuss the timing and movement of elements within a predetermined or undetermined order. Sequence makes its way into these new media principles through film and hypertext theory. In films, readers see sequences - the movement of individual movie cells or frames as they are shown in a pre-determined order (through the filming and editing process). Sequentiality contextualizes elements as a reader encounters them (through navigational choices and/or through animation; see, e.g., Rosen, 1993, p. 86), which helps readers juxtapose certain (available) elements in order to make meaning. In "Murmuring Insects," within each scene the order of elements is predetermined by the designer and always follows the same sequence. Because the reader cannot navigate within the scenes, I discuss sequence here in relation to the order, timing, and animation of elements within a scene.

In the water scene of "Murmuring Insects," for instance, a reader can describe the length of and sequence in which elements appear on screen, showing juxtapositions between them. In Rather's audio track, which runs nearly the length of the scene, a reader hears him says, "that sees beyond the years" (quoted from "America, The Beautiful”). This phrase falls in sequence with the appearance of the lines of poetry, "well up in my eyes." The juxtaposition of the aural "sees" and visual "eyes" (in addition to the photograph of the eye) demonstrates the power a timed sequence can have in that the metaphor for sight is heightened by its appearance in three different modal elements. The combination of these elements suggests, perhaps, that even though a reader may want to be saddened by the events of 9-11 (as Rather was, since he wept over the song lyrics), a reader should look forward to more comforting days. By relating these elements together through their sequence, a reader can interpret their connection as a reinforcement of the new media text's purpose — to remember the events of 9-11. 
Another instance when timing affects the significance of the elements is when Rather reads the subsequent line: "thine alabaster cities gleam." As this line is spoken, the written text tweens into the crescent moon shape, appearing bright near the center of the screen until the word "gleam" is spoken. At that point, the crescent moon dims and begins to fall down screen. The dimming is triggered by its opposite: the contrasting "gleam." Rather's statement in this audio track - that the North American people cannot have the same meaning for "America, The Beautiful" as they did before the attacks - combined with the dimming of the crescent moon suggests that US cities will no longer "gleam" because the cities are no longer "umdimmed by human tears." The connection, made by the specific sequence of elements, supports the purpose of this scene (and this text) as one of remembrance.

\subsection{Benefits of a new media reading strategy}

In each of the sections above, I have tried to show how particular elements within the text come together to satisfy the text's purpose, that of paying homage to the confusing, scary attacks of September 11, 2001, in an effort to help readers cope with that event. By using the thirteen terms (i.e., text, element, audience, purpose, context, emphasis, contrast, color, framing, organization, alignment, proximity, and sequence), I pulled the most useful features of the rubrics I addressed in the previous chapters to accommodate a consistent interpretation of a new media text. For instance, this reading distinguished the many modes (and media and genres) that functioned in the text, which Kress and van Leeuwen's (2001) production and distribution strata also would have shown - but with the benefit that within the reading strategy I present here, readers also need to account for themselves as readers. That is, with the rhetorical terms audience and purpose included, readers can acknowledge why such modes are being used by a designer. And instead of Kress and van Leeuwen's discourse stratum asking readers to identify what contexts are at work in "Murmuring Insects," readers can make meaning from those contexts (such as the historical framework in which the text was published) by connecting their use with 
elements that display, say, proximity. More specifically, when I associated the animation of flying geese covering the contrails in the "air" scene, I saw this design feature as a moment when the attacks were temporarily not emphasized, not meant to be in the reader's attention.

Another example of how this strategy is beneficial when interpreting new media texts can be demonstrated by comparing its attention to choosing significant elements to those theories I discussed in relation to Iser's (1978) acts of interpretation in chapter 3 and Foss's (2004) methods of rhetorical criticism in chapter 4. Each of these reading processes suggested that readers needed to know which elements were the most important to a text in order to form a consistent interpretation - and they assumed that readers had a level of knowledge when it came to reading print-based texts that would allow them to determine those significant elements. However, as I showed with Celia's reading of Lexia to Perplexia, new media texts often present unexpected uses of semiotic modes as part of their designs, modes that readers are unfamiliar with interpreting. The term element, included in the thirteen principles outlined above, encourages readers - who even as they might be unfamiliar with how the elements are used can typically recognize themname them and to pay attention to them across modes. In being able to name multimodal elements used in a new media text, readers can become more adept at and aware of the necessity of extricating elements from a new media text. And, by examining their list of elements in relation to the other terms (i.e., comparing the sequence of elements in the "water" scene) readers might be more likely to make meaning from elements (and modes and media) that, perhaps, they had not been able to previously. Finally, by addressing the elemental properties — and moving from understanding to interpreting — readers can choose which elements correspond to a text's purpose in their reading to produce a consistent interpretation. 


\section{Conclusion}

My intention in providing these thirteen terms for reading new media texts is to show that while strategies that other authors have put forth for describing and/or interpreting texts can be somewhat useful when applied to new media texts, many of these strategies assume a level of knowledge that readers have not yet had to provide in relation to the multimodal elements in new media texts. The strategy I suggest, however, accommodates readers who are just learning to interpret these unexpected elements that are often found in overtly designed, new media texts. In the next chapter, I offer a heuristic based on these terms to show how this reading strategy can be useful to many kinds of text. In showing its portability across modes and materialities, I argue that while this rubric, too, has its limitations, it will help readers come closer to understanding and interpreting new media texts and will open the field for more research on nontraditional, multimodal texts in writing classrooms. 
Table 2. Heuristics for a new media reading strategy

\section{Terms Questions/Descriptions}

Text - Where is the text located? Is the text digital, online, analog, and/or print-based?

- How does the text work (i.e., is it cinematic, physically interactive; does it include mouseovers, etc.)?

- What are the main ideas/themes a reader might gather from an initial reading (e.g., "Red Peppers" was about a father, daughter, and cooking)?

- Is the text broken into distinguishable sections or scenes?

- What software was the text made in (i.e., Flash, Quicktime, Photoshop, etc.)?

- What features does that software offer that other programs might not?

- How does the software help determine a reader's expectations?

Element - What are some genres in the text?

- What reading conventions are associated with those genres?

- What modes and media are used in the text (e.g., audio, video, HTML, graphics, voiceovers, mouseovers, soundtracks, color, written text, animation, etc.)?

- List as many individual elements as possible, including any modes or media that those elements employ.

- What do those individual elements mean (i.e., metaphorically, rhetorically, socially, contextually, etc. - this might best be determined after analyzing the context and purpose of the text)?

Audience

- Based on the elements, context, and purpose of a text, whom does the reader imagine the designer had in mind when composing the text?

- What elements suggest this intended audience?

- How does the reader fit (or not) the designer's intended audience?

Purpose - What are the significant elements in each section/scene or whole of the text?

- What meanings do those elements, when juxtaposed, create?

- What is the intention/point of those juxtaposed meanings? 
Context - What relations does the text or individual elements have to historical, cultural, and/or social events (e.g., a scanned letter written in 1941 would have the historical context of pre- or post-World War II; the cultural context would depend, perhaps, on whether the letter writer were Japanese, North American, or another nationality; the social context would depend on what class, gender, or other identity marker the author was; etc.)?

- What relations does the text or individual elements have to other texts (i.e., intertextual contexts, genres, etc.)?

- What economic indicators does the text or elements signal?

- Are there other contexts at work?

- How does the accumulation of the contextual associations serve the text's purpose?

Emphasis - Based on what elements are contrasting, stand out (through color or another mode), and/or are framed to be a focal point, what elements does the reader consider significant?

- Significant elements should provide a consistent meaning to correspond with the purpose of the text (i.e., a reader cannot perform an adequate reading by suggesting that a significant element means something that doesn't equate with the text's overall purpose).

Contrast - What size, shape, color, animation, or other mode do elements use?

- Do certain elements use color, size, shape, animation, or another mode to stand apart from the others?

- If a text is divided into sections, scenes, or screens that have more than one element in each, which elements stand out?

Color - What colors are used, and what are their cultural/ metaphorical meanings?

- Are bright colors used for emphasis?

- Do certain elements stand out more because of their colors? 
Framing - Are there elements that create a frame within (or around) the text (i.e., like a picture frame)?

- What is the focal point of the text?

- What is the purpose of the focal point—what elements are emphasized and how does that relate to the text's purpose?

Organization - What reading paths are available in the text (i.e., does a reader click on random links, follow a next-button linknode path, or simply watch)?

- What navigational structures are used (e.g., this question might be related to the above question, but might also include menus on a website, pages in a book, play/rewind buttons, etc.)?

- What relation do these organizational elements have to the text's purpose?

Alignment - Are the elements within a scene or text aligned along a left, right, central, or mixed axis/line (i.e., if a reader can draw a line such that elements all start or end on the same line, then they are aligned)?

- Are elements that are similarly aligned related in theme or purpose? If so, what is that purpose, and does it relate to the text's overall purpose?

- Even if elements don't appear on screen at the same time, they may be aligned across the time-space of a text. If this is the case, what connections can a reader draw from these similarly aligned elements?

Proximity - Are elements on screen close together or far apart from each other?

- If they are close together, are those elements related thematically and/or related to the purpose?

- If the elements are far apart (spatially), does their distance signify a break from the theme?

- Do elements overlap in ways that support the purpose of the text?

Sequence - Do elements in the text appear in a certain order? How does that order relate to the text's purpose?

- If the appearance of elements occurs based on a reader's interaction with the text (i.e., the reader can choose which order the elements appear), what sequences are possible?

- What sequences (or do all possible sequences) relate to the text's purpose? 


\section{Conclusion: Possibilities and issues}

\section{A new media reading heuristic}

Because I have applied these thirteen terms to a single new media text thus far, let me offer a broader method of application that would be useful for any new media text. Table 2 lists the thirteen terms with example questions that readers can apply when reading a new media text. This list of questions is a starting point, from which teachers can add other heuristics as the text and situation calls.

Readers of this dissertation might discredit this reading strategy as only being applicable to the textual examples I've used. These examples might typically be classified as relating to classes in composition, literature, rhetoric, and creative writing. For instance, the classifications that many readers (or their authors) would give for each text is listed after its citation:

- Hypertext Gardens (Bernstein, 1996) [literary hypertext essay],

- "While Chopping Red Peppers" (Ankerson \& Sapnar, 2000) [Flash-based poem],

- Lexia to Perplexia (Memmott, 2000) [net.art or literary hypertext],

- Violence of Text (Miles, 2003b) and "Digital Multiliteracies" (Miles \& Taylor, 2003) [scholarly new media text], and

- "Murmuring Insects" (Ankerson, 2001) [Flash-based poem]

With the exception of the Violence of Text collection, these examples are couched within creative writing and literary traditions, if in naming conventions only. (Perhaps this is to attract readers wandering the Internet who would be likely to read, say, a poem or essay but not an unclassified, hard-to-describe new media text.) But, what would happen if a technical/professional writing teacher wanted to have students examine "Digital Multiliteracies" as a way to produce help files in new ways? Or have students apply what 
they learn from that text to produce training videos for just-in-time learning? These texts, because they combine many genres and materialities in their designs, are useful across many classroom settings.

What is also important to note is that the reading strategy I've outlined above, while applicable to new media texts, is also useful for understanding a range of texts. For instance, in the CD-ROM ix: visual exercises (Ball \& Arola, 2004), Kristin Arola and I applied these terms to pop-culture texts that emphasized visual design. In each of the examples we used (there are more than 60), we strove to make the text's design overt by describing and analyzing the example in relation to one (or more) of the thirteen terms. $i x$ uses materials and texts such as timelines, emails, typefaces, magazine advertisements, photo essays, business cards, clip art, collages, and movies.

In an ad like Altoids" "Freeze" (see Figure 5.10), each of the thirteen terms can be applied to form a

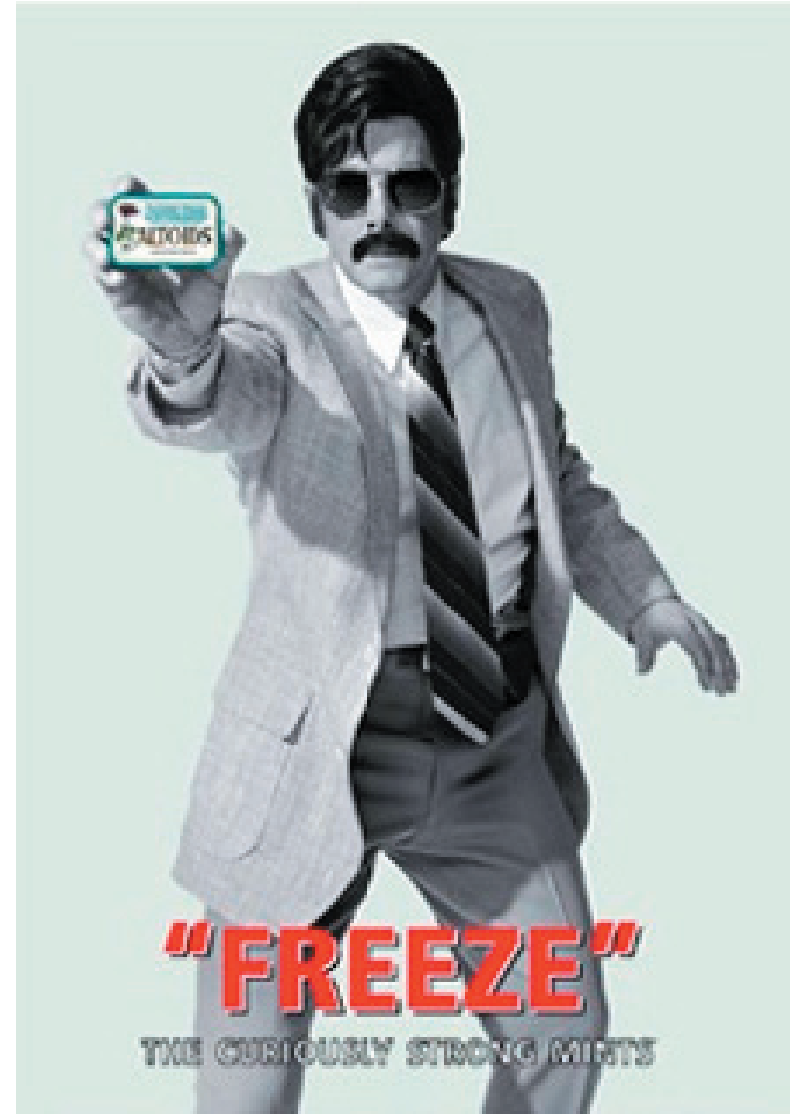

Figure 6.1. A sample text used in the "Element and Contrast" unit of ix: visual exercises (Ball \& Arola, 2004). consistent reading of the text. Let me provide a brief outline of how the 13 terms can be used to read "Freeze." The text is an Altoids ad in which a man holds a wintergreenflavored Altoids tin. Elements of the ad include the man (and his outfit and hair), the tin (including its color), the words "Freeze" in red, the words "The Curiously Strong Mint" in white outline, and the mint-green background color. The purpose of this ad is to sell the 
mints, given the genre of advertising, although secondary purposes might also be present (e.g., to make the audience laugh; to get the audience to associate the wintergreen mints with the word "freeze," etc.). The ad's context might include where it was published, which could be a number of places and media, so let me focus instead on what kinds of intertextual, cultural, and social contexts this ad relates. The man's outfit (bad suit and tie with sunglasses) and his hair can be read in context of dated police dramas (e.g., Dragnet, etc.). In addition, younger audiences for this ad might recognize this detective in relation to the music video for The Beastie Boys" "Ill Communication," which stereotypes the 1970s police dramas and movies in a humorous way.

The framing of the man's arms draw the audience's attention to the tin, which he holds like a detective might be pointing a gun or, more likely, holding a badge. The element of the word "Freeze" is emphasized because it contrasts to the subdued colors of the background and the man's suit, which draws readers' attention to the importance of the word. Also, the background color is a cool green, reinforcing the association of the wintergreen mints with a freezing effect. This combination of elements tries to sell readers the notion that wintergreen Altoids are the coolest (i.e., most cool; freezing cold) mints around. The proximity of the words "The Curiously Strong Mints" in relation to "Freeze" further compound this interpretation. The ad is organized so that the two most important elements are foregrounded — the tin of mints and the word "Freeze." My attention competes between these two elements, drawing a connection between what otherwise is elements that lack proximity. Finally, sequence can be used to read the layers of elements in this ad (a useful transition of the meaning of the term when animation or other movement isn't provided for the reader). I see the elements layered on the page in a specific order (from backgrounded to foregrounded elements): the background, the man, the group of written words, and the tin. In the end, the tin is the object that Altoids is selling; the tin is the product and is situated as the most important thing in the ad. 
The problem with the above example is that not all English teachers want to focus on advertisements as a place for finding texts. In a forthcoming version of $i x$ that uses the same thirteen terms, the focus is on texts that technical communication students typically encounter in classroom settings (Ball \& Arola, 2005). For instance, this version of the CD includes examples such as résumés, instruction sets, bar graphs, pie charts, and FLASHbased training videos. In these examples, the focus is not only on the nonwritten modes but also on the written text, such as why a designer placed a caption for one segment of an instruction set within, rather than below, the frame.

Another problem with these CDs is that they only address the visual elements within designed texts. They don't, for instance, address how sound is used in texts (it is mentioned briefly in the first version of the $\mathrm{CD}$, in the unit on sequence, where "Murmuring Insects" is an example). The lack of attention to sound is a by-product of the current nature of composition curricula: For the most part, English teachers are only just beginning to bring visual rhetoric into their classrooms and, thus, a textbook-like product asking those teachers to extend into yet another area of multiliteracies isn't yet marketable. Bringing an aural rhetoric — which I hope is partly addressed by this new media reading strategy as demonstrated by my attention to sonic elements such as Adrian Miles' voice in "Digital Multiliteracies" and the soundtracks in "Murmuring Insects"-is still a long way off. But, what I hope - more so than showing how sound or visual or other individual, nontraditional modes of communication might be used in English classrooms - is that this new media reading strategy will help expand the way readers see texts, will help them, in other words, recognize the value of design in new media texts.

\section{The pay-off}

Frequently, the question I hear when I introduce the new media reading strategy and heuristic that I've written about here is: "So what?" This question usually translates into teachers of first-year writing who want to know why they should take time from 
the other matters they have to address in their classes to introduce students to texts that seem completely unrelated to the work of composition. I can't answer that question for all teachers - many, after all, are required to teach with a standard curriculum, one that doesn't allow for shifting modes of communication. Others are interested in new media texts, but aren't sure how useful they will be in writing classes. And others have already begun to analyze new media texts in their classes and have no use for a different rubric. It has not been my intention to convince writing teachers that they must include the analysis of new media texts as part of their syllabi - only to demonstrate that it is possible to read these texts with as much attention to all of their attendant modes as it is to read a written text. And, that readers can use strategies with which they are already somewhat familiar to interpret new media texts. As I stated in the introduction to chapter 5 , the thirteen terms are simply a conglomeration of key concepts used in fields that, as readers of everyday texts such as films, menus, commercials, websites, advertisements, novels, and so on, we carry the capacity to shift our knowledges from analyzing a singular mode of communication (writing) to multiple modes even when those modes are used in such an odd combination that we may be unfamiliar with how or why they are being used as they are in new media texts. Audience is audience is audience whether reading a research paper, an advertisement, or a new media text. And discussing elements of a text can apply to a novel (i.e., plot, character, theme, etc.) or to a new media text like "Murmuring Insects" (i.e., audio voiceovers, animated visuals, written text, etc.). This new media reading strategy suggests that readers have to shift their attention from monomodality to multimodality when interpreting texts, and the heuristic helps them to perform that shift.

I hope that the contribution the heuristic in Table 2 provides to English teachers is an outlet for including/expanding the use of multimodal and new media texts (and visual and aural and spatial and all sorts of texts) into their classes. The benefit of the heuristic is that it, too, can expand depending on a particular teacher's or reader's base of knowledge. Someone with more experience than myself in interpreting cinematic texts may be able 
to provide students with a different way for understanding sequence in a new media text. Or, a teacher with graphic arts experience could expand on how framing and emphasis are used in visual media — and then demonstrate how that contribution might better explain how particular elements in a new media text work. The terms I've provided, then, function as a flexible basis from which to teach, read, and learn. This flexibility isn't always preferred, however, as I show in the next, and final, section.

\section{Questions to carry away}

I've built this dissertation up to the conclusion of needing a reading strategy that can be effective for interpreting new media texts, demonstrating along the way why this is the case. The thirteen terms are the culmination of this research, and I've shown how they fill a gap in reading strategies. But what I haven't shown is how useful the terms can be in classroom settings. The CD that contains these terms (with accompanying explanations, analyses, and assignments around a broad range of texts) has been adopted by a number of writing programs to give students a common language for analyzing visual texts. Yet knowing a specific number of adoptions does not suggest (a) that instructors and students are actually using the free CDs that come bundled with textbooks or (b) how well the exercises on the CDs are accomplishing the task of helping students understand visual compositions. While there is anecdotal evidence to suggest that the CDs are of use in these settings, more research is needed to see if this flexible rubric is, indeed, helping students learn to analyze visual or new media texts.

Another question that arises out of this rubric happens when I compare it to the sample readers' struggles to understand the texts I presented in this dissertation. If, for instance, I could go back and ask Celia, or the students in the Revisions class, to make meaning from Lexia to Perplexia (Memmott, 2000) or Hypertext Gardens (Bernstein, 1996) using the thirteen terms, would they be able to do it? What level of interpretation could they perform? It is unlikely that their readings would match those I provided 
herein, given my experience with these kinds of texts. At what point in the reading process would readers new to new media need support in the form of contextual help or modal help from a more experienced reader/teacher? Is such help necessary if readers are able to make meaning and choose significant elements in a text, even if their reading differs from a more experienced reader?

My initial reaction to this question is that this process is exactly what student/readers undergo now to explicate Shakespeare or Chaucer or to write a personal or research essay. The teacher is there to help pull out meanings for them. So then the question becomes at what point will teachers be able to accomplish the pulling-out of meanings from new media texts for their students. And what prevents readers (teachers or students or others) from accomplishing those interpretive goals? What specific kinds of knowledges are necessary to interpret new media texts? This gap (and filling of that gap) in the process is another area for study.

I want to conclude on a final suggestion for new media research that will become more needed in the immediate future: assessment. I've addressed reading strategies for new media texts - processes and possibilities of analysis - and yet, as I mentioned at the very beginning of this dissertation, the direction of new media is turning toward production. I did not address production as a method of learning new media texts because it is an entirely other (and large) project than the one I presented here. However, many teachers are incorporating production into their writing-class curricula. With students designing new media texts, a method or methods for responding, critiquing, and grading them is necessary. Although the thirteen terms I presented could be used as an assessment strategy of-sorts, more thorough work in this area is needed to show exactly how teachers might accomplish this task at the assignment level and at the class and programmatic levels. With successful representations of how new media can be assessed, the production and analysis of such texts will be projected into more and more classrooms until one day (probably fairly soon) new media will no longer be "new." 


\section{References}

Anderson, Daniel. (2003). Prosumer approaches to new media composition: Consumption and production in continuum. Retrieved July 2, 2004, from Kairos, $8(1)$ : <http:// english.ttu.edu/kairos/8.1/binder2.html?http://www.hu.mtu.edu/kairos/CoverWeb/ anderson/index.html>.

Ankerson, Ingrid. (2001). Murmuring insects [Flash Player text]. Poems That Go. Retrieved September 19, 2003, from <http://www.poemsthatgo.com>.

Ankerson, Ingrid, \& Sapnar, Megan. (2000). While chopping red peppers [Flash text]. Poems That Go. Retrieved June 2, 2004, from <http://www.poemsthatgo.com/gallery/ spring2000/redpeppers/start.htm>

Ball, Cheryl E., \& Arola, Kristin L. (2004). ix: visual exercises. Boston: Bedford/St. Martin's Press.

Ball, Cheryl E., \& Arola, Kristin L. (2005, forthcoming). tc_ix: visual exercises for technical communication. Boston: Bedford/St. Martin's Press.

Bang, Molly. (2000). Picture this: How pictures work. New York: SeaStar Books.

Barthes, Roland. (1957). Mythologies. Trans. Annette Lavers. New York: Hill \& Wang.

Berkenkotter, Carol \& Hutchins, Thomas. (1995). Genre knowledge in disciplinary communication: Cognition/culture/power. Hillsdale, NJ: Lawrence Erlbaum.

Bernstein, Mark. (1996). Hypertext gardens [Hypertext essay]. Retrieved October 15, 2003, from $<$ http://www.eastgate.com/Gardens $>$.

Bitzer, Lloyd. (1968, January). The rhetorical situation. Philosophy and Rhetoric, 1, $1-14$.

Block, Bruce. (2001). The visual story: Seeing the structure of film, tv, and new media. Boston, MA: Focal Press.

Bolter, Jay David, \& Grusin, Richard. (2000). Remediation: Understanding new media. Cambridge, MA: The MIT Press. 
Calvino, Italo. (1981). If on a winter's night a traveler. New York: Harcourt.

Cope, Bill, \& Kalantzis, Mary. (Eds.). (2000). Multiliteracies: Literacy learning and the design of social futures. New York: Routledge.

Eco, Umberto. (1984). The role of the reader: Explorations in the semiotics of texts. Bloomington, IN: Indiana University Press.

Edminster, Judith R. (2002, May). The diffusion of new media scholarship: Power, innovation, and resistance in academe. [Dissertation]. University of South Florida. Retrieved March 11, 2004, from <http://etd.fcla.edu/SF/SFE0000035/etd.pdf>.

Fischer, Katherine M. (1996). Down the yellow chip road: Hypertext portfolios in Oz. Computers and Composition [Special issue: Electronic portfolios], 13, 169-184.

Foss, Sonja K. (2004). Rhetorical criticism: Exploration and practice. Prospect Heights, IL: Waveland.

George, Diana. (2002). From analysis to design: Visual communication in the teaching of writing. College Composition and Communication, 54, 11-39.

Golson, Emily. (1995). Student hypertexts: The perils and promises of paths not taken. Computers and Composition, 12, 295-308.

Gossett, Kathie, Lamanna, Carrie A., Squier, Joseph, \& Walker, Joyce R. (2002). [Continuing to] Mind the gap: Teaching image and text in new media spaces. Kairos, 7(3). Retrieved January 23, 2003, from <http://english.ttu.edu/kairos/7.3/binder2. html? coverweb/Gossett/index.html>.

Gruber, Sibylle. (2003). The language of web texts: Teaching rhetorical analysis. In Pamela Takayoshi \& Brian Huot (Eds.), Teaching writing with computers (pp. 153165). New York: Houghton Mifflin.

Halio, Marcia Peoples. (1996). Multimedia narration: Constructing possible worlds. Computers and Composition, 13, 343-352.

Hall, Stuart. (1997). The work of representation. In Representation: Cultural representations and signifying practices (pp. 13-74). London: Sage Publications. 
Handa, Carolyn. (Ed.). (2001). Computers and Composition [Special double-issue: Digital rhetoric, digital literacies], 18(1) \& 18(2).

Harkin, Patricia. (2005). The reception of reader-response theory. College Composition and Communication, 56, 410-425.

Hayles, N. Katherine. (2002). Writing machines. MediaWorks Pamphlet Series. Cambridge, MA: MIT Press.

Heba, Gary. (1997). HyperRhetoric: Multimedia, literacy, and the future of composition. Computers and Composition, 14, 19-44.

Hocks, Mary, \& Kendricks, Michelle. (Eds.). (2003). Eloquent images. Cambridge, MA: MIT Press.

Hocks, Mary. (2003a). Teaching and learning visual rhetoric. In Pamela Takayoshi \& Brian Huot (Eds.), Teaching writing with computers (pp. 202-216). New York: Houghton Mifflin.

Hocks, Mary. (2003b). Understanding visual rhetoric in digital writing environments. College Composition and Communication, 54.

Iser, Wolfgang. (1978). The act of reading. Baltimore, MD: Johns Hopkins University Press.

Johnson, James William. (1993). Lyric. In Alex Preminger \& T.V.F. Brogan (Eds.), The new Princeton encyclopedia of poetry and poetics. Princeton, NJ: Princeton University Press.

Joyce, Michael. (1989). afternoon, a story. [Literary hypertext.] Boston, MA: Eastgate Systems.

Junod, Tom [writer], \& Drew, Richard [photographer]. (2003, September). The falling man. Esquire, 176-181.

Krause, Steven D. (2002). Where do I list this on my CV? Considering the values of selfpublished web sites. CCC Online, 54(1). Retrieved December 12, 2002, from $<$ http:// www.ncte.org/ccc/54.1/krause_copy.html>. 
Kress, Gunther. (2000). Multimodality. In Bill Cope \& Mary Kalantzis (Eds.), Multiliteracies: Literacy learning and the design of social futures (pp. 182-202). New York: Routledge.

Kress, Gunther. (2003). Literacy in a new media age. New York: Routledge.

Kress, Gunther, \& van Leeuwen, Theo. (1996). Reading images: The grammar of visual design. New York: Routledge.

Kress, Gunther, \& van Leeuwen, Theo. (2001). Multimodal discourse: the modes and media of contemporary communication. New York: Oxford University Press.

Landow, George. (Ed.). (1994). Hyper/Text/Theory. Baltimore, MD: Johns Hopkins University Press.

Landow, George. (Ed.). (1997). Hypertext 2.0. Baltimore, MD: Johns Hopkins University Press.

Lynch, Dennis, \& Wysocki, Anne Frances. (2003). From first-year composition to second-year multiliteracies: Integrating instruction in oral, written, and visual communication at a technological university. Journal of the Council of Writing Program Administrators, 26(3), 149-170.

Manovich, Lev. (2001). The language of new media. Cambridge, MA: The MIT Press.

Markel, Mike. (1998). What students see: Word processing and the perception of visual design. Computers and Composition, 15, 373-386.

McAuley, Thomas. (2001). Introduction. 2001 waka for Japan 2001. Retrieved September 17, 2003, from <http://www.shef.ac.uk/japan2001/introduction.shtml $>$.

Memmott, Talan. (2000). Lexia to perplexia [Literary hypertext]. In Iowa Review Web. Retrieved May 9, 2001, from <http:/www.uiowa.edu/ iareview/tirweb/hypermedia/ talan_memmott/index.html>.

Miles, Adrian. (2002). Digital Multiliteracies. Paper presented at Symposium on Digital Literacy, RMIT University, Melbourne, Australia, 2002.

Miles, Adrian. (2003a). Introduction. In Violence of text: Online academic publishing 
exercise. Retrieved October 15, 2003, from Kairos [Special issue: New media], 8(1): $<$ http://english.ttu.edu/kairos/8.1/binder2.html?coverweb/vot/index.html $>$.

Miles, Adrian. (Ed.). (2003b). Violence of text: Online academic publishing exercise. Published in Kairos, 8(1). Retrieved July 8, 2003, from < http://english.ttu.edu/ kairos/8.1/binder2.html?coverweb/vot/index.html>.

Miles, Adrian, \& Taylor, James. (2003). Digital multiliteracies. In Adrian Miles (Ed.) Violence of text: Online academic publishing exercise. Retrieved October 15, 2003, from Kairos [Special issue: New media], 8(1): <http://english.ttu.edu/kairos/8.1/ binder2.html?coverweb/vot/index.html>.

Moulthrop, Stuart. (1992). Victory garden [Interactive CD-ROM; Literary hypertext]. Boston, MA: Eastgate Systems.

Murray, Janet H. (1997). Hamlet on the holodeck: The future of narrative in cyberspace. New York: The Free Press.

Parrish, Katherine. (2002). New media literature: A roundtable discussion on aesthetics, audiences, and histories, part one. NCl (Spring/Summer 2002).

Peterson, Patricia Webb. (2002). Writing and publishing in the boundaries: Academic writing in/through the virtual age. The Writing Instructor. Retrieved August 1, 2002, from $<$ http://flansburgh.english.purdue.edu/twi/essays/webb.html $>$.

Reid, Alexander. (2003). New media's long history and global future: The Uniplanet project. Kairos: Rhetoric, Technology, Pedagogy, 8(1). Retrieved April 3, 2005, from $<$ http://english.ttu.edu/kairos/8.1/binder2.html?coverweb/reid/reid.swf $>$.

Reid, Kathaleen. (2004). The Hay-Wain: Cluster analysis in visual communication. In Sonja K. Foss (Ed.) Rhetorical criticism: Exploration and practice, $3^{\text {rd }}$ ed. (pp. 7893). Prospect Heights, IL: Waveland.

Rosen, Philip. (1993). Document and documentary: On the persistence of historical concepts. In Michael Renov (Ed.), Theorizing Documentary (pp. 58-89). New York: Routledge. 
Rosenblatt, Louise M. (1994). The reader, the text, the poem: The transactional theory of the literary work. Carbondale, IL: Southern Illinois University Press.

Ross, Heather. (2003). Digital video and composition: Gauging the promise of a lowmaintenance high-reward relationship. Retrieved July 2, 2004, from Kairos, 8(1): $<$ http://english.ttu.edu/kairos/8.1/binder2.html?http://www.hu.mtu.edu/kairos/ CoverWeb/ross/index.html>.

Salvo, Michael. (1997). Bridging amnesia with multimedia. Computers and Composition, 14, 111-136.

Sapnar, Megan. (2002). New media literature: A roundtable discussion on aesthetics, audiences, and histories, part one. NCl (Spring/Summer 2002).

Selfe, Cynthia, George, Diana, Faigley, Lester, \& Palchik, Anna. (2004). Picturing Texts. New York: W.W. Norton.

Sirc, Geoffrey. (1997). Nevermind the tagmemeics...Where's the Se..x Pistols? Pre/ Text: Electra(lite), 1(1). Retrieved January 23, 2003, from $<$ http://www.utdallas.edu/ pretext/PT1.1/PT1Sirc.html>.

Sirc, Geoffrey. (2001). Virtual urbanism. Computers and Composition, 18, 11-19.

Sirc, Geoffrey. (2002). English composition as a happening. Logan, UT: Utah State University Press.

Sirc, Geoffrey. (2004). Box-Logic. In Anne Frances Wysocki, Johndan Johnson-Eilola, Cynthia L. Selfe, \& Geoffrey Sirc (Co-authors), Writing new media: Theory and applications for expanding the teaching of composition (pp. 111-146). Logan, UT: Utah State University Press.

Smith, Erin. (2001). Reading and [mis]reading the eneriwomaninterface. Kairos, 6(2). Retrieved June 27, 2004, from < http://english.ttu.edu/kairos/6.2/binder.html?features/ smith/index.htm>.

Sorapure, Madeleine. (2004). Five principles of new media, or, playing Lev Manovich. Kairos: Rhetoric, Technology, Pedagogy, 8(2). Retrieved May 28, 2004, from $<\mathrm{http}: / /$ 
english.ttu.edu/kairos/8.2/binder2.html?coverweb/sorapure/index.htm >.

Sorapure, Madeleine, Inglesby, Pamela, \& Yatchisin, George. (1998). Web literacy:

Challenges and opportunities for research in a new medium. Computers and Composition, 15, 409-424.

Syverson, M.A. (2001). Thinking through Worlds Fair: Evolutionary rhetoric. Computers and Composition [Special issue: Digital rhetoric, digital literacy], 18, 163-176.

Takayoshi, Pamela, \& Huot, Brian. (Eds.). (2003). Teaching writing with computers. New York: Houghton Mifflin.

Trumbo, Jean. (1997). The spatial environment in multimedia design. Design Issues, 13(3), 19-28.

Turco, Lewis. (1986). New book of forms. Lebanon, NH: University Press of New England.

UNESCO. (2001). ETD Models. The guide to electronic theses \& dissertations.

Retrieved March 8, 2003, from <http://etdguide.org/models/>.

Williams, Robin, \& Tollett, John. (1999). The non-designers design book. Atlanta, GA: Peachpit Press.

Williams, Sean D. (2001a). Part 1: Thinking outside the pro-verbal box. Computers and Composition [Special issue: Digital rhetoric, digital literacy], 18, 21-32.

Williams, Sean D. (2001b). Part 2: Toward an integrated composition pedagogy in hypertext. Computers and Composition [Special issue: Digital rhetoric, digital literacy], 18, 123-136.

Women's Early Art. (n.d.). Poetry of Otagaki Rengetsu and the Music of Keiko Abe. Women's Early Art. Retrieved September 17, 2003, from <http://www. womensearlyart.net/reference/tengetsuabe.html>.

Wysocki, Anne Frances. (2001). Impossibly distinct: On form/content and word/image in two pieces of computer-based interactive multimedia. Computers and Composition [Special issue: Digital rhetoric, digital literacy], 18, 137-162. 
Wysocki, Anne Frances. (2002). A bookling monument. Kairos, 7(3). Retrieved March 3, 2003, from <http://english.ttu.edu/kairos/7.3/binder2.html?coverweb/wysocki/index. html>.

Wysocki, Anne Frances. (2003). with eyes that think, and compose, and think: On visual rhetoric. In Pamela Takayoshi \& Brian Huot (Eds.), Teaching writing with computers (pp. 182-201). New York: Houghton Mifflin.

Wysocki, Anne Frances. (2004a). Opening new media to writing: Openings \& justifications. In Anne F. Wysocki, Johndan Johnson-Eilola, Cynthia Selfe, \& Geoffrey Sirc (Co-authors), Writing new media: Theory and applications for expanding the teaching of composition (pp. 1-41). Logan, UT: Utah State University Press.

Wysocki, Anne Frances. (2004b). The sticky embrace of beauty. In Anne F. Wysocki, Johndan Johnson-Eilola, Cynthia Selfe, \& Geoffrey Sirc (Co-authors), Writing new media: theory and applications for expanding the teaching of composition (pp. 147197). Logan, UT: Utah State University Press.

Wysocki, Anne Frances, Johnson-Eilola, Johndan, Selfe, Cynthia L., \& Sirc, Geoffrey. (Co-authors). (2004). Writing new media: Theory and applications for expanding the teaching of composition. Logan, UT: Utah State University Press.

Wysocki, Anne Frances, \& Lynch, Dennis A. (2005, forthcoming). compose/design/ advocate: a rhetoric for integrating the written, visual, and oral. New York: Longman Press. 